University of Redlands

\title{
Mapping a Soldier's Journey through the American Civil War
}

A Major Individual Project submitted in partial satisfaction of the requirements for the degree of Master of Science in Geographic Information Systems

by

Nicholas Clayton Dunn

Mark Kumler, Ph.D., Committee Chair

Fang Ren, Ph.D.

December 2015 

Mapping a Soldier's Journey through the American Civil War

Copyright (@) 2015

by

Nicholas Clayton Dunn 

The report of Nicholas Clayton Dunn is approved.

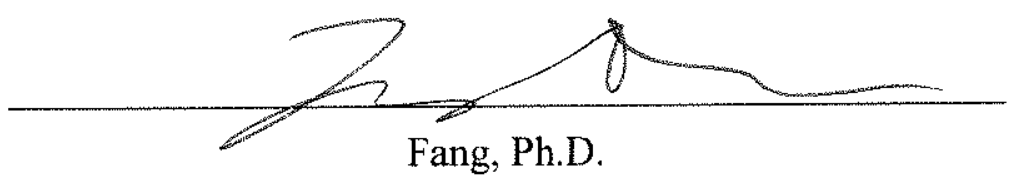

$220<1$

Mark Kumler, Ph.D., Committee Chair

December 2015 



\section{Acknowledgements}

I would first like to acknowledge my family in supporting me through my endeavors and their encouragement to follow my heart. I would like to thank the faculty of the University of Redlands for all their efforts, guidance, and patience during my two years with the program, especially to Dr. Kumler for helping me to be Done on time. I am grateful to Dr. John Glover for bringing this exciting idea forward and trusting me with the responsibility of bringing it to life.

Thank you to all the people of Cohorts 24, 25, 26, and 27, not just for their help from within the program, but for all the moments shared between friends. And lastly, a special thanks to Joseph, Neel, and Shilpi, for your help and patience through all my moments of confusion and redundant questions. I am proud to call you all my friends, for no man is a failure who has friends. Thank you. 



\author{
Abstract \\ Mapping a Soldier's Journey through the American Civil War \\ by \\ Nicholas Clayton Dunn
}

The purpose of this project was to organize a selection of historical documents from the Lincoln Memorial Shrine archives and develop an application that could promote the archives by allowing easy public access to the documents via the Internet. The Lincoln Memorial Shrine provided sixty-one personal letters of a United States soldier during the American Civil War with the wishes that the soldier's journey could be mapped so that his story could be told in a visual context. In order to begin this project, location and date data were taken from the original letters and organized inside a geodatabase for storage. Historical maps were georeferenced to allow the data to have a visual context, along with supporting layers. Using Esri's Journal Map application template with additions from ArcGIS API for JavaScript, an interactive web application was developed that could allow the public to view the maps and data following the life of the Civil War soldier Logan Crawford and his regiment, the 15th Iowa Infantry. 



\section{Table of Contents}

Chapter 1 - Introduction ................................................................................................ 1

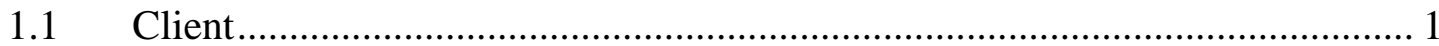

$1.2 \quad$ Problem Statement ................................................................................ 1

$1.3 \quad$ Proposed Solution ............................................................................... 2

1.3.1 Goals and Objectives ........................................................................... 2

1.3.2 Scope

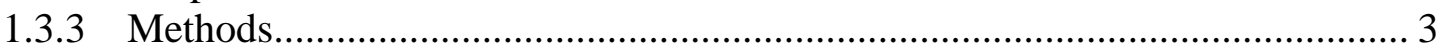



1.5 Overview of the Rest of this Report ........................................................... 3

Chapter 2 - Background and Literature Review ............................................................. 5

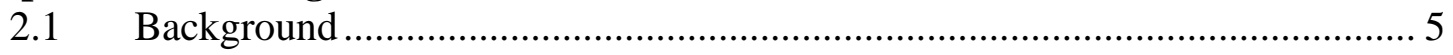

2.1.1 Corresponding during the Civil War............................................................... 6

2.1.2 The Lincoln Memorial Shrine and Logan Crawford ....................................... 9

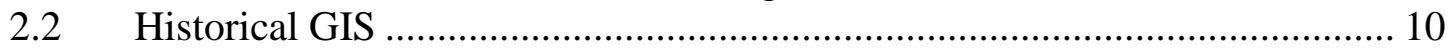

2.3 Web GIS and Story Maps ………………............................................... 11

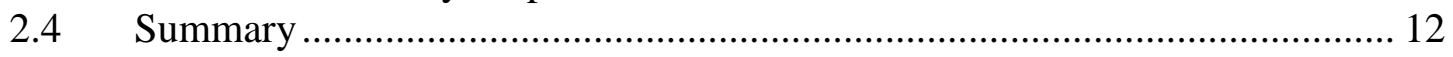

Chapter 3 - Systems Analysis and Design......................................................................... 13

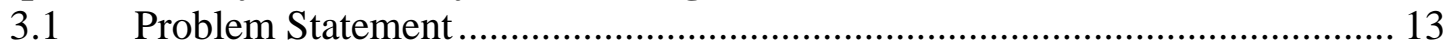

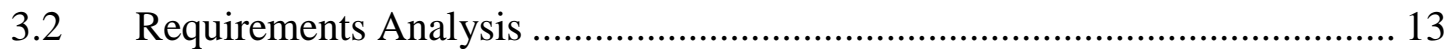

3.2.1 Functional Requirements ......................................................................... 13

3.2.2 Non-Functional Requirements ................................................................. 14



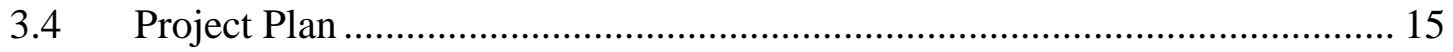

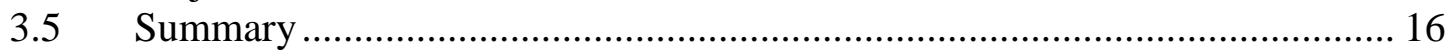

Chapter 4 - Database Design.......................................................................... 17

4.1 Conceptual Data Model ..................................................................... 17

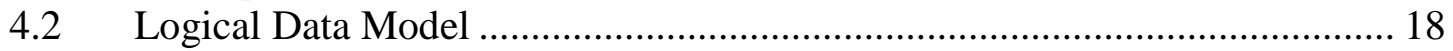

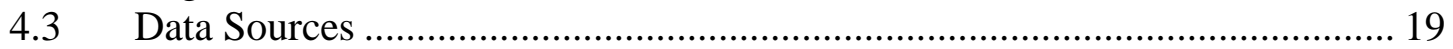

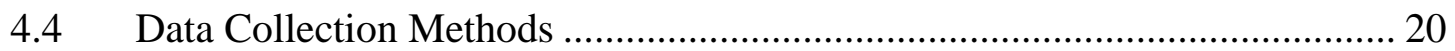



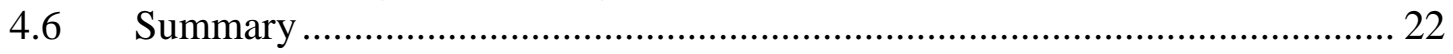

Chapter 5 - Implementation............................................................................................ 23

$5.1 \quad$ Final Data Preparations ......................................................................... 23

5.2 Publishing Services ……………………………................................ 24

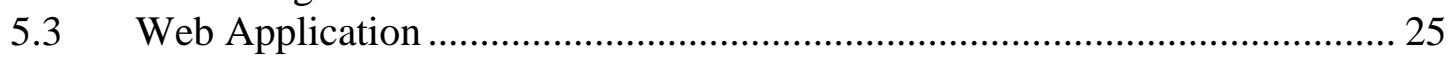

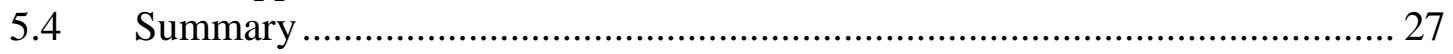

Chapter 6 - Results and Analysis.................................................................................... 29

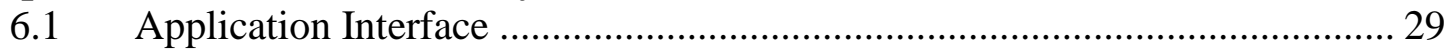

6.1.1 Viewer Application Interface................................................................ 29

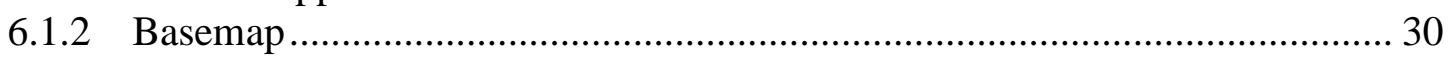

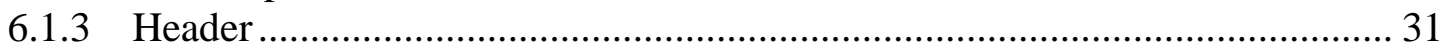




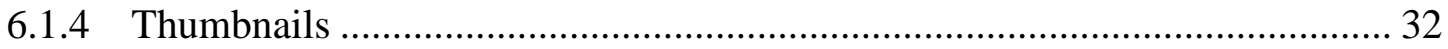

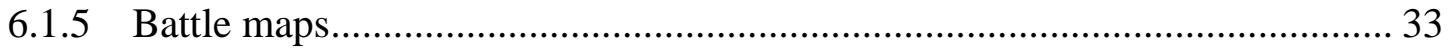

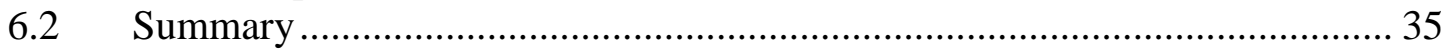

Chapter 7 - Summary and Future Work ..................................................................... 37

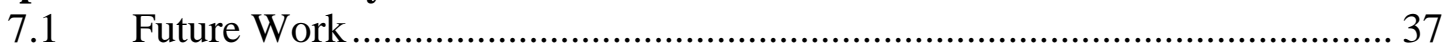

Works Cited $\quad$.........................................................................39

Appendix A. Important but Extraneous Information ................................................... 41

Appendix B. Basemaps ................................................................................................ 63

Appendix C. Lincoln Memorial Shrine Project Web Application Script............... 73 


\section{Table of Figures}

Figure 2- 1. Examples of locations and dates written within letters........................ 7

Figure 2- 2. Union envelope specific for the $99^{\text {th }}$ Pennsylvania Infantry listing participated battles (source: American Civil War Website, 2015) ......8

Figure 2- 3. Example of the utilization of space in letter writing. ........................... 8

Figure 2- 4. Portrait of Logan Crawford (year unknown). (source: Iowa Genealogy Website, 2015) ........................................................................ 10

Figure 2- 5. Samples of story maps from The ArcGIS Book. ............................... 12

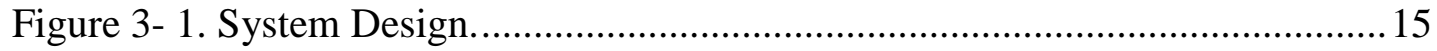

Figure 4- 1. Conceptual Data Model.............................................................. 17



Figure 4- 3. Sample of written location and date in a Civil War letter.................... 19

Figure 4- 4. Example of the Regimental History of the 15th Volunteer Iowa...........20

Figure 4- 5. 1862 Historical War Map...............................................................21

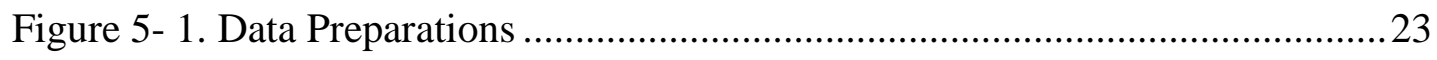

Figure 5- 2. Differences between historical and modern geographical maps............24

Figure 5- 3. ArcGIS Online Web Map............................................................25

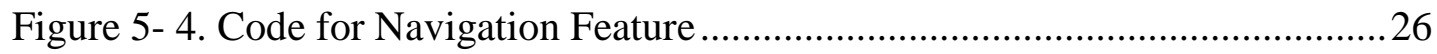

Figure 5- 5. Code for Mouse-over and Mouse-out Feature …................................2 27

Figure 6- 1. Primary image of the web application. ...........................................29

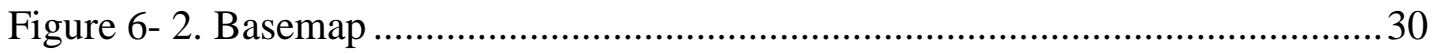

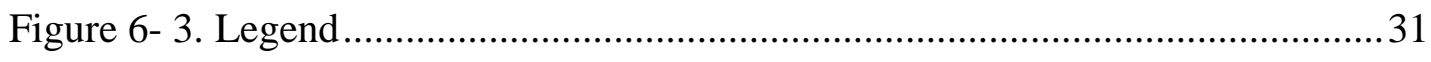

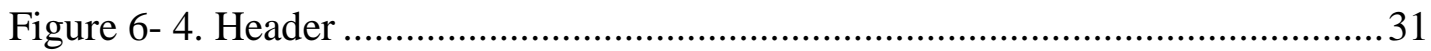




Figure 6- 6. Selected Pop-up Example.

Figure 6- 7. Example of polygon feature. .......................................................... 34

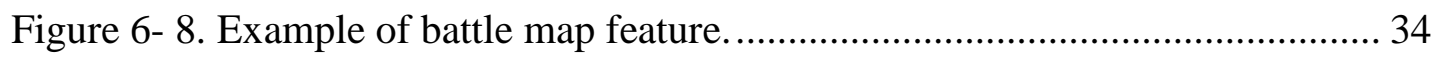




\section{List of Tables}

Table 3-1. Functional Requirements........................................ 14

Table 3-2. Non-functional Requirements.................................... 14

Table 3-3. Initial Project Plan............................................. 16 



\section{List of Acronyms and Definitions}

$\begin{array}{ll}\text { API } & \text { Application Program Interface } \\ \text { CSA } & \text { Confederate States of America } \\ \text { CSV } & \text { Comma-Separated Value } \\ \text { EGDB } & \text { Enterprise Geodatabase } \\ \text { GIS } & \text { Geographical Information Systems } \\ \text { LMS } & \text { Lincoln Memorial Shrine } \\ \text { LMSP } & \text { Lincoln Memorial Shrine Project } \\ \text { UI } & \text { User Interface } \\ \text { US } & \text { United States } \\ \text { WGS } & \text { World Geodetic System } \\ \text { XML } & \text { Extended Markup Language }\end{array}$





\section{Chapter 1 - Introduction}

The American Civil War (1861-1865) can be considered the first modern war in world history, with military trained generals and educated enlisted men, along with the change from Napoleonic war tactics to mechanized warfare. These changes are often observed to be a major reason for the massive loss of life throughout the war, however there is also another change that is often overlooked as historically significant. With the rapid education of the American citizen, the American Civil War became the first war where soldiers could easily correspond with family and loved ones back home through letters. As a product of this, these personal letters have been collected for over 150 years by families and museums throughout the United States. These letters pre-date any military censorship and contain not only personal accounts of the Civil War, but valuable historical and spatial data. This project explores how this historical and spatial data can be utilized and mapped using modern GIS applications.

\subsection{Client}

The client for this project was Dr. John Glover, Professor and Chair of the Department of History at the University of Redlands, California. Dr. Glover was representing the Lincoln Memorial Shrine, located in Redlands, California, which is a museum and research facility dedicated to Abraham Lincoln and the Civil War. All data and original documents for this project were approved and provided by Dr. Nathan Gonzales who is the archivist and head of special collections at the A.K. Smiley Public Library and curator of the Lincoln Memorial Shrine.

\subsection{Problem Statement}

Since its creation in 1932, the Lincoln Memorial Shrine has collected thousands of historical documents, containing letters, diaries, newspapers, and maps which show a detailed history of individual soldiers' lives during the American Civil War. However, the problem with such a collection is how to display it to the public in an efficient and positive way. Communicating historical documents and maps can be challenging, especially to an audience with basic or no analytical skills. The client requested assistance in mapping and displaying the archive, and after a series of meetings with the client, we identified an interactive web map as the preferred method for conveying the data compiled by the Lincoln Memorial Shrine. The problem addressed by the client was to create a web map that people of all ages and cultures could easily access and understand, even without any prior knowledge of history or GIS knowledge.

In addition, at the initiation of the project, another problem with what the Lincoln Memorial Shrined faced, is that they had not begun a process of selecting a potential soldier for the required mapping service. This meant that there was no data present and that a process of selection of reading through historical letters and documents would be needed in order to learn whether there was any spatial information for potential mapping. Without this initial step of finding a spatial reference, the letters could not be placed in a spatial context within a GIS system. 


\subsection{Proposed Solution}

After discussions with the client and curator of the Lincoln Memorial Shrine, it was decided that a joint effort would be undertaken to select a potential historical candidate for the mapping service. Upon the selection of a candidate, spatial data would be taken from the letters and then transferred to a comma separated values (.csv) file and that the end result should take the form of a web application. The application should make use of a georeferenced historical map of the period and that a functional layer should display the journey that the soldier undertakes as conveyed from within his letters. In addition, there should be points representing the archival and non-archival materials that had been spatially referenced to these specific point locations. These point locations, when clicked by a user within the web application, should display a thumbnail of the original letter, a transcribed version of the letter, and any other information and metadata relevant to that location.

\subsubsection{Goals and Objectives}

The goal of this project was to develop a prototype that could illustrate how modern geographical tools could bring to life a small portion of the massive archive of the Lincoln Memorial Shrine. Namely, using a soldier's or soldiers' personal correspondence to map their journey throughout the American Civil War, implement it in GIS, and convert it into an application that could be accessed by a wider audience through the Internet. The objective was to develop for the Lincoln Memorial Shrine an interface that would address these set goals, yet be as simple as possible in order to provide easy public access and educational value to any user interested in the project. This object was conceived so that a user could not only interact with a part of history and acquire knowledge of the Lincoln Memorial Shrine, but possibly stimulate interest in history and a desire to generate their own story maps of their lives and history.

\subsubsection{Scope}

After several meetings with the client, it was agreed that due to restrictions of time and scope that one case study with one soldier would be implemented displaying many point samples through one journey. It was deemed unfeasible to attempt to try to single out more than one soldier from the LMS collection in an effort to build multiple timelines for each soldier, because of the amount time it would take to find multiple soldier samples with completed journeys. Therefore, the client selected a soldier with a collection of sixty-one letters that would span a timeline of two and half years of the war, of which twenty personal letters would be used, with additional letters from his commanding officers.

After the selection of the case study, requirements of the project required the collecting, processing, and organizing of data for the creation of a database. The project also required a selection of a historical map that would be georeferenced to be used as a base map for the web application. Further requirements of the project called for the development of the web application that would display the map, the route taken by the soldier throughout the war, and the individual point data that could be selected by the users in the form of popups. After development of the web application, the product was 
hosted on the University of Redlands server, as the Lincoln Memorial Shrine did not have a server at that time. It was the responsibility of the client to manage and update the web application or data after the completion of the project. Finally, a copy of the product and an instruction manual was delivered to the client.

\subsubsection{Methods}

In order to complete the project, a series of different methods were undertaken at various stages. The point data were collected, organized, and then processed by placing it in a CSV file for future inclusion in Esri's ArcMap 10.2. A base map was selected and georeferenced using a modern map of the United States, and an auxiliary extended markup language (XML) file was created containing all of the rectification and spatial data for the georeferenced map. Two new point feature classes from the uploaded point data, as well as two line feature classes and a single polygon feature class were created. The web application was developed with the ArcGIS Application Program Interface (API) for JavaScript tool.

\subsection{Audience}

The intended audience for this project report includes anyone interested in Historical GIS, Story Map creation, and web GIS application development. In addition, this report and application could be useful to any historian or private individual who has a collection of historical documents and is looking for new method in how to visually convey the events portrayed within those documents.

\subsection{Overview of the Rest of this Report}

Continued reading of this report consists of six additional chapters. Chapter 2 includes the research for the historical background and modern uses of historical maps in GIS applications. Chapter 3 covers the system design and project planning. Chapter 4 discusses conceptual, logical models, and the processes of data collection. Chapter 5 details the implementation and completion of the project. Chapter 6 illustrates the results and analysis of the application. Finally, Chapter 7 includes a project summary, conclusions, and suggestions for future work. 



\section{Chapter 2 - Background and Literature Review}

Chapter 2 examines a brief history of the events leading to the American Civil War and the widespread usage of personal correspondence during the war, the work of the Lincoln Memorial Shrine, previous work explored in the field of historical GIS, and practical uses in Web GIS. Section 2.1 will give a brief history of the American Civil War and how letter writing impacted soldiers' everyday lives. Additionally, it will look at the goals of the Lincoln Memorial Shrine and a background of the soldier selected for the project. Section 2.2 discusses the fairly new field of historical GIS and the limitation of historical maps used in GIS. Section 2.3 will look at the incorporation of Web GIS and how the usage of Story Maps can enrich the storytelling of history.

\subsection{Background}

The United States as we know today as "one nation, indivisible," was not the America citizens lived under a hundred and fifty years ago, but resembled more two Americas of North and South. There were many issues that caused this division such as economics and cultures, but no more than the issue of slavery. Since the Missouri Compromise of 1819 , slavery could not be permitted in new states north of the $36^{\circ} 30^{\prime}$ line, formed at Missouri's southern border. This agreement changed however, in late 1840, when the war with Mexico brought in the new territories of California, New Mexico and what would be named Arizona, which existed below the $36^{\circ} 30^{\prime}$ line of latitude. Further decisions in Congress in years to come only deepened the rift between slave and free states, and Southerners feared that the booming North would dominate the South economically and dictate to them politically (Kagen \& Hyslop, 2009). The division finally led to outright secession with the election of 1860, where an anti-slavery Republican Party, led by Abraham Lincoln, won the U.S. Presidency. Southern fears had come true with Abraham Lincoln winning the election with just 39\% of popular vote, yet he had won 180 of the 313 electoral votes, all of which were from Northern states. Even though there were four candidates running for the presidency, with a combined $60 \%$ of the popular vote to one candidate, a Southern candidate would have lost the election to Lincoln (Crocker, 2008). Fearing that Lincoln and his fellow Republicans in Congress would not only prohibit slavery in Western territories but also repeal the Fugitive Slave Act, potentially triggering slave rebellions in areas where blacks greatly outnumbered whites, a secessionist movement rapidly gained traction (Kagen \& Hyslop, 2009). By early 1861, the Deep South states of South Carolina, Mississippi, Florida, Alabama, Georgia, Louisiana, and Texas had seceded from the United States and formed a new government under the Confederate States of America (CSA). Lincoln attempted for months to smoothen relationships, but war seemed unavoidable as tensions began rising around a U.S. held Fort in Charleston Harbor called Fort Sumter. The Confederate government demanded control of all U.S. held forts in the South, even offering to compensate the U.S. government financially for its investment. U.S. President Lincoln refused to acknowledge the legitimacy of the new CSA government and offered an ultimatum to the southern government: either allow the fort to be resupplied by U.S. forces, or fire upon it (Crocker, 2008). On April 12th, after negotiations had failed, Confederate forces opened fire on Fort Sumter, resulting in the surrender of the Fort two days later. On April 15th, Lincoln 
called for an army of 75,000 volunteers combined from each state to put down the rebellion. Mid-South states of Arkansas, North Carolina, Virginia, and Tennessee chose to secede as well, rather than aid in the suppression of the other Southern States, and the Confederate capital was moved to Richmond, Virginia (Crocker, 2008). Thus began the American Civil War, which would last a bloody four years between 1861 and 1865, with one side fighting to form a new Republic and the other to preserve the old.

\subsubsection{Corresponding during the Civil War}

Postal delivery was very difficult during the Civil War, especially for those whose letters were the only communication between loved ones at home and soldiers in the field. Correspondents often had to wait for days or weeks at a time to receive mail. Letter exchanges proceeded incrementally, against the constant possibility of being discontinued without notice (Barton \& Hall, 1999). While it was relatively easy for the army postal service to find soldiers when they were encamped for several weeks, periods of intense action saw both armies in perpetual motion. Regardless of this, families and friends persisted in writing, since the letters they exchanged were their only connection to their men at the front line (Burke, 2005). The desire to receive and send more letters was also impacted as each letter could also be the last the soldier ever wrote. A Union soldier from Maine wrote this passage to a loved one at home while stationed in a coastal garrison:

"Sophronia, you cannot think how much good it does a poor soldier out here to get a kind, cheering word from home now and then. It shows him he is not forgotten and gives him courage to stand up against hardships he has to endure." (Robert \& Kagen, 2011)

Regardless of the volume of letters written, there was no guarantee that a letter would be received at a soldier's last known address, therefore soldiers would often include information containing his whereabouts and possible future locations. Within the majority of most letters written during the Civil War, a current or future location and a date were written in the top right portion of the letter (Figure 2-1). As a result, these letters contained military information, and letters traveling between North and South where often confiscated by both sides in the hopes of learning enemy secrets (Crown, 1976). 


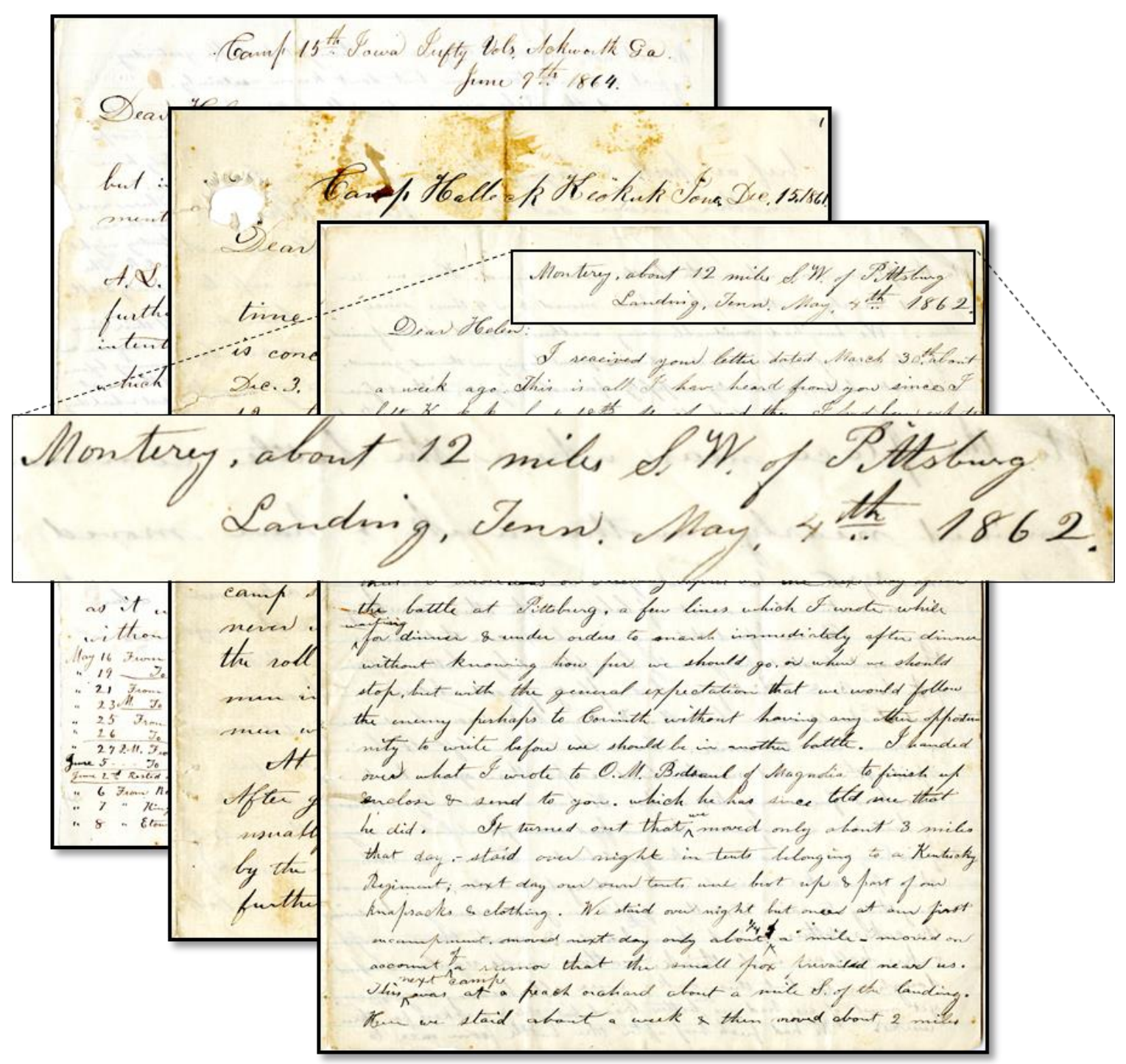

Figure 2- 1. Examples of locations and dates written within letters.

Solders during the Civil War wrote many letters, and as a society we are lucky that so many have been preserved, for they often contain valuable historical and spatial data. For example, in some cases individual regiments had custom envelopes with a regimental history of which engagements they were active in (Figure 2-2). From just this simple list of battles, a reader can ascertain a quick history and timeline of where that small amount of men have traveled and at what approximate dates. 




Figure 2- 2. Union envelope specific for the $99^{\text {th }}$ Pennsylvania Infantry listing participated battles (source: American Civil War Website, 2015)

The best example of spatial value is from the amount of writing and data that is contained within one letter from a soldier (Figure 2-3). Paper was a valuable commodity to soldiers and this can be seen in how there is often writing in the margins or on top of other written lines. When historians read these letters, they can get an idea of what the soldiers were like, what they thought, and the surrounding they were placed in while away from home.



Figure 2- 3. Example of the utilization of space in letter writing.

Though this information is valuable to us now, sometimes soldiers were telling friends and people at home information that the military wanted to be kept secret (American Civil War Website, 2015). As a result, the American Civil War is the last 
American war where soldiers' letters were not subject to military censorship, so that soldiers could not give pertinent information to the enemy.

\subsubsection{The Lincoln Memorial Shrine and Logan Crawford}

The Lincoln Memorial Shrine, the client for this project, is the only museum and archival collection dedicated to the study of Abraham Lincoln and the American Civil War west of the Mississippi River. Since its dedication in 1932, the Lincoln Shrine houses thousands of pieces of memorabilia, manuscripts, artwork and even locks of Lincoln's hair cut by a physician after the president was shot at Ford's Theatre in 1865 (Lincoln Memorial Shrine Website, 2015). The Lincoln Memorial Shrine selected from its archives the soldier of which this project is focused, however the data provided was in the forms of his personal correspondence during the Civil War from late 1861 to mid-1864. Further research was needed to fully understand the background of the soldier, Logan Crawford, and his life before and after the Civil War.

Logan Crawford (Figure 2-4) was born in Union, Connecticut, on January 13, 1822, and descends from Scotch-Irish ancestry. Crawford spent his early life on his father's farm, attending school in Brooklyn, Connecticut, where he obtained a business education. In 1847, Crawford relocated to Dodge County, Wisconsin, where he gained employment at a local sawmill, and later in 1851, as a flagman on the railway company. Crawford married Helen Rising in 1851 with whom he would have five children between the years 1852-1857, of which three would reach adulthood. He was later transferred to Illinois to run the Northwestern rail from Chicago towards Janesville, Wisconsin, but after only a few years he decided to move west. In 1857 the Crawford family established a home in St. John's Township, Iowa, where he began a small farm that would eventually grow to three hundred and sixty acres. 


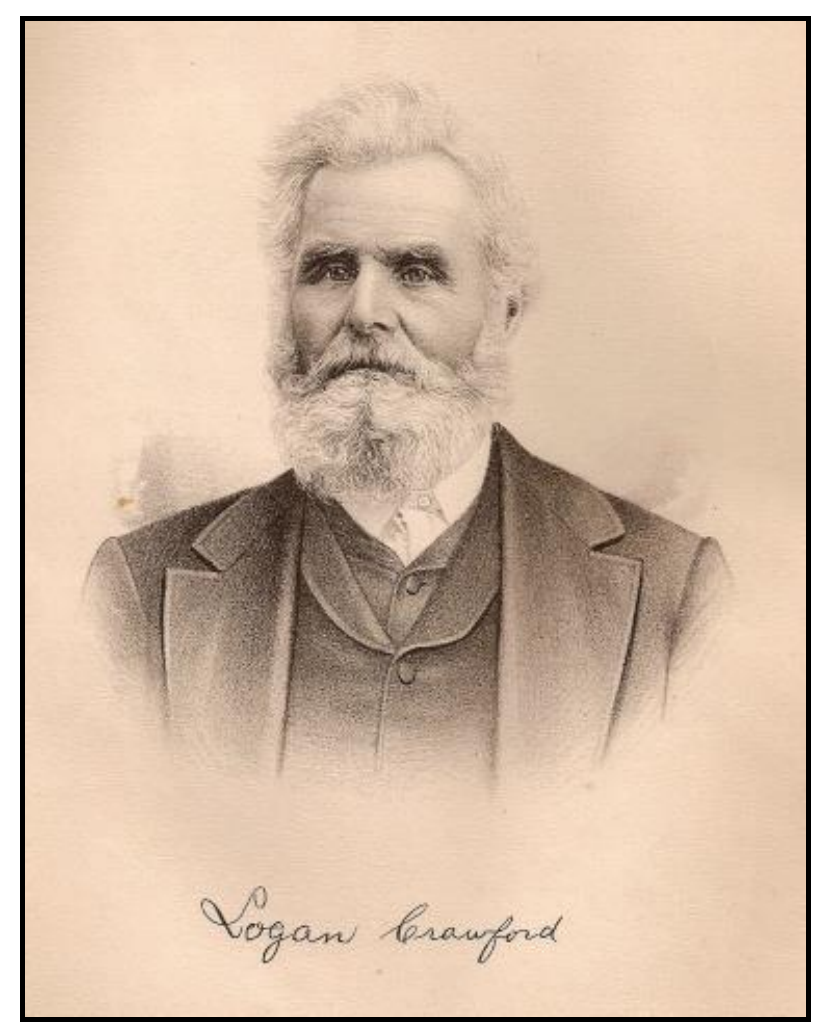

Figure 2- 4. Portrait of Logan Crawford (year unknown). (source: Iowa Genealogy Website, 2015).

As the Civil War began, Logan Crawford at the age of 39, enlisted in Company $\mathrm{H}$ of the Fifteenth Iowa Infantry, as a private, and was assigned to the Army of the West. Throughout his first commission he was involved in the major engagements of: Shiloh, Corinth, and Vicksburg, where at the battle of Corinth he was wounded in the head by a gun shot and later promoted to Second Lieutenant. After his terms of service had expired, he re-enlisted in the Veteran Corp in 1864 and joined General Sherman on his march to the sea through the state of Georgia. At the battle of Atlanta, Georgia, he was shot in the chest, captured by rebel forces, and sent to a prison camp in Macon, Georgia. At the end of August 1864, as General Sherman's forces approached Macon, Crawford was sent to Rickersville, South Carolina (current Charleston, South Carolina), where he remained until December. A prisoner exchange was scheduled at Charleston Harbor, South Carolina, on December 14, 1864, where Crawford would be returned to Davenport, Iowa, and eventually discharged from service on February 19, 1865. After the war, it is stated that Mr. Crawford was a supporter of the Republican Party, was elected County Surveyor twice and Justice of the Peace for the Calhoun Township (Iowa Genealogy Web Project, 2015).

\subsection{Historical GIS}

Since the mid-1990s, there has been a rapid increase in awareness of the potential of geographical information systems (GIS) in historical research, such that a new field, historical GIS, has emerged (Gregory \& Ell, 2007). Historical GIS offers an alternate 
view of history through the dynamic representation of time and place within cultures. It stands alongside - but does not replace - traditional interpretive narratives, inviting participation by the naïve and knowledgeable alike (Bodenhamer, 2008). By consolidating vast amounts of data that can vary in temporal and spatial reference into a visual medium, the information can be quickly conveyed to, and understood by, the general public (Owens, 2007). The obstacle, then, for GIS is to use technology to probe, explore, challenge, and complicate, in sum, to allow us to see, experience, and understand human behavior in all its complexity. The goal is less to produce an authoritative or ultimate answer than to prompt new questions, develop new perspectives, and advance new arguments or interpretations (Bodenhamer, Corrigan \& Harris, 2010).

As with any new approach, enthusiasm for GIS is not without risks. GIS originated in disciplines that use quantitative and scientific approaches in data-rich environments. Historical geography though, is rarely data-rich; in fact, data are frequently incomplete and error-prone (Gregory \& Ell, 2007). One of the main problems with Historical GIS is that it often requires researchers to create their own data layers because so little historical evidence comes ready-made for use in GIS. In the process of constructing digital historical layers, one becomes immediately aware of the imprecision of the data, the compromises necessary to make it compatible with GIS formats, and how the data changes at each stage of digital manipulation (Knowles, 2008). For example, in the use of historical maps where metadata is not available, the data requires georeferencing, which is the process of transforming data layers to align to a known coordinate system. Balletti states that with georeferencing, "This implies the use procedures, which are based on the use of transformations known in modern mapping sciences, which are distinguished as global (projective, affine, similarity, polynomial) or as local (finite element, point based or feature based warping)" (p.32, 2006). He concluded that the definitions and properties of mapping have changed over time and that no transformation will be completely accurate, but will maintain a level of precision. It is important that any work within Historical GIS address the quality of sources and kinds of uncertainty and error resulting from their use in spatial analysis.

\subsection{Web GIS and Story Maps}

GIS is evolving from an information model centered around local files on a single computer into a system of distributed web services that are accessible in the cloud. ArcGIS has become a Web GIS platform that can be used to deliver authoritative maps, geographic information layers, and analytics to wider audiences (Harder, 2015). In fact, any GIS that uses web technology to communicate between components is termed as Web GIS. Web GIS is intended for a broad audience, including public users who may know nothing about GIS, a major reason the evolution of Web GIS over Desktop GIS (Fu \& Sun, 2011).

Web maps can be classified into two categories, static and dynamic maps, allowing the developer to allow the user to see the map in a view only and interactive mode, but still permits users to gain geographic information and knowledge (Kraak \& Brown, 2001). The most popular and rapidly growing way to view geographic information over the web is in a mashup. A mashup is a web page, or a web application, that uses content from more than one source to create a single new service displayed in a single graphical interface (Soylu, Modritscher, Wild, De Causmaecker, and Desmet, 
2012). Through these mashup web-pages, consumers are able to access a variety of services such as: crime maps, conservations maps, or real-time traffic maps over street maps. Today, services such as Google Maps and ArcGIS Online allow users to create mashups with their own data, or other data available on the web (Fu \& Sun, 2011). A popular example of how mashups work is through an Esri Story Map, which can tell a story of a place, event, issue, trend, or pattern in a geographic context (Figure 2-5).

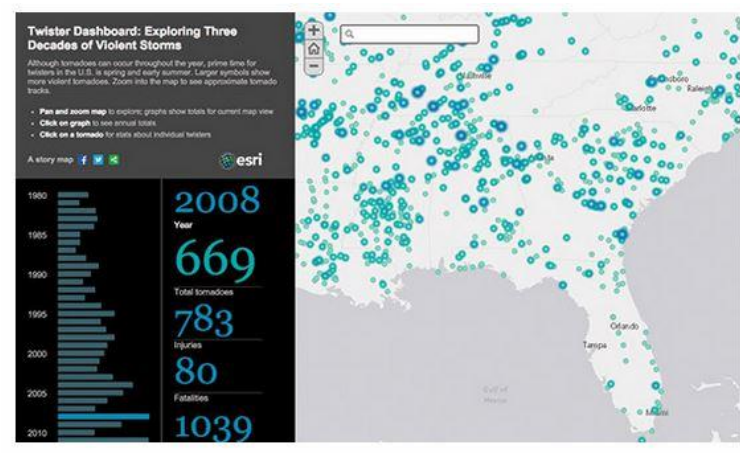

The Twister Dashboard beautifully synthesizes 30 years of tornado data.

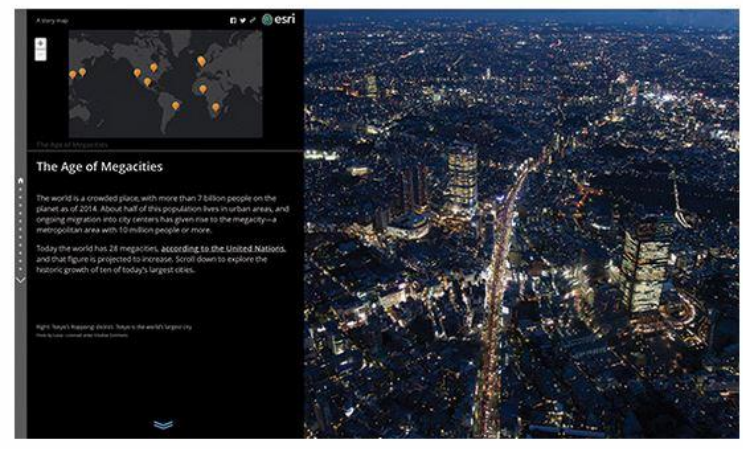

The world is a crowded place, with more than 7 billion people on the planet as of 2014. About half of

Figure 2- 5. Samples of story maps from The ArcGIS Book.
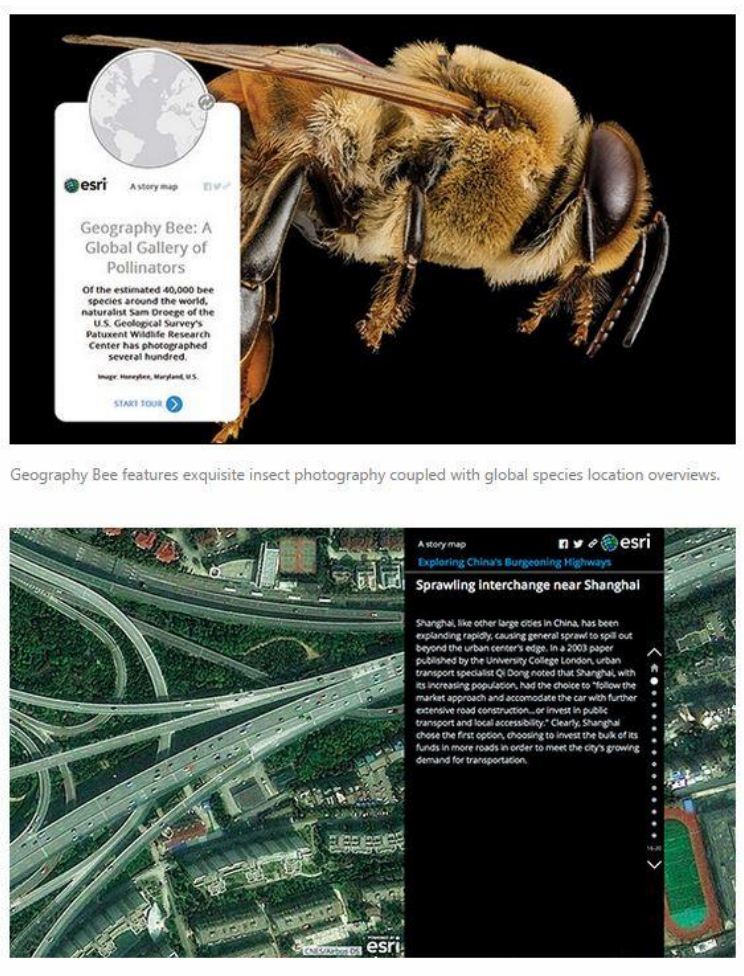

This map tells the story of rapid highway development and love of the car in China. 


\section{Chapter 3 - Systems Analysis and Design}

This chapter describes the design and requirements of the Lincoln Memorial Shrine Project (LMSP). In order to implement a project plan, the problem must first be understood so that a designed set of goals and solutions can be developed and a time table established to fulfill the project in an orderly fashion. Included in this chapter is the project plan implemented for the development of a prototype application for the LMSP.

\subsection{Problem Statement}

The Lincoln Memorial Shrine hosts a collection of thousands of historical documents, containing letters, diaries, newspapers, and maps pertaining to the American Civil War and President Abraham Lincoln. The problem with such a collection is how to display it to the public in an efficient and positive way. Communicating historical documents and maps can be challenging, especially to an audience with basic or no analytical skills. The client requested assistance in mapping and displaying the archive, and after a series of meetings with the client, we identified an interactive web map as the preferred method for conveying the data compiled by the Lincoln Memorial Shrine.

\subsection{Requirements Analysis}

During the first meeting with Dr. John Glover, the client representing the Lincoln Memorial Shrine, it was decided that preparations and requirements would be needed to fully articulate what the end product should look like and what functions should be developed. Discussions included how a user should be able to interact with the product and what items should be displayed for an easier user experience. Through these discussions with the client, the basis for the functional and non-functional requirements for this project were outlined.

\subsubsection{Functional Requirements}

The functional requirements of the project describe how users can access the Lincoln Memorial Shrine Web Application and what functionalities can be used within the application. The developed web application displays a georeferenced historical basemap as well as several georeferenced battle maps and historical documents that users would be able to access when selected with the associated point. Table 3-1 outlines the functional requirements for the project. 


\begin{tabular}{|l|l|}
\hline Requirement & Description \\
\hline Access to the Application & $\begin{array}{l}\text { Ability to access the application at both the LMS or } \\
\text { online at home. }\end{array}$ \\
\hline View maps associated & $\begin{array}{l}\text { User can access basemap and other maps associated } \\
\text { with the story }\end{array}$ \\
\hline View letter point location & $\begin{array}{l}\text { User can access the historical letters at the point } \\
\text { location associated with that letter in chronological } \\
\text { order }\end{array}$ \\
\hline Access to original letters & $\begin{array}{l}\text { A thumbnail attachment will link to a full sized } \\
\text { transcribed version of the original letter }\end{array}$ \\
\hline
\end{tabular}

\section{Table 3-1. Functional Requirements.}

\subsubsection{Non-Functional Requirements}

This project also has non-functional requirements that are associated with how the system will work. These requirements manage the technical and operational aspects of the project so that the finished product can perform and be displayed as originally envisioned.

The Lincoln Memorial Shrine Project required non-functional elements for the georeferencing of historical maps and the creation of the geodatabase. Also, services were needed to develop, maintain, and host the web application. The non-functional requirements are listed in Table 3-2.

\begin{tabular}{|l|l|}
\hline Requirement & Description \\
\hline ArcGIS for Desktop 10.2 & $\begin{array}{l}\text { Used for georeferencing the historical } \\
\text { basemap and battlemaps, as well as } \\
\text { creation of feature classes }\end{array}$ \\
\hline ArcGIS for Server 10.2 & $\begin{array}{l}\text { Used for publishing feature classes as } \\
\text { feature layers so that they can be accessed } \\
\text { in the Web Application }\end{array}$ \\
\hline ArcGIS JavaScript API 3.10 & $\begin{array}{l}\text { Used for consuming the feature layers and } \\
\text { making a story map for the client }\end{array}$ \\
\hline ArcGIS Online & $\begin{array}{l}\text { Used for creating the web map and linking } \\
\text { it to the application }\end{array}$ \\
\hline File Geodatabase & Used for storing input data \\
\hline
\end{tabular}

Table 3-2. Non-Functional Requirements. 


\subsection{System Design}

The system design for the Lincoln Memorial Shrine Project was divided into two phases that are demonstrated in Figure 3-1. The first phase began with two sets of data, one composed of the raw data and the other of georeferenced historical maps. The first data set was composed of multiple letters from the client and additional research data, which were converted into point, line, and polygon feature classes and saved into a file geodatabase. These were published as multiple features services to the ArcGIS Online organizational account of the University of Redlands. The second data set was a collection of TIFF images that were georeferenced using ArcMap, where auxiliary files containing transformation and metadata information were automatically created for each image and published as a tile service to ArcGIS for Server 10.2, hosted by the University of Redlands.

The second phase utilizes Esri web services to make the data available through a web application. All the feature services and the tile service were added in a web map which was used for the development of the story map.

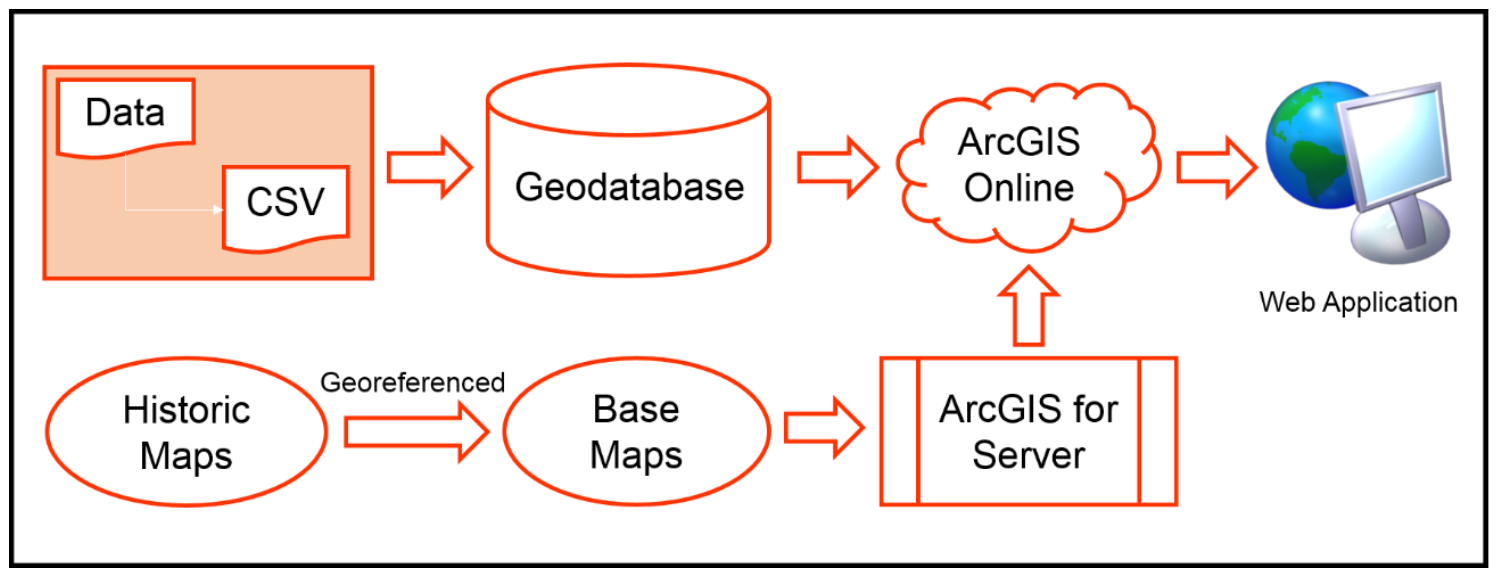

Figure 3- 1. System Design.

\subsection{Project Plan}

Creating and following a project plan is a proven way to successfully complete an organized project. The project plan for the Lincoln Memorial Shrine Project included three phases - planning, initiation, and completion. The planning phase began with understanding the client's problem statement, researching previous work, and identifying the most feasible solutions. The initiation phase consisted of the researching and collecting of data, building a geodatabase, and developing the web application. The completion phase entailed the writing of the final report and presenting the finished product to the client. Although, no project is accomplished the way it is originally envisioned; through discussions with the client and from delays due to time conflicts with the MSGIS program or from incomplete data, some elements were delayed or altered from their original intent. Table 3-3 illustrates the original time schedule of the project when initiated. 


\begin{tabular}{|l|l|l|l|l|l|l|l|l|l|l|l|l|}
\hline Activity & Jan & Feb & Mar & Apr & May & Jun & Jul & Aug & Sep & Oct & Nov & Dec \\
\hline Planning & & $\mathrm{X}$ & $\mathrm{X}$ & $\mathrm{X}$ & & & & & & & & \\
\hline $\begin{array}{l}\text { Collection of } \\
\text { Client Data }\end{array}$ & & & & $\mathrm{X}$ & $\mathrm{X}$ & & & & & & & \\
\hline Data Research & & & & & $\mathrm{X}$ & $\mathrm{X}$ & & & & & & \\
\hline Georeferencing & & & & & & & $\mathrm{X}$ & & & & & \\
\hline $\begin{array}{l}\text { Database } \\
\text { Creation }\end{array}$ & & & & & & & $\mathrm{X}$ & & & & & \\
\hline $\begin{array}{l}\text { Web App } \\
\text { Development }\end{array}$ & & & & & & & & $\mathrm{X}$ & $\mathrm{X}$ & & & \\
\hline Testing & & & & & & & & & & $\mathrm{X}$ & & \\
\hline Documentation & & $\mathrm{X}$ & $\mathrm{X}$ & $\mathrm{X}$ & $\mathrm{X}$ & $\mathrm{X}$ & $\mathrm{X}$ & $\mathrm{X}$ & $\mathrm{X}$ & $\mathrm{X}$ & $\mathrm{X}$ & \\
\hline $\begin{array}{l}\text { Project } \\
\text { Delivery }\end{array}$ & & & & & & & & & & & & $\mathrm{X}$ \\
\hline
\end{tabular}

Table 3- 3. Initial Project Plan.

The planning phase of the project progressed as planned, meeting with the client to work out time schedules and learn more about requirements and solutions. The first change from the original plan was in the second stage of initiation. The collection of the original letters used for original data was supposed to be selected and received during the month of May so that a thorough screening of the spatial value could be attained, however the letters were received in early June, 2015. Upon examining the provided data, the spatial value contained in the letters was not always clearly stated. Further research into the regimental history as well as locating historical battle maps were needed to confirm locations indicated in the source letters. This further research delayed the project by a month, completing and organizing the data into an Excel file by early July, 2015. The second change in the project plan came with the building of the Web Application. Originally, since the client did not possess a server, the plan had been to publish the story map as a web service to ArcGIS Online, where an account could be created and the owner make desired changes as needed from the site. However, ArcGIS Online did not provide the flexibility and customization required for the finished product, therefore it was decided to host the service on the University of Redlands local server and develop the application in ArcGIS JavaScript API for the custom developments. Upon the completion of the initiation phase, other minor delays occurred for the final product and were addressed as needed.

\subsection{Summary}

In order to maintain a working schedule and complete the project as the client desired, it was necessary to create the project plan. Within this project plan a list of functional and non-functional requirements, a system design, and a time table were established through cooperation with the client. However, due to delays from acquisition of the original data source and additional requirements, the project plan was altered from its original design. 


\section{Chapter 4 - Database Design}

Chapter 4 describes the conceptual data model, logical model, data sources, and data processing for the Lincoln Memorial Shrine Project. Section 4.1 describes the conceptual model and the associations among the data, followed by Section 4.2 that outlines the logical database structure. Section 4.3 states the sources of the original data provided by the client, whereas Section 4.4 describes the methods of data collection. Section 4.5 discusses the organization of the data and how it was implemented into the project structure. Finally, Section 4.6 summarizes the chapter.

\subsection{Conceptual Data Model}

The conceptual model is a method of how to convey the client's problem through the creation of domains and the description of these domains through their functionalities and shared relationships. Figure 4-1 illustrates the conceptual model for the Lincoln Memorial Shrine Project and will be outlined in this section.

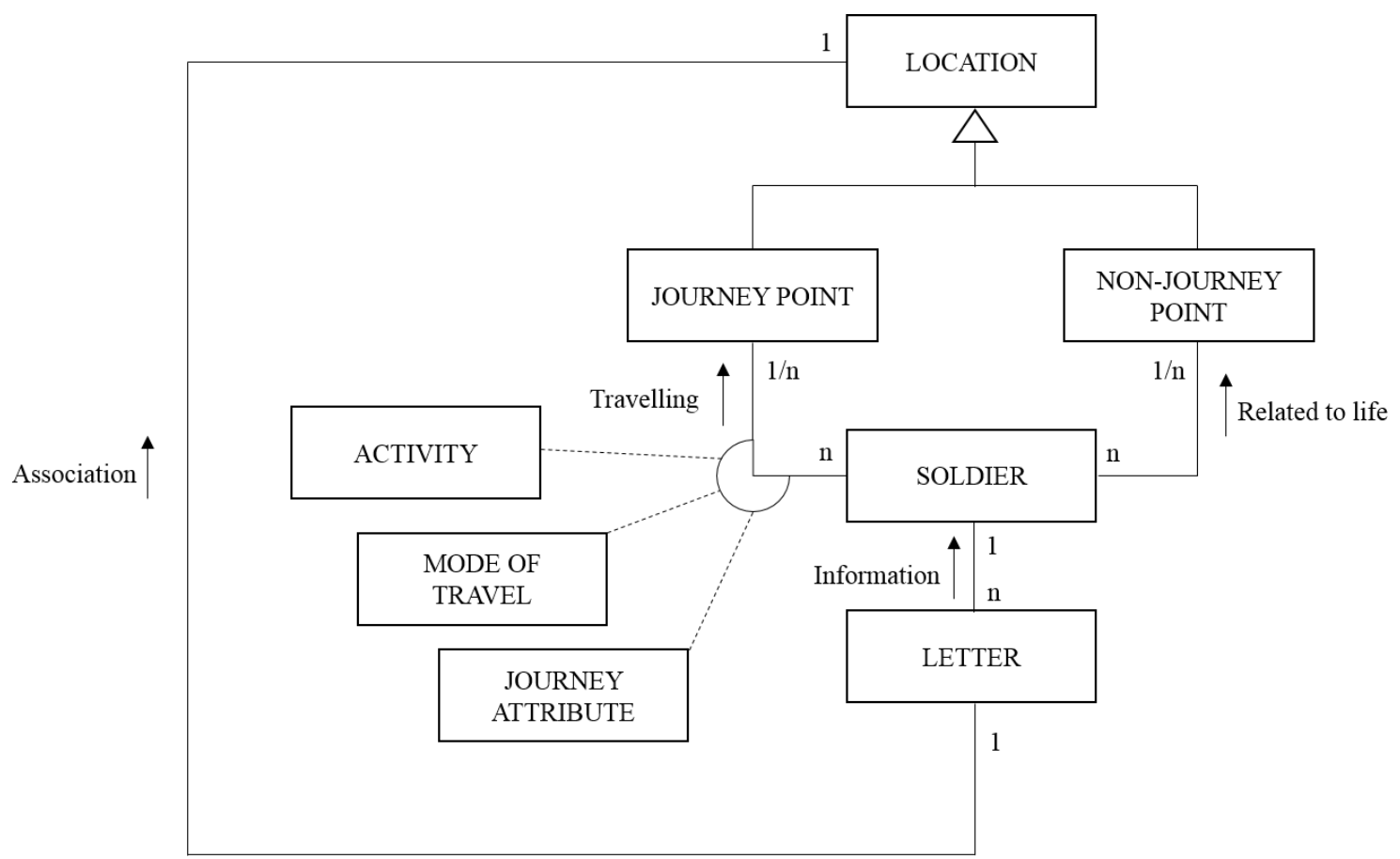

Figure 4- 1. Conceptual Data Model.

The primary class is location which is divided into two sub-classes of journey point and non-journey point. Serving as a common element between the journey and nonjourney points is the soldier class, where there is a one to many or a many to many relationships. The soldier class is associated to the journey point based on the concept that the soldier is traveling to the journey points, whereas the soldier is associated with the non-journey points based on the concept that the non-journey point is related to the soldier's life. There are three attributes for the link between the soldier class and the 
journey point - activity, mode of travel, and journey attribute. The activity describes the actions and doings of the soldiers, the mode of travel holds the details the way a soldier reached the location, and the journey attribute contains details like date and time. Soldier class is also linked to another class known as letter, which has a one to many association with the soldier class based on the concept that it has information about the soldier. The location class is also associated to the letter class with a one to one relationship, which means one letter per location/time.

\subsection{Logical Data Model}

The logical model is the representation of the geodatabase design and details the data requirements that were addressed within the conceptual model. Figure 4-2 illustrates the logical model for the Lincoln Memorial Shrine Project and will be outlined in this section.

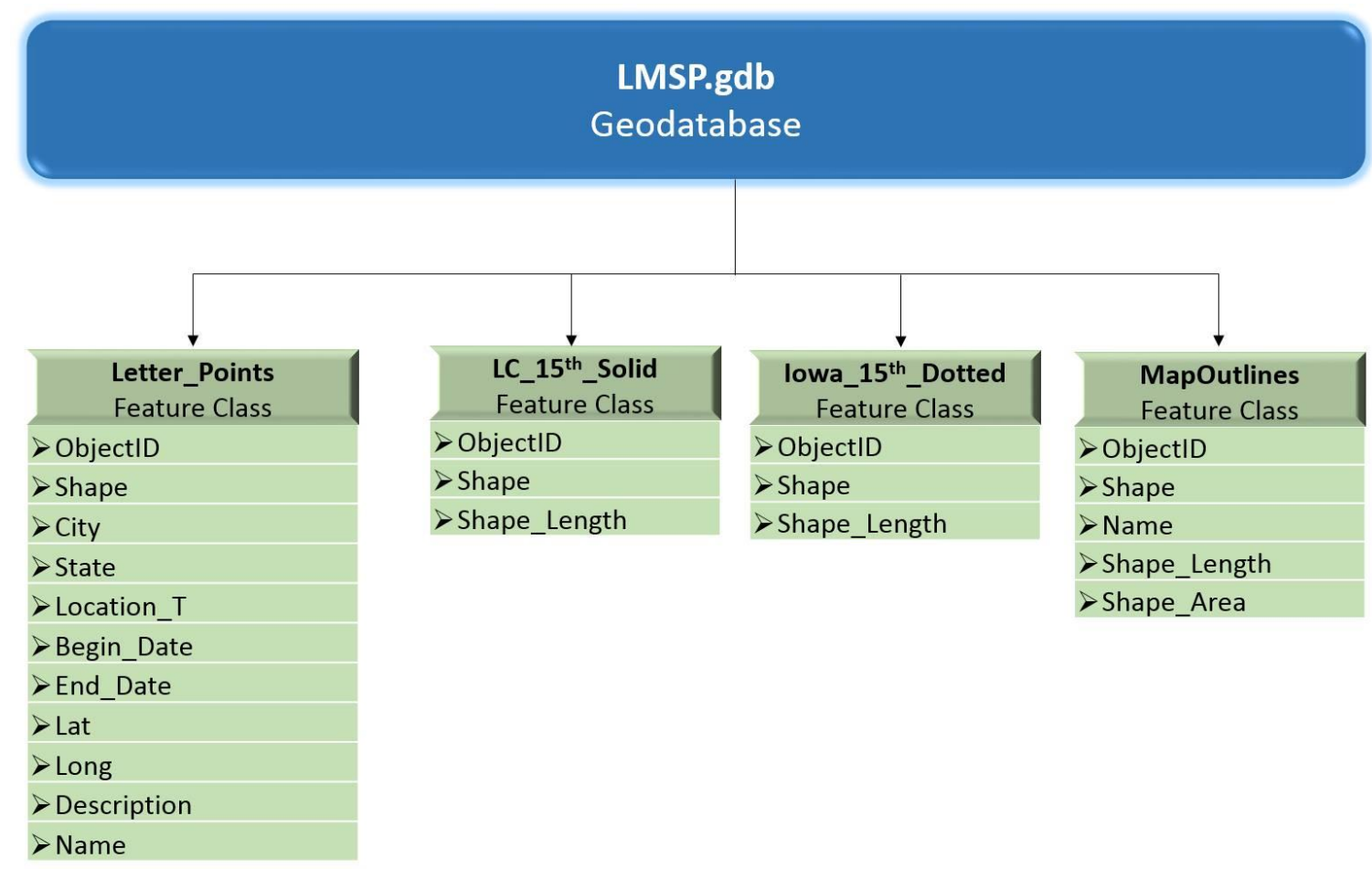

Figure 4- 2. Logical Data Model.

The logical model consisted of one geodatabase that was constructed of four feature classes. The first of these feature classes is Letter Points, a point feature class which holds the location information of the letter data and the activities associated with the American Civil War and with the soldier's journey. The second feature class is the line feature class Logan Crawford and the $15^{\text {th }}$ Iowa, which shows the journey of Logan Crawford and the $15^{\text {th }}$ Iowa Regiment from early 1862 to mid-1864. The third feature class is another line feature class called The $15^{\text {th }}$ Iowa Infantry that follows the events of the $15^{\text {th }}$ Iowa regiment after the capture of Logan Crawford in July of 1864 . The last feature class, Map Outlines, is a polygon feature class that contains the outline polygons 
of the eight battle maps overlaid upon the original base map. These polygons were designed to show the visual footprint of each georeferenced battle map, acting as an interactive layer within the web application.

\subsection{Data Sources}

The Lincoln Memorial Shrine has a collection of personal letters from various soldiers during the American Civil War. It was decided during the month of March 2015 that the curator of the Lincoln Memorial Shrine (LMS), Nathan Gonzales, along with the client John Glover, would select one soldier from the archive. In April, Gonzales and Glover selected Logan Crawford, a Union soldier that the LMS had begun the process of archiving his personal letters before the initiation of the project. In June, the client provided a list of 61 personal letters of Crawford's along with five letters from his commanding officers. Figure 4-3 is an example of a letter with a written date and general location that was often included in military correspondence at that time. These 61 letters were evaluated for their spatial value and significance, but due to redundancies of location or irrelevant content, only twenty would be used in the final product. These twenty letters would make up the basis and overall substance of the Lincoln Memorial Shrine Project.



Figure 4- 3. Sample of written location and date in a Civil War letter. 


\subsection{Data Collection Methods}

The original twenty letters presented by the Lincoln Memorial Shrine provided enough data for a starting point and an overall timeline for the project. Yet through further discussions with the client, a decision was made to research the regimental history of Logan Crawford to not only confirm his locations, but to find additional locations that could possibly add further detail to the story.

The Regimental History of the 15th Iowa Infantry (Figure 4-4) provided a detailed chronology of the troop movements and military engagements, as well as personal accounts from officers' reports. With this new data, the story expanded from the original twenty points of Crawford's to 46 points that now included Crawford, the Regimental history, and other points of historical significance. However, even with the inclusion of the regimental histories, not all chronological data were presented. Some dates between locations were not included, especially if those locations were of minor troop movements or of small engagements. Therefore, the data between two unknown points were left with partial data with the first point with the start date and the second point with the end date.



Figure 4- 4. Example of the Regimental History of the 15th Volunteer Iowa.

With the point data now completed, a set of maps was needed to portray the point data in a visual context. An 1862 historical map of the time period was selected from the David Rumsey Collection that displayed the area needed as well as military locations, railroads, rivers, and roads (Figure 4-5). Additional maps of individual battles were also acquired that display military positions related to Crawford and the 15th Iowa Infantry or display a battle of historical significance. All samples of battle maps can be found in Appendix B. 


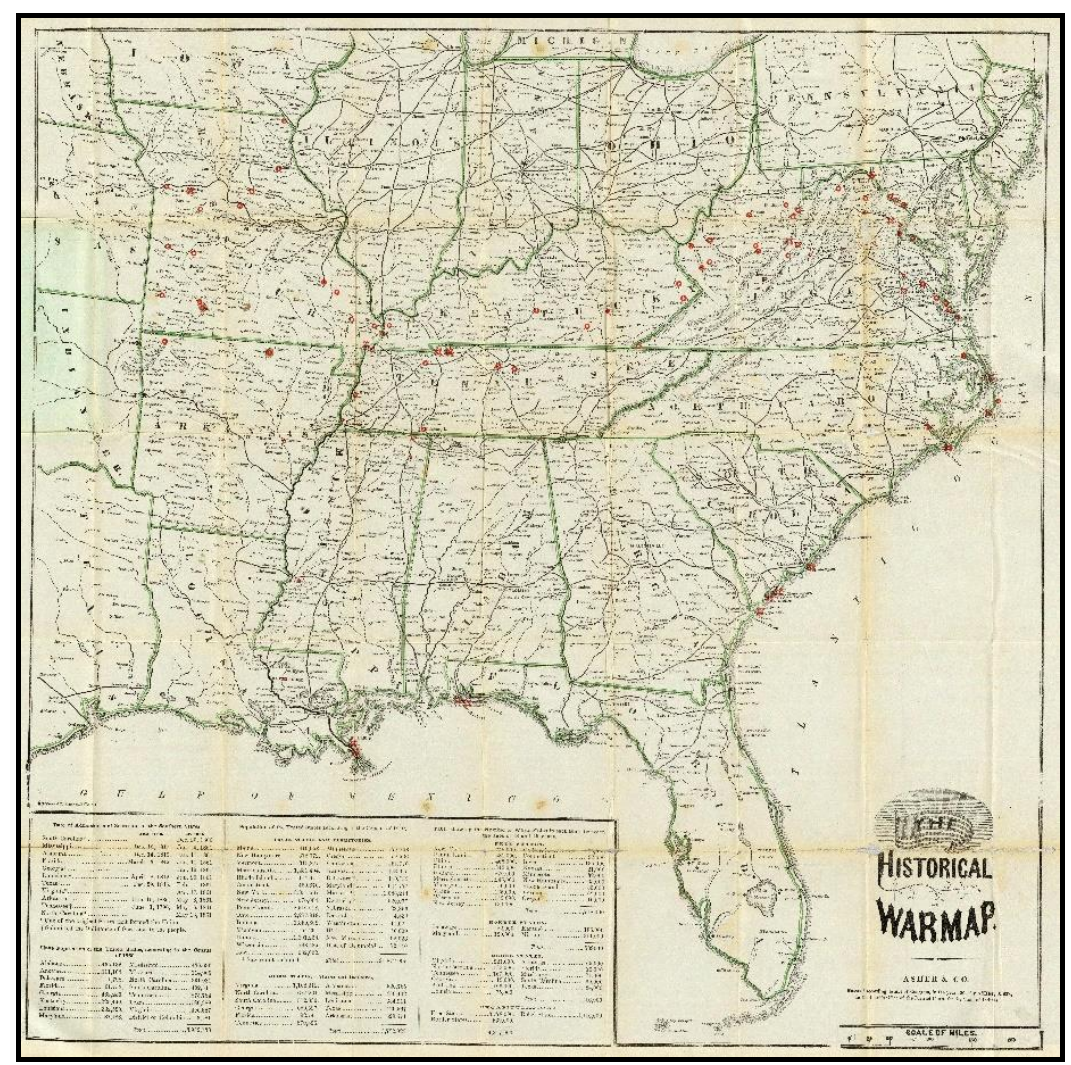

Figure 4- 5. 1862 Historical War Map.

\subsection{Data Scrubbing and Loading}

The data collected from the original twenty letters provided by the Lincoln Memorial Shrine and the additional data compiled from the regimental history of the 15th Iowa Infantry had no spatial reference, only a general location. Therefore the data would have to be placed manually by creating a single comma separated value (.csv) format file and converted into a feature class that could then be published to a feature service for use in the web application. In order to make the data as accurate as possible, the general locations were cross-referenced with the original letters, regimental histories, and battle map locations. The determined point would then be placed as closely as possible to the geographic area described or near a noted landmark.

Starting with the map image shown in Figure 4-5, the original projection of the map document must be determined to allow minimal warping during the georeferencing process. It was decided that the World Polyconic was the correct projection, as it was commonly used in the 19th Century. The coordinate system was set to WGS 1984, and a USA State Boundaries basemap was added as a separate layer to be used as a reference for placing ground control points. In order to accurately georeference an image, a pair of control points must be connected from the non-georeferenced source image to the referenced base map to establish a link. In order for first polynomial georeferencing a minimum of three control points is necessary for global accuracy, but does not guarantee local accuracy. In order to have the best local accuracy, twenty-three control points were used to place the map image correctly on the basemap using spline transformation, 
usually on unique feature such as state boundaries or intersections. However, there were still some inaccuracies in the new georeferenced map, due to the limitations in spatial accuracy of the hand drawn cartography methods of the late 19th Century. The transformation process described here was repeated for the eight additional battle maps, but only three control points needed for the first polynomial transformation were needed to successfully georeference each of these maps. By using the first polynomial transformation on the battle maps, the straight lines of the original rasters were preserved and avoided warping by addition additional control points. After completion of the georeferencing process, all maps were then published to ArcGIS Online for inclusion in the Web Application.

In order to form an interactive element to the web application, eight battle maps were georeferenced. Then eight polygons were created by manually digitizing the outside borders of the battle maps using the Create Features tool in ArcMap. Once all the polygons had been created, attributes were manually entered for each feature. The polygon feature class was included in the geodatabase and were published as a service on ArcGIS Online. The polygons served as graphical indicators of an underlying map of importance when hovered over by the user within the web application. When the user would click on the polygon feature the underlying map would become the new basemap and zoomed to the new extent. Chapter 5 will go into more detail on the specifics of development of the interactive web application.

\subsection{Summary}

This chapter discussed the conceptual and logical data models for the development of the web application for the Lincoln Memorial Shrine Project. The chapter also discussed data collection and the methods taken to insure the accuracy of the data before its use in the web application. Further discussion of the deployment of the data is articulated in more detail in Chapter 5. 


\section{Chapter 5 - Implementation}

This chapter explains how the project was implemented. There are four sections in this chapter entailing the final data preparations in Section 5.1, the publication of web services in Section 5.2, and development of the web application in Section 5.3. The chapter concludes with the summary in Section 5.4.

\subsection{Final Data Preparations}

The work for the Lincoln Memorial Shrine Project prior to this point was in preparing the data for the building of the application which displays the journey of Logan Crawford and the 15th Iowa Infantry in an interactive user interface (UI). Several steps were still required before the application could be implemented and transferred over to the web for public use. These final steps included defining the point, line, and polygon features and publishing all the data to a server.

As discussed in chapter 4, data were created from the historical letters of Logan Crawford and from information gathered from the regimental history of the 15th Iowa Infantry. It was then saved in an Excel document with the categories of City, State, Location Type, Start Date, End Date, Latitude, and Longitude. Thereafter, the data was uploaded in ArcGIS for Desktop to get a series of point data that were symbolized with small bright red circles (Figure 5-1a).

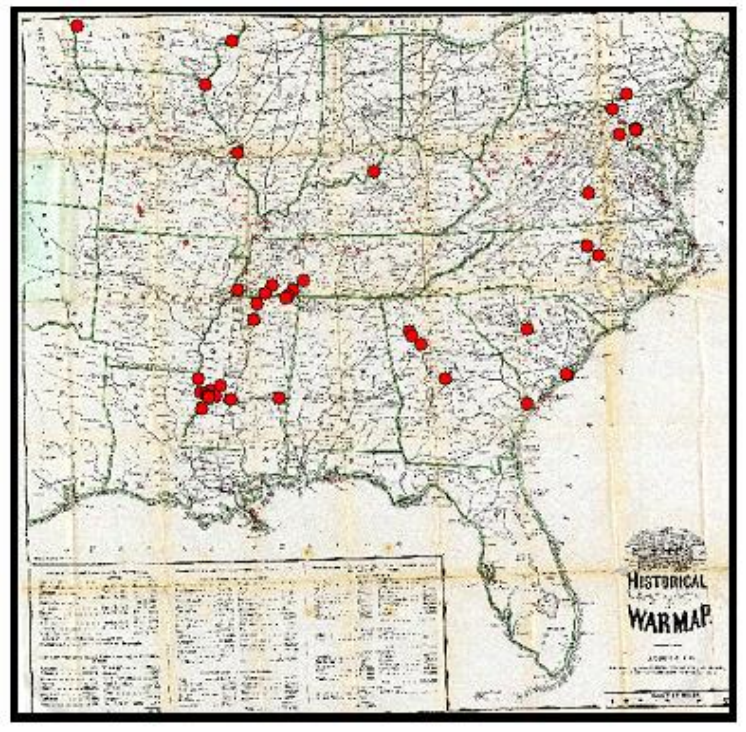

(a)
Points

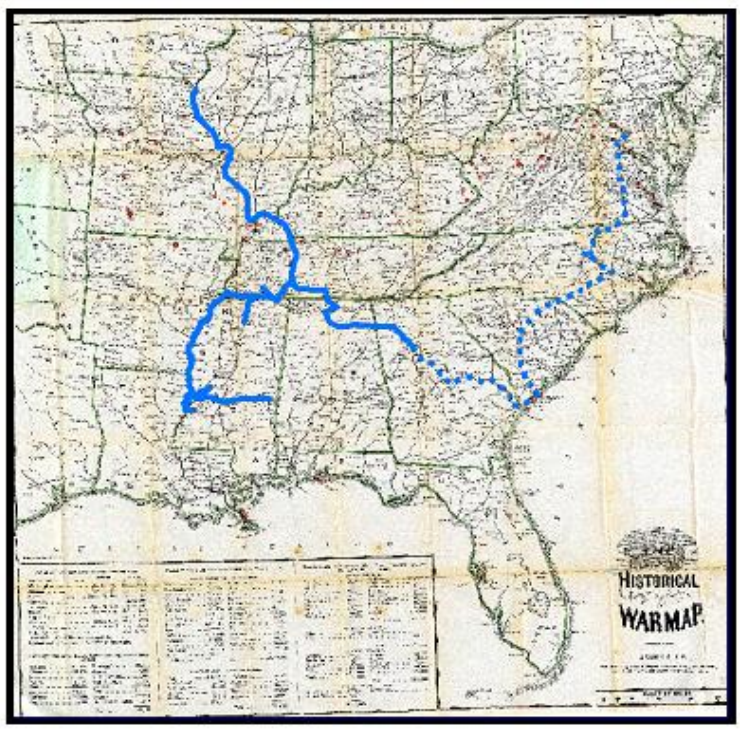

(b) Lines

Figure 5- 1. Data Preparations

In order to give the points a visual order, indicating the path of Crawford and the $15^{\text {th }}$ Iowa Infantry, two line feature classes were created. The first was a solid blue line (Figure 5-1b) indicating the path of Crawford with the $15^{\text {th }}$ Iowa Infantry from the time of the regiment's creation in December of 1861 until Crawford's capture in July of 1864. 
The second was a dotted blue line (Figure 5-1b) indicating the path of the $15^{\text {th }}$ Iowa Infantry from the time of Crawford's capture in July of 1864 until the Grand Review in Washington D.C. in May of 1865. These line features were drawn based on travel routes indicated in Crawford's letters or through the regimental history of the $15^{\text {th }}$ Iowa Infantry. Although due to some lack of data in the letters or research, some lines were drawn with an assumption that troop movements would be taken by the most accessible road or pike. Other discrepancies with the line features were due to the cartographic inaccuracies of the hand drawn historical 1862 basemap, which does not align accurately with modern geographic maps. The differences can be seen in Figure 5-2 that display in light blue the river path in the modern basemap verses the dark blue line which illustrates the river path from the historical basemap.

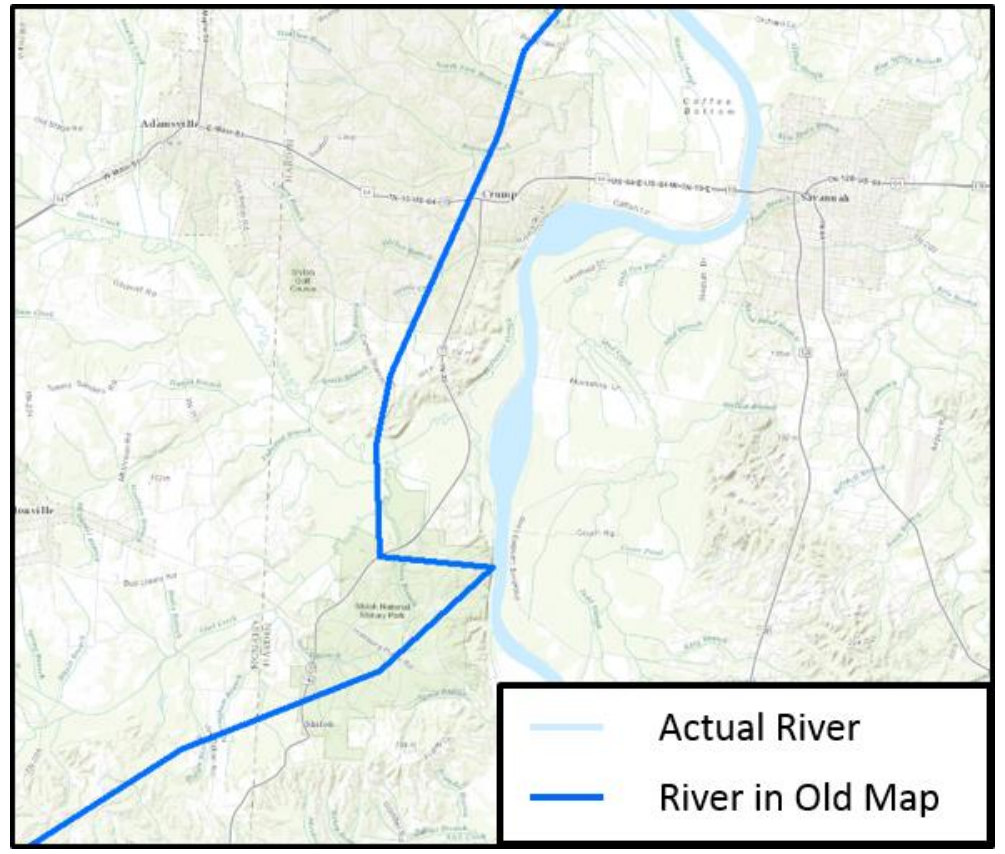

Figure 5- 2. Differences between historical and modern geographical maps.

\subsection{Publishing Services}

With the point, line, and polygon data stored in a file geodatabase and the historical map documents georeferenced to their map locations, these feature classes now needed to be published as map services, so that a web application could be created. For the data, there were two available sharing options- either publish to ArcGIS Online or publish to ArcGIS for Server, both provided by the University of Redlands. Publishing the data to ArcGIS for Server would require an Enterprise geodatabase (EGDB) to register or copy the data, where the data could be synced for automatic updating. This option was not needed to fulfill the scope of the project, and after looking at editing options with Esri's Journal Map template, an EGDB would have been problematic. The reason an EGDB would be problematic is that with the Journal Map template each slide and zoom level is configured manually within the template, therefore, if a new information is needed to updated the application, it also must be done manually. If an EGDB would have been constructed for use, the new data would be updated in the database, but the updates 
would not be reflected in the Journal Map. Therefore, the better option was to publish the data on ArcGIS Online. The same two options of publishing to ArcGIS for Server or ArcGIS Online were also available for publishing the map data, but after exploring options for ArcGIS Online, it was discovered that because of the size of the maps, the usage of Esri ArcGIS Online credits would have been at great cost to cache services. These services were therefore published to the University of Redlands ArcGIS for Server and then linked to ArcGIS Online.

\subsection{Web Application}

Once services were published, the development of the web application began. First, all the data layers were collected in the web map, where all point, line, and polygon features could be defined and metadata were created, as shown in Figure 5-3.

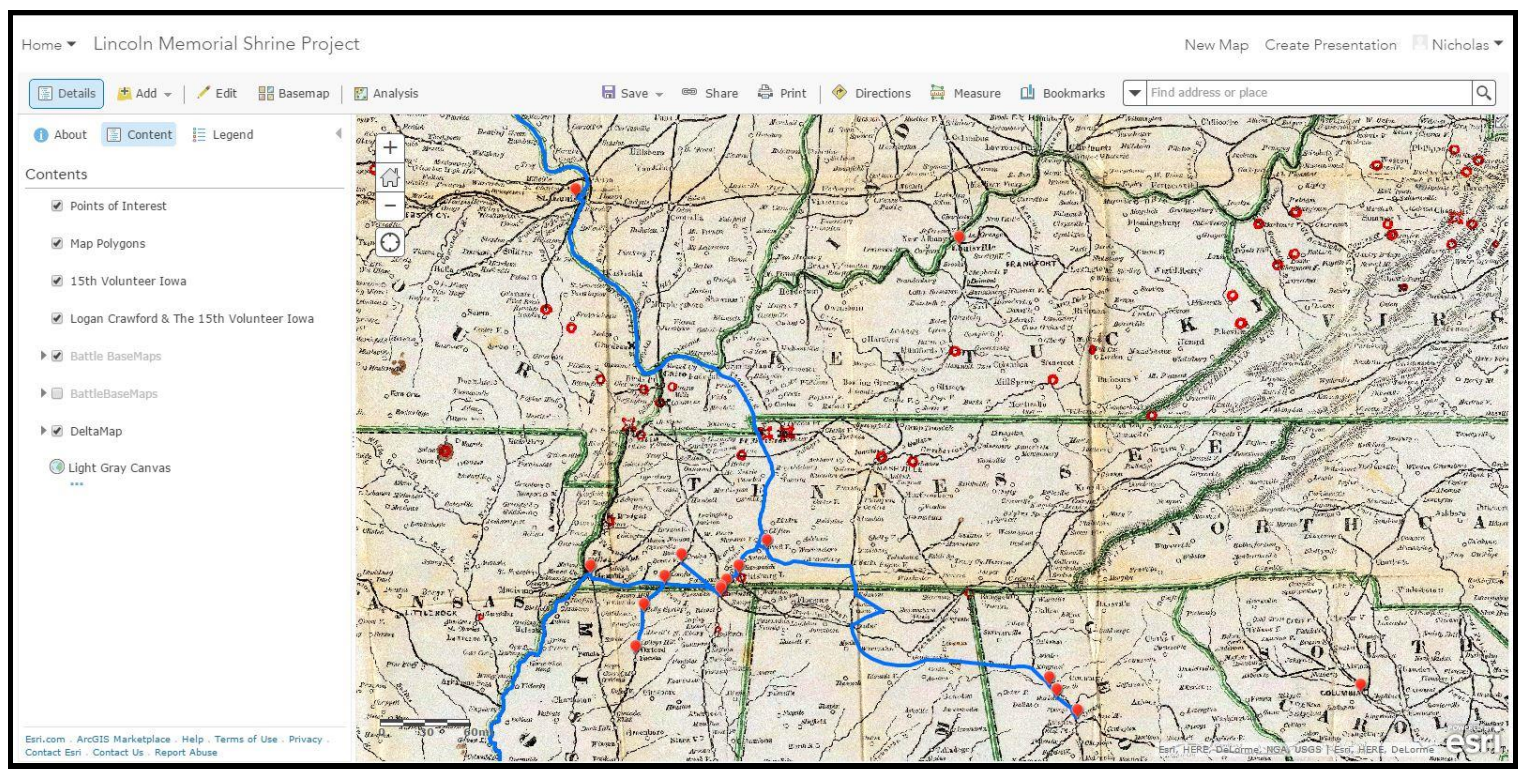

Figure 5- 3. ArcGIS Online Web Map.

The visibility setting of city scale was applied to all the battle maps and the full extent was used for the main map. Next, the web map was configured to the Journal Map template in ArcGIS Online, where the template could be customized and the zoom extent of the various locations could be configured. In building of the Journal Map, point descriptions, historical images, scans of the original documents, links to transcribed versions of historical letters, and additional information were provided to the multiple locations in chronological order. After the skeleton of the Journal Map was created, a unique ID was generated to which the map could be linked to the ArcGIS API for JavaScript.

An interactive element was added to the Journal Map in the form of eight individual battle maps. The purpose of this interactive element was to give an opportunity to the user to explore the map and give a sense of discovery for them. In order to make this custom element for the web application, some custom code was needed to allow the 
necessary changes. By accessing Esri's repository on Github, the developer code for the Journal Map template was downloaded and modified based on the requirements of the client. The unique ID for the Journal Map was then added to the downloaded developer code to establish a link to the data from ArcGIS Online. The code was first modified for a Map Navigation feature (Figure 5-4), which allows the user to manually follow the story by clicking on any point within the Journal Map and the selection will then zoom to the associated slide.

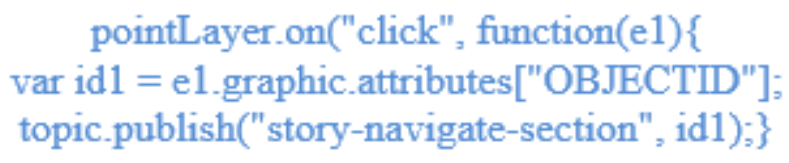

Figure 5- 4. Code for Navigation Feature

The second code modification (Figure 5-5), was developed for a Move-over and Move-out feature, which highlights the eight polygon features from the data in ArcGIS Online. Once the user clicks on the polygon, the Journal Map zooms to the battle map, showing the surrounding area and military positions to give a spatial context, and is also directed to the related data page in the Journal Map. The complete code written for this project can be found in Appendix C. 


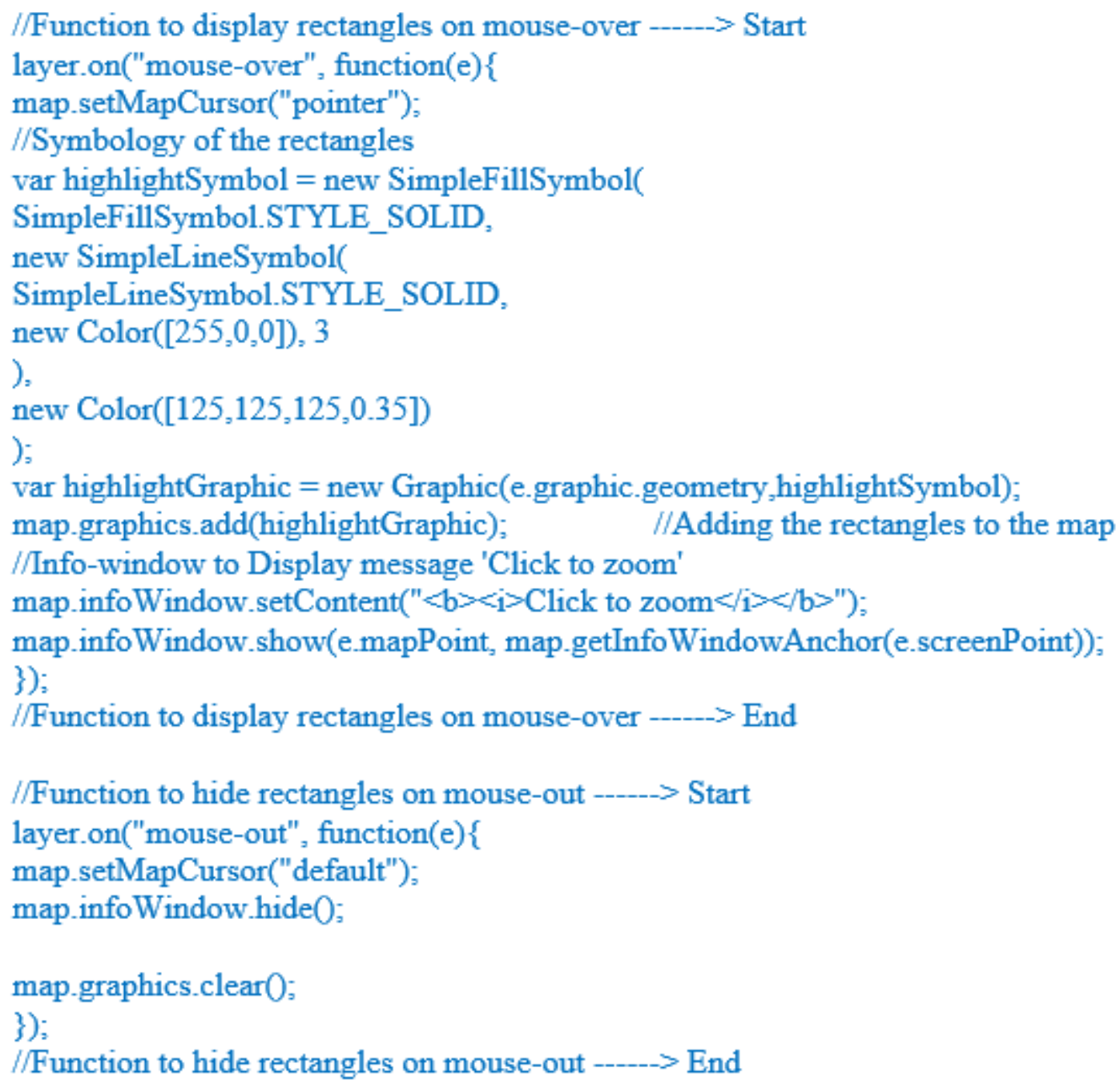

Figure 5- 5. Code for Mouse-over and Mouse-out Feature

\subsection{Summary}

This chapter detailed the deployment of the implementation process for the project. Section 5.1 covered the final stages of the preparation of the data to be shared with web application. Section 5.2 explained the publication of the feature and image services from ArcGIS for Desktop for their usage on the web. Section 5.3 discussed the development of the web application and the custom code for the application. 


\section{Chapter 6 - Results and Analysis}

This chapter provides an overview of the Journal Map application for the Lincoln Memorial Shrine and how it will help users to better understand the American Civil War, historical GIS, and appreciate history. The American Civil War is a popular topic among U.S. history scholars and hopefully through displaying a two dimensional object, such as a letter, in a visual context may inspire new ways of teaching history.

\subsection{Application Interface}

The development of the web application for the Lincoln Memorial Shrine was for the purpose of organizing and demonstrating archival letters into a visual learning experience. The Journal Map template was customized to tell the story of Logan Crawford and the 15th Iowa Infantry and include historical points of significance of the American Civil War. The application displayed the locations of Logan Crawford and the 15th Iowa Infantry based on the locations and paths indicated within the original letter documents and the regimental histories. Customized maps of significant battles were also embedded within the basemap to be displayed when the user accessed those points on the map.

\subsubsection{Viewer Application Interface}

The viewer application was developed from the Journal Map template from ArcGIS Online and modified with Esri's ArcGIS API for JavaScript. The interface was designed so that anyone regardless of age or skill could easily navigate the web application. When the Journal Map is first accessed, the user sees the historical 1862 basemap of the eastern half of the United States at a scale of 1:8,000,000 and the main paths taken by Logan Crawford and the 15th Iowa Infantry (Figure 6-1).

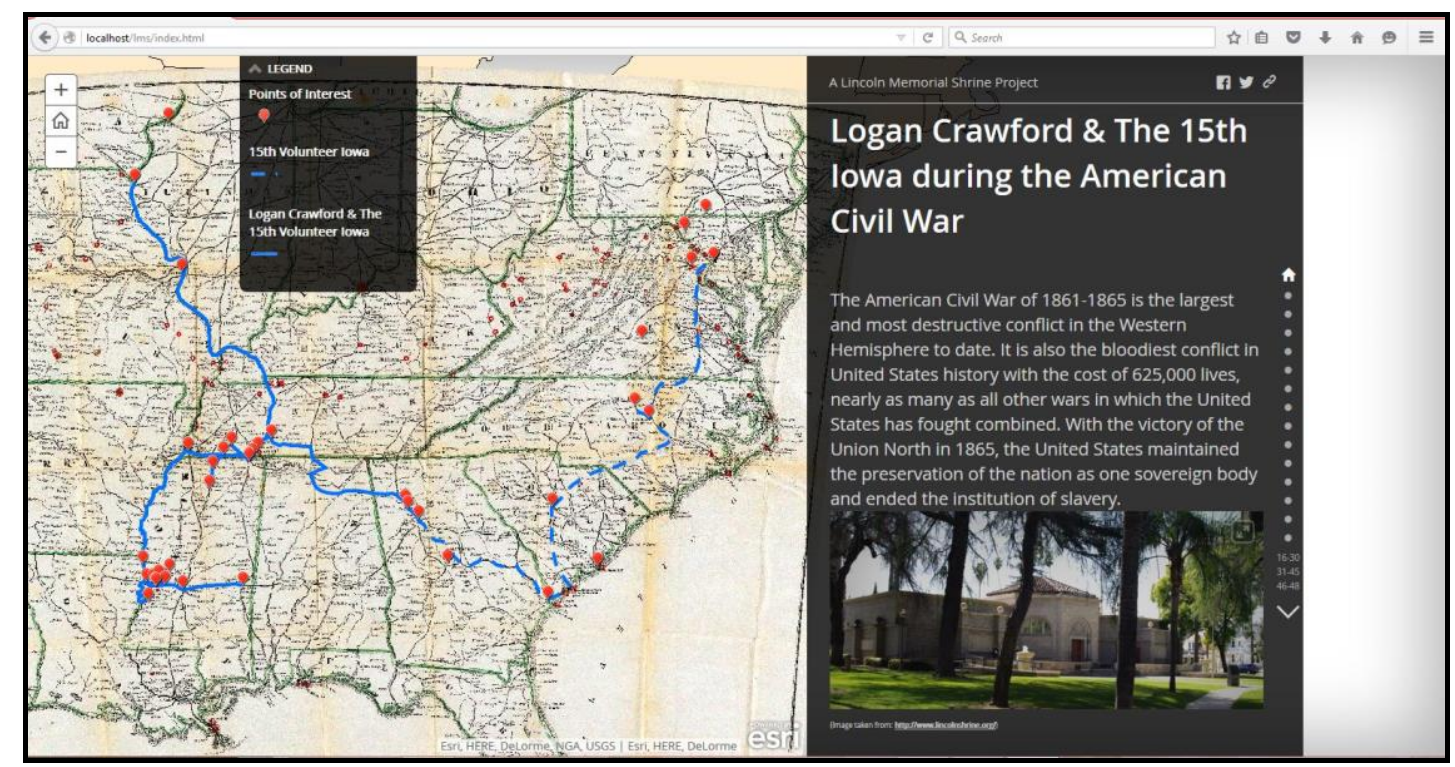

Figure 6- 1. Primary image of the web application. 


\subsubsection{Basemap}

The web application also displays the introductory column with a brief detailed description of the American Civil War, the Lincoln Memorial Shrine, and an About the map section with an included instructional video. The application also displays components that are important to describe.

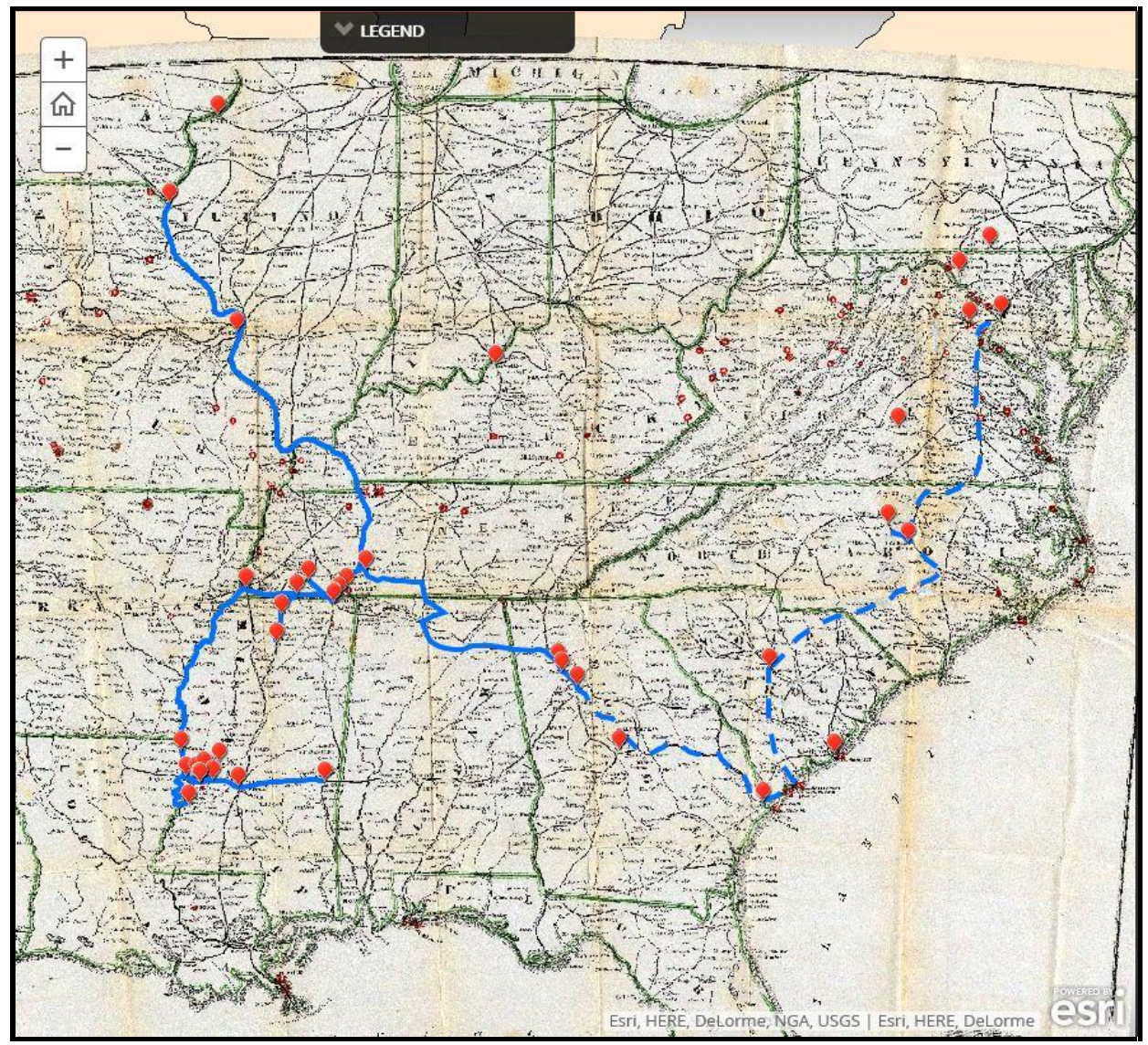

Figure 6- 2. Basemap

The basemap shows where the journey begins, where it ends, and its course through the southeastern United States. One way a viewer can have a better understanding of the data shown in the basemap is by accessing the Legend (Figure 6-3). 




Figure 6- 3. Legend

The Legend details the three elements placed inside the basemap. Points of Interest, indicated by red icons, show the point data collected from the personal letters of Logan Crawford, the regimental history of the 15th Iowa Infantry, and points of historical significance pertaining to the American Civil War. 15th Volunteer Iowa, indicated by a blue dotted line, shows the path of the 15th Iowa Infantry after July 22, 1864 when Logan Crawford was taken as a prisoner of war. Logan Crawford \& the 15th Volunteer Iowa, indicated by a solid blue line, follows the path of Logan Crawford and the 15th Iowa Infantry from its formation in December of 1861 through Crawford's capture on July 22, 1864 at the Battle of Atlanta. By understanding the Legend, a user can simply follow the journey paths within the basemap, click on the points of interest to access the point's popup and receive information about each event and the time passed between each point.

\subsubsection{Header}

The slide header gives an introduction of the overall topic pertaining to each individual slide (Figure 6-4). It is identified by the larger text than the rest of the topic in the slide to grab the attention of the audience. The header also provides a link to the website of the Lincoln Memorial Shrine and links for sharing the application to Facebook and Twitter.

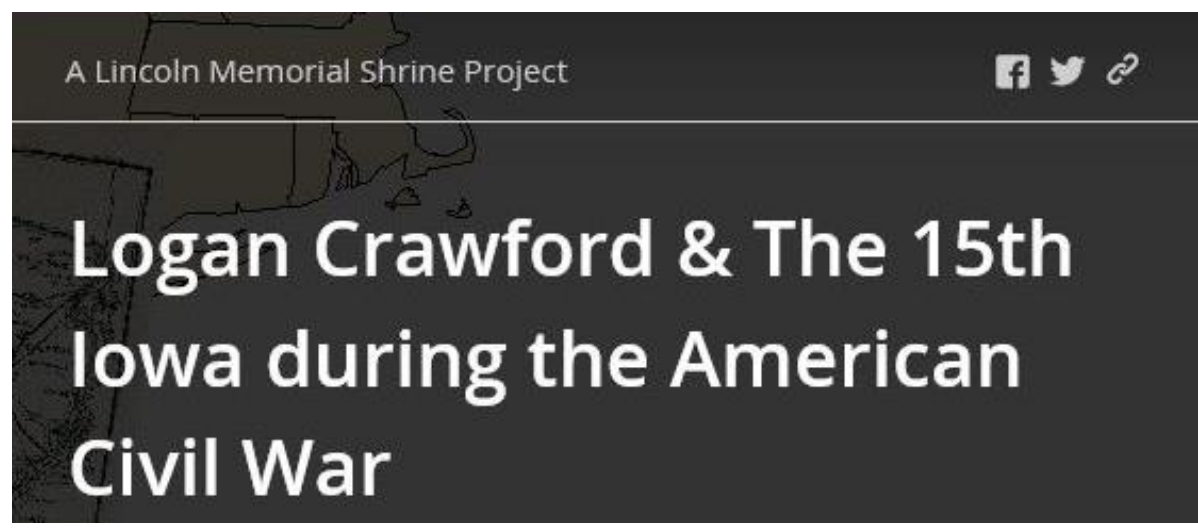

Figure 6- 4. Header 


\subsubsection{Thumbnails}

On the right hand side of the interface there is a vertical column of thumbnail bullets (Figure 6-5). These thumbnails present a chronological order that creates a timeline of the story of Logan Crawford and the 15th Iowa Infantry during the Civil War. The user may access new thumbnails by scrolling down, by clicking on the arrow below the bullets, or by clicking directly on the bullets. When selected, the new thumbnail will zoom to that location on the basemap and provide information about a specific event related to Logan Crawford or the Civil War.

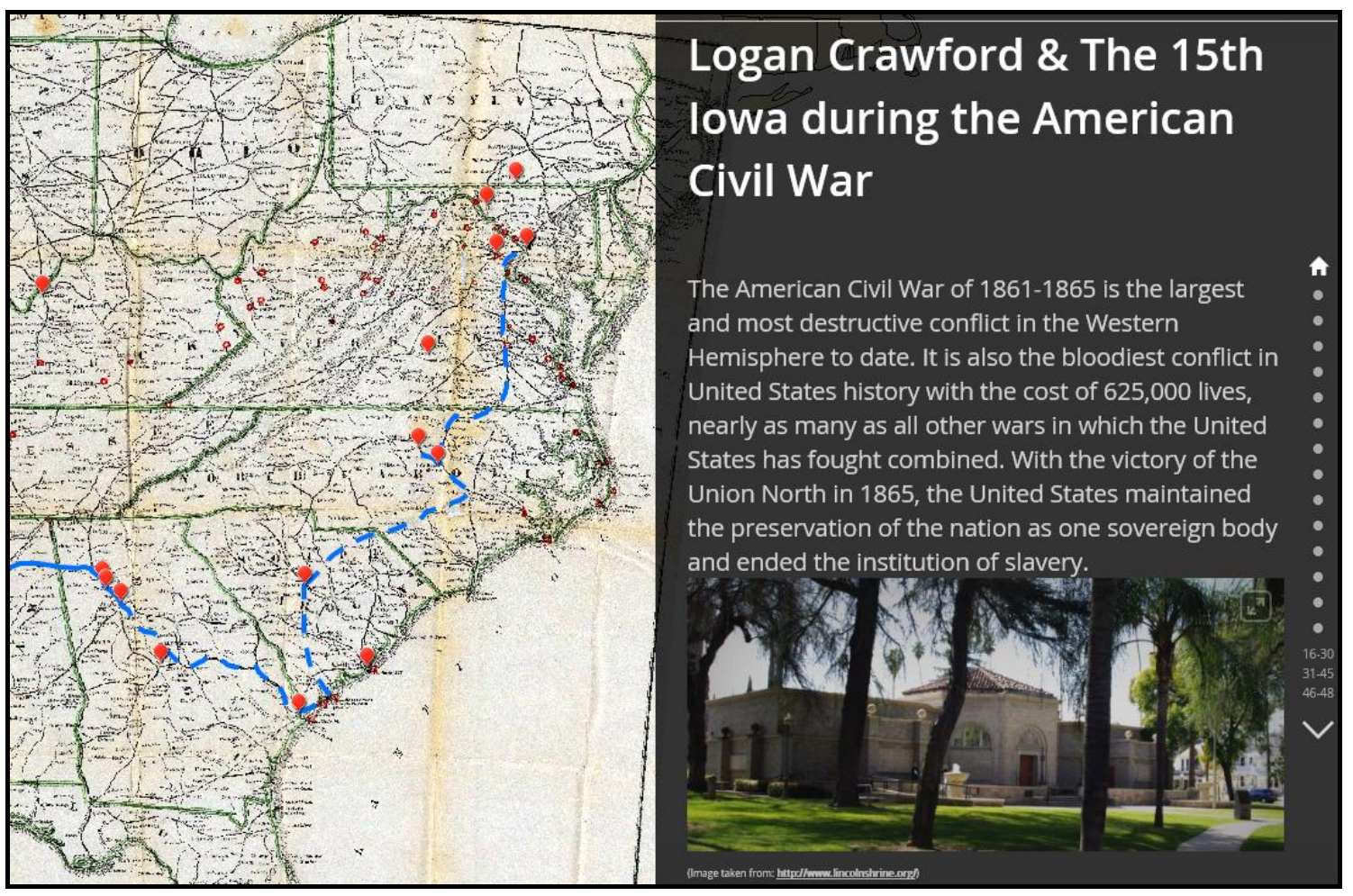

Figure 6- 5. Thumbnail Bullet.

The selected location will have an associated point visible in the map that will provide a pop-up of the location name and start and end date of that location's data. However, due to the lack of precise start and end dates from lesser known historical events, in some pop-ups only the start or end date is listed. Figure 6-6 provides a view of a selected location with a pop-up window. 


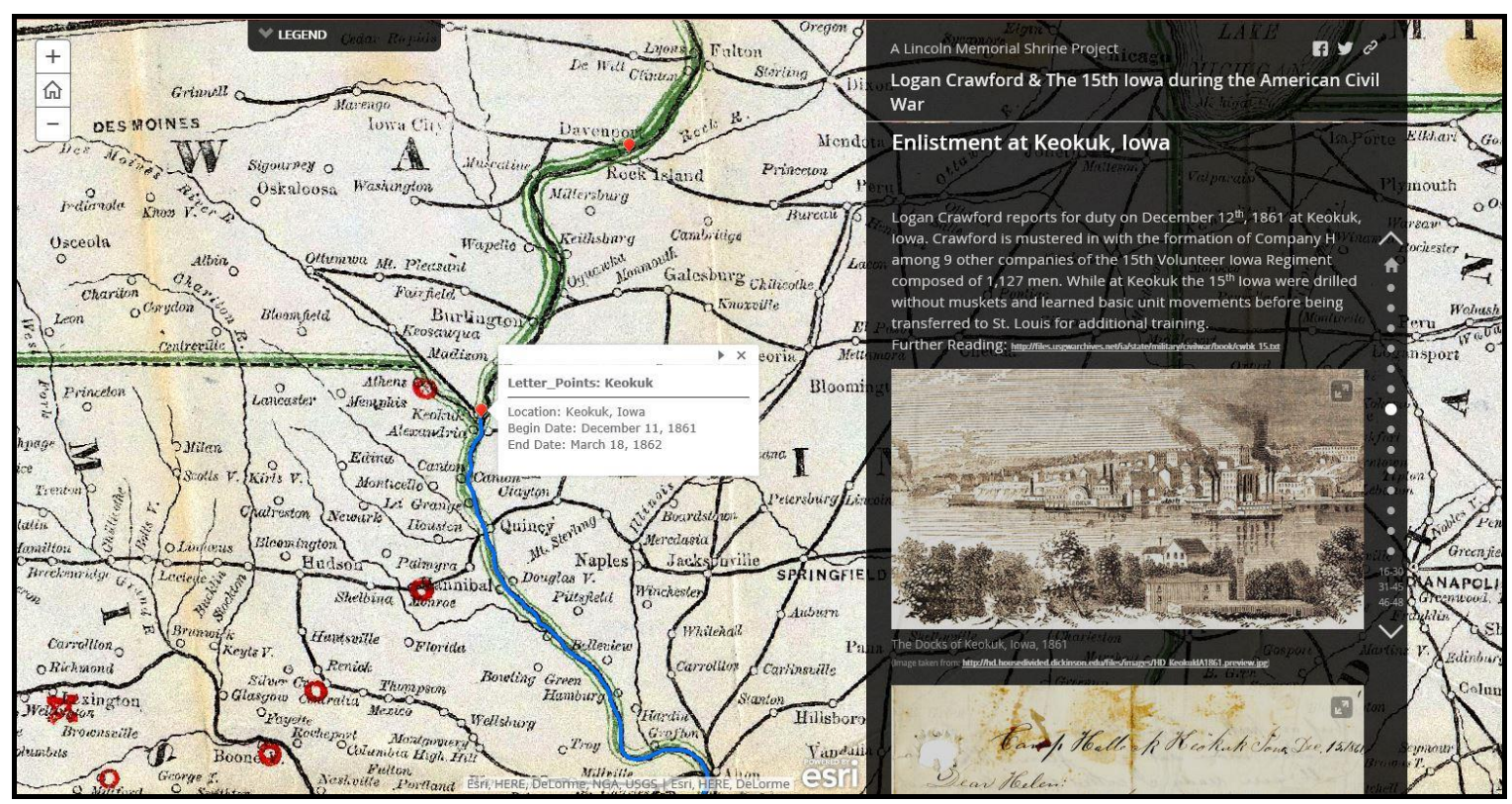

Figure 6- 6. Selected Pop-up Example.

In addition, when the user is accessing a specific point within the Journal Map application, the header will indicate the name of the event associated with that point, followed by a brief history and an internet link for further reading. An historical image will be attached to give the user a depiction of the events as documented at the time of the event. Finally, a copy of the original letter written by Logan Crawford will be attached and a link to a typed version of the letter will be provided.

\subsubsection{Battle maps}

An application created for this project provides an interactive element for the battle maps associated with eight points of interest. These battle maps are maps that depict the lines of battle of Union and Confederate forces, associated with the battles of Logan Crawford and the 15th Iowa Infantry or other battles of historical significance. The application is best utilized if the user is accessing the basemap manually by panning through the map. When the user hovers over a location of one of the battle maps a rectangular box will appear in red (Figure 6-7). 


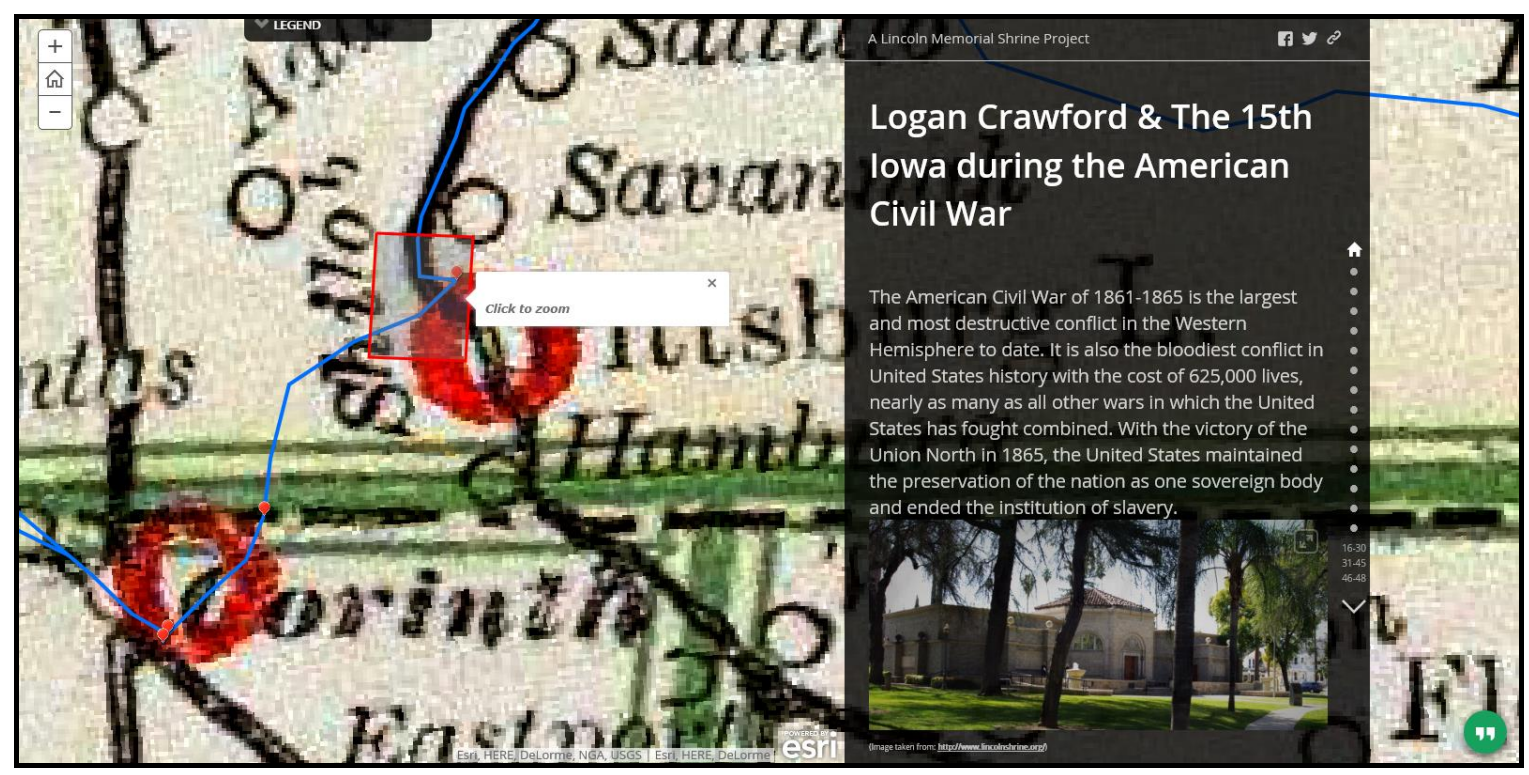

Figure 6- 7. Example of polygon feature.

When the polygon is selected, the application will zoom to that selected point and the associated data will appear. The hidden battle map will now be the new basemap illustrating the battle depicted with the connected point data and history (Figure 6-8).

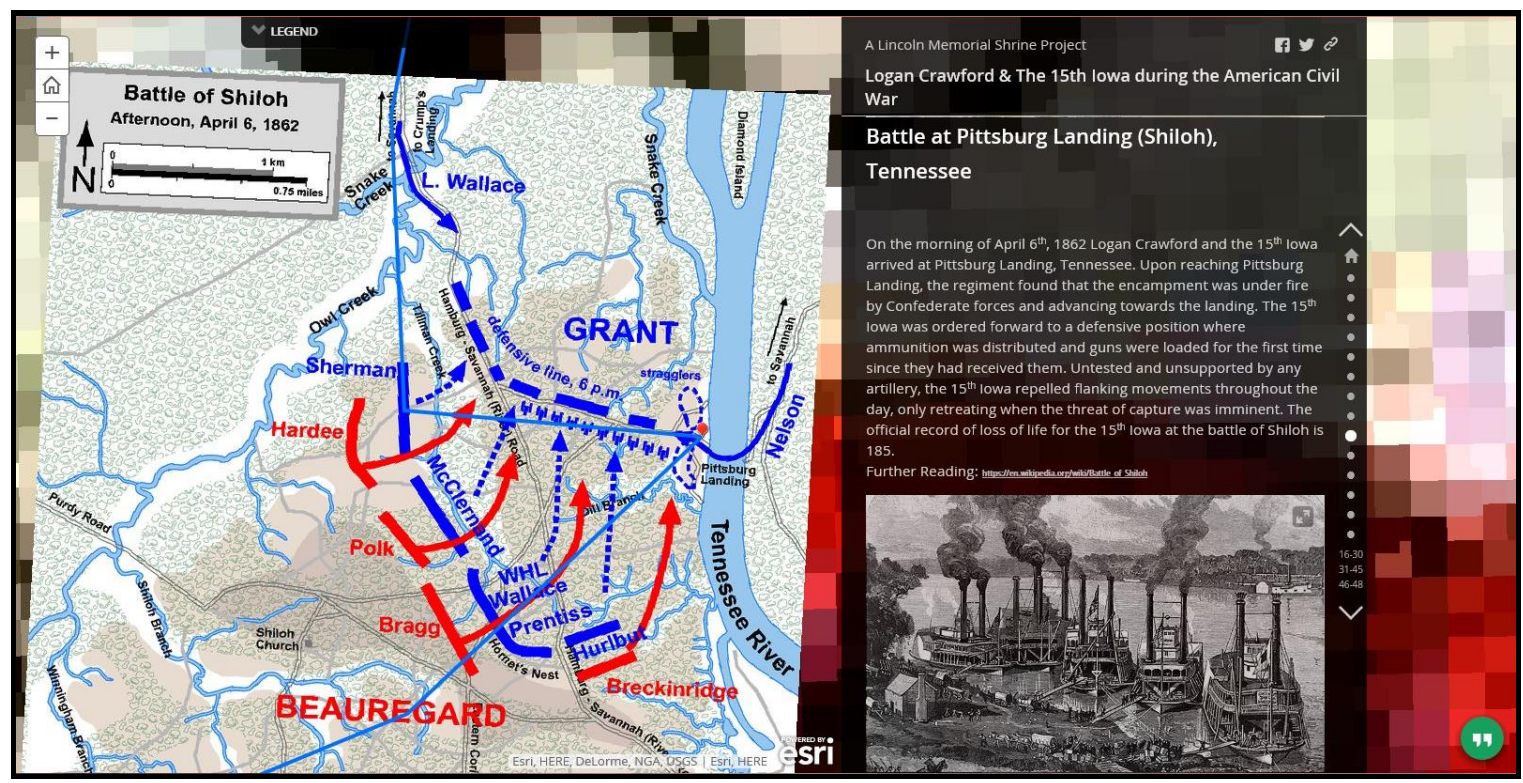

Figure 6- 8. Example of battle map feature.

The battle map feature allows the user to see the size and area of where the actual battle occurred. If the user is confused as to the location of the area, the user may zoom out of the battle map basemap to see the surrounding area. Once zoomed out the battle map will disappear and the original basemap will reappear. 


\subsection{Summary}

This chapter illustrated the usefulness of the application and the functionalities of the user interface. The interface was constructed so that a user could navigate the application with little experience in order to provide an educational story of Logan Crawford and the 15th Iowa Infantry. The web application provides detailed information about Crawford, his letters, and the histories associated with points on the map. The application also provides a sample of battle maps that allow the user to view the location and troop positions in a spatial context. 


\section{Chapter 7 - Summary and Future Work}

The goal of this project was to use a small sample of unorganized historical letters from the Lincoln Memorial Shrine and develop an application that could demonstrate how the letters could be used in a visual context for public consumption. The topic of the developed application was focused around the Union soldier Logan Crawford and his regiment of the 15th Iowa Infantry, following their routes of deployment throughout the American Civil War. The application was created so that a visitor to the Lincoln Memorial Shrine or a person visiting the Lincoln Memorial Shrine's website can easily access some of the collections and understand the importance of the archive.

The project satisfied a set of functional and non-functional goals agreed upon with the client and with the University of Redlands faculty. The goals of the project were achieved with the use of ArcGIS for Desktop for the georeferencing of maps, creation of supporting layers, the creation of a geodatabase for data storage, and the development of the web application using ArcGIS API for JavaScript.

The application that was created allows the viewer to follow Crawford and the 15th Iowa Infantry in chronological order from the regiment's creation in December of 1861 until the end of the war in May 1865. Within the application are forty-seven points that each include a brief history, illustrations of the event, and a copy of Crawford's original letter, and if relevant, an attached map illustrating a battle that took place at that point. Links are also provided to direct the viewer to web pages for further reading, to transcribed versions of Crawford's letters, and to the Lincoln Memorial Shrine's website.

\subsection{Future Work}

There is some potential future work that could be added to the application if time and additional research were available. The first of these additions would be to create more data by further researching other members of the 15th Iowa Infantry or other regiments that followed the same path as Logan Crawford. During the research for this project many day to day journals from other soldiers in the 11th and 14th Iowa were found that, if included in future work, could fill in time spaces between Crawford's letters or give more detail to Crawford's statements.

A second addition to the application could be a time enabled map. For the Excel table created for this project, there was a Begin Date and End Date column that indicated when Crawford arrived and when he left the point associated with his letter. There were considerations to include a time enable element to the application, but after realizing that Crawford was only in some locations for one or two days and for months at a time in another location, further research or additional points would be needed to make the application follow a more steady timeline. 


\section{Works Cited}

American Civil War Website. (2015). American Civil War Soldier Letters Home. Retrieved from AmericanHistory.com:

http://americancivilwar.com/kids_zone/soldiers_letters_civil_war.html

Balletti, C. (2006). Georeference in the analysis of the geometric content of early maps. e-Perimetron, 1(1), 32-42. Retrieved from http://cartography.web.auth.gr/Maplibrary/New/e_Perimetron/Vol_1_1/Balletti/B alletti.pdf

Barton, D. and Hall, N., eds. (1999). Letter writing as a social practice. Philadelphia: John Benjamins Pub.

Bodenhamer, D.J., (2008). History and GIS: Implications for the discipline. (A.K. Knowles, Ed.) Redlands, CA: Esri

Bodenhamer, D.J., Corrigan, J., \& Harris, T.M., (2010). The Spatial Humanities. Bloomington, IN: Indiana University Press.

Burke, K. (2005). Letter Writing In America. Retrieved Sept. 20, 2015, from Smithsonian National Postal Museum: http://postalmuseum.si.edu/letterwriting/lw04.html

Crocker, H.W. III. (2008). Civil War. Washington D.C.: Regnery Publishing

Crown, F.J.Jr., ed. (1976). Confederate postal history. Lawrence, MA: Quarterman Publications, Inc.

Fu, P., and Sun, J. (2011). Web GIS Principles and Applications. Redlands: Esri Press.

Gregory, I.N., and Ell, P.S. (2007). Historical GIS. New York, NY: Cambridge University Press.

Harder, C., ed. (2015). The ArcGIS Book. Redlands: Esri Press.

Iowa Genalogy Web Project Website. (2015). Biographies - 1891 History of Harrison County, Iowa. Retrieved from Iagenweb.org: http://www.iagenweb/harrison/bio/geneal72.htm

Kagen, N., and Hyslop, S. (2009). Atlas of the Civil War. Washington D.C.: National Geographic Society (U.S.)

Knowles, A.K. (2008). What Could Lee See at Gettysburg? Redlands, CA: Esri

Kraak, M.J. \& Brown, A. (2001). Web Cartography: Developments \& Prospects, Taylor and Francis: London. 
Lincoln Memorial Shrine Website. (2015). History. Retrieved from LincolnShrine.org: http://www.lincolnshrine.org/history/

Owens, J.B. (2007). What Historians Want. Retrieved from Esri.com: http//www.esri.com/news/arcnews/summer07articles/what-historians-want.html

Robertson, J. \& Kagen, N. (2011). The Untold Civil War. Washington D.C.: National Geographic Society (U.S.)

Soyln, A., Moderitscher, F., Wild, F., De Caumaecher, P., \& Desmet, P. (2012).

Mashups by Orchestration and Widget-based Personal Environments: Key Challenges, Solutions Strategies, and an Application. Electronic Library and Information Systems 46. 


\section{Appendix A. Important but Extraneous Information}

Intro: The American Civil War of 1861-1865 is the largest and most destructive conflict in the Western Hemisphere to date. It is also the bloodiest conflict in United States history with the cost of 625,000 lives, nearly as many as all other wars in which the United States has fought combined. With the victory of the Union North in 1865, the United States maintained the preservation of the nation as one sovereign body and ended the institution of slavery.

The Lincoln Memorial Shrine of Redlands, California, is the largest facility west of the Mississippi River dedicated to the legacy of Abraham Lincoln and the American Civil War. It is through the collections of the Lincoln Memorial Shrine that allowed the genesis of this story map. The Lincoln Memorial Shrine has attained a massive collection of personal memorabilia, manuscripts, and artwork from the Civil War era, and selected the Union soldier, Logan Crawford, and his personal letters to be the focus of this project. The story map presented here follows Logan Crawford and his regiment, the $15^{\text {th }}$ Iowa Volunteer Infantry, throughout its formation in December of 1861 to its disbandment in June of 1865, as well as including other focus points of historical significance that occurred throughout the war.

ABOUT THE MAP: The basemap for this project is from the David Rumsey Collection, http://www.davidrumsey.com/, and is a Historical War Map from 1862, originally published by Asher \& Company. As this is an historical map, there are inaccuracies and marks that are included either due to the original design of the map or from limitations to cartographic elements of the time. A series of points were added to the map to highlight locations where Crawford and the $15^{\text {th }}$ Iowa were positioned during the war, as well as line features that show the routes in which they moved from point to point.

For those interested in an instructional video of how the story map works, please click here.

1) Washington, D.C.

Point of Interest

$11 / 06 / 1860-11 / 06 / 1860$

Lat: $38.889823 \quad$ Long: -77.00965

After years of political tension amongst Free and Slave states, Abraham Lincoln, running on the Anti-slave Republican ticket, is elected the 16th President of the United States on November $6^{\text {th }}, 1860$. Although only winning 39 percent of the popular vote and no states below the Mason-Dixon Line, many Southern states threaten to leave the Union.

Further Reading:

https://en.wikipedia.org/wiki/United_States_presidential_election,_1860

Image 1, Lincoln's First Inauguration:

https://upload.wikimedia.org/wikipedia/commons/6/60/Abraham_lincoln_inaugur ation_1861.jpg

Image 1.1, Lincoln Takes the Oath of Office:

http://a.abcnews.go.com/images/Politics/gty_abraham_lincoln_1861_inauguration ll_130118_wb.jpg 
2) Columbia, South Carolina

Point of Interest

$12 / 20 / 1860-12 / 20 / 1860$

Lat: $33.999921 \quad$ Long: -81.03294

Viewing the election of the Anti-slave Republican Abraham Lincoln as a "hostile action," on December $20^{\text {th }}, 1860$, South Carolina becomes the first state to secede from the United States. Within the next few months, Mississippi, Louisiana, Alabama, Texas, Florida and Georgia soon join with South Carolina to form the Confederate States of America.

Further Reading: https://en.wikipedia.org/wiki/South_Carolina_in_the_American_Civil_War Image 2, South Carolina Secedes: http://i844.photobucket.com/albums/ab7/Oklahomey/scteal.jpg

3) Fort Sumter, South Carolina

Point of Interest 04/12/1861 - 04/14/1861

Lat: $32.752413 \quad$ Long: -79.874624

Six days after the secession of South Carolina, U.S. forces stationed in Charleston, South Carolina withdrew to Fort Sumter. After four months of failed negotiations with the U.S. government, Confederate forces issued an ultimatum to surrender the fort or be fired upon. At 4:30 am on April 12, 1861 Confederate forces open fire upon Fort Sumter, resulting in a thirty-four hours bombardment before U.S. forces surrendered the Fort. Although considered the opening shots of the war, the bombardment resulted in no causalities and the Confederacy gave a 50-gun salute as the U.S. flag was lowered.

Further Reading: https://en.wikipedia.org/wiki/Battle_of_Fort_Sumter Image 3, Attack on Fort Sumter: https://upload.wikimedia.org/wikipedia/commons/d/d6/Attack_on_Fort_Sumter.j $\mathrm{pg}$

Image 3.1, Bombardment of Fort Sumter: https://upload.wikimedia.org/wikipedia/commons/5/57/Bombardment_of_Fort_S umter,_1861.png

4) Washington, D.C. Point of Interest 04/15/1861 - 04/15/1861

Lat: $38.897523 \quad$ Long: -77.036607

On April $15^{\text {th }}, 1861$ following the bombardment upon Fort Sumter by Confederate forces, President Lincoln calls for a 75,000 Volunteer Army to put down the rebellion. Some slave states refused to send troops against their neighboring states, as a result, Arkansas, North Carolina, Virginia, and Tennessee join the Confederacy. Further Reading: https://en.wikipedia.org/wiki/President_Lincoln\%27s_75,000_volunteers 
Image 4, Lincoln's Call for 75,000:

http://cdn2.americancivilwar.com/americancivilwar-

cdn/authors/Joseph_Ryan/150-Year-Anniversary/April-1861/What-Happened-in-

April-1861_files/image019.jpg

Image 4.1, Newspaper On To Richmond:

http://publications.newberry.org/lincoln/archive/fullsize/ln0150_on_to_richmond i22045_d0105ce470.jpg

5) Manassas, Virginia

Point of Interest

07/21/1861 - 07/21/1861

Lat: $38.805148 \quad$ Long: -77.571313

On July $21^{\text {st }}, 1861$, the first major battle of the Civil War commenced at Manassas Junction, otherwise known as the Battle of Bull Run. Both sides were evenly matched with roughly 18,000 men fighting in the engagement and was the largest and bloodiest battle in United States history up to that point. The result was a Confederate victory and a hasty retreat of Union forces back to Washington D.C. In the aftermath, both sides realized the war would be longer and more brutal than anyone had imagined.

Further Reading: https://en.wikipedia.org/wiki/First_Battle_of_Bull_Run

Image 5, Map of the Battle of Bull Run:

https://upload.wikimedia.org/wikipedia/commons/9/9b/First_Bull_Run_July21_1 400.png

Image 5.1, Illustration of the Battle of Bull Run:

https://upload.wikimedia.org/wikipedia/commons/4/48/First_Battle_of_Bull_Run Kurz_\%26_Allison.jpg

6) Calhoun, Iowa

Point of Interest

$11 / 27 / 1861-12 / 03 / 1861$

Lat: $41.629813 \quad$ Long: -95.89623

Logan Crawford, born Jan 13th, 1822 in Union, Connecticut, enlists in the U.S. Army at the age of 39. On Nov 27, 1861 and leaves his farm near Calhoun, Iowa for Keokuk, Iowa on Dec 3rd, 1861 to report for duty.

Further Reading, a brief biography of Logan Crawford:

http://iagenweb.org/harrison/bio/geneal72.htm

Image 6, Logan Crawford: provided by the Lincoln Memorial Shrine, Redlands, California.

7) Keokuk, Iowa

Training Facility

$12 / 12 / 1861-03 / 19 / 1862$

Lat: $40.391781 \quad$ Long: -91.377654

Logan Crawford reports for duty on December $12^{\text {th }}, 1861$ at Keokuk, Iowa.

Crawford is mustered in with the formation of Company $\mathrm{H}$ among 9 other

companies of the 15th Volunteer Iowa Regiment composed of 1,127 men. While 
at Keokuk the $15^{\text {th }}$ Iowa were drilled without muskets and learned basic unit movements before being transferred to St. Louis for additional training.

Further Reading:

http://files.usgwarchives.net/ia/state/military/civilwar/book/cwbk_15.txt

Image 7, Keokuk Docks:

http://hd.housedivided.dickinson.edu/files/images/HD_KeokukIA1861.preview.jp

$\mathrm{g}$

8) St. Louis, Missouri

Training Facility

03/21/1862 - 04/01/1862

Lat: $38.664992 \quad$ Long: -90.220142

Logan Crawford and the $15^{\text {th }}$ Volunteer Iowa arrive at Benton Barracks, St. Louis (present day St. Louis Fair Ground Park) on March 21 ${ }^{\text {st }}, 1862$. Here they receive its arms, basic equipment and additional training. On the morning of April $1^{\text {st }}$, the $15^{\text {th }}$ Iowa are issued orders to report to General Grant at Savannah, Tennessee.

Further Reading: https://en.wikipedia.org/wiki/Benton_Barracks

Image 8, Soldier's Drilling at Benton Barracks:

http://ozarkscivilwar.org/photographs/wp-content/uploads/2011/09/2nd-WiscCav-30837.jpg

Image 8.1, Illustration of Barracks:

http://freepages.genealogy.rootsweb.ancestry.com/ greenwolf/johnson/fremont-

st-louis2.jpg

9) Pittsburgh Landing, Tennessee

Battlesite

04/06/1862 - 04/08/1862

Lat: $35.14958 \quad$ Long: -88.318372

On the morning of April $6^{\text {th }}, 1862$ Logan Crawford and the $15^{\text {th }}$ Iowa arrived at

Pittsburg Landing, Tennessee. Upon reaching Pittsburg Landing, the regiment

found that the encampment was under fire by Confederate forces and advancing towards the landing. The $15^{\text {th }}$ Iowa was ordered forward to a defensive position where ammunition was distributed and guns were loaded for the first time since they had received them. Untested and unsupported by any artillery, the $15^{\text {th }}$ Iowa repelled flanking movements throughout the day, only retreating when the threat of capture was imminent. The official record of loss of life for the $15^{\text {th }}$ Iowa at the battle of Shiloh is 185 .

Further Reading: https://en.wikipedia.org/wiki/Battle_of_Shiloh

Image 9, Steamers docking at Pittsburgh Landing:

http://www.bgmcclure.com/Civil/Pittsburg\%20Landing.jpg

Image 9.1, Map of the Battle of Shiloh, first day:

https://upload.wikimedia.org/wikipedia/commons/thumb/f/fa/Shiloh_Battle_Apr6 pm.png/754px-Shiloh_Battle_Apr6pm.png

Image 9.2, Illustration of the Battle of Shiloh:

https://upload.wikimedia.org/wikipedia/commons/thumb/2/21/Thure_de_Thulstru p___Battle_of_Shiloh.jpg/1280px-Thure_de_Thulstrup_-_Battle_of_Shiloh.jpg 
10) Acton, Tennessee

Encampment

04/29/1862 - 05/30/1862

Lat: $35.008328 \quad$ Long: -88.459531

Soon after the battle of Shiloh, the $15^{\text {th }}$ Iowa took part on the advance upon

Corinth, Mississippi to which the defeated Confederate army had retreated to protect the important railroad junction and supply depot. The Union lines continued to slowly advance upon Corinth, eventually laying siege to the town. Further Reading: https://en.wikipedia.org/wiki/Siege_of_Corinth Image 10, Skirmishes at Corinth, MS: http://www.legendsofamerica.com/photosmississippi/battlecorinth-600.jpg

11) Corinth, Mississippi

Encampment 06/01/1862 - 07/31/1862

Lat: $34.93775 \quad$ Long: -88.529753

As the Union Army's siege of Corinth came to an end, on May $30^{\text {th }}$ the $13^{\text {th }}$ Iowa discovered that Confederate forces had abandoned the town the night before. After taking possession of the town, the $15^{\text {th }}$ Iowa was moved inside the earthwork fortifications within the city, acting as guard. Here they remained stationed throughout June and July of 1862.

Image 11, Soldiers occupying earthworks at Corinth, MS:

http://www.legendsofamerica.com/photosmississippi/Confederate\%20dead\%20in\%20front $\% 20$ of $\% 20$ Fort $\% 20$ Robinette, $\%$ 20Corinth.jpg

12) Bolivar, Tennessee

Encampment 08/01/1862 - 09/20/1862

Lat: $35.255977 \quad$ Long: -88.987656

At the end of July, the $15^{\text {th }}$ Iowa regiment was ordered to Bolivar, Tennessee to re-inforce that important position. The Confederates in large force in the surrounding area had constantly threatened attack, but this had all been a ruse to draw Union troops away from Corinth. Upon the Confederate attack at Iuka, MS near Corinth on Sept. 19th, the $15^{\text {th }}$ Iowa was ordered to return to Corinth. Further Reading, Battle of Iuka, MS: https://en.wikipedia.org/wiki/Battle_of_Iuka

13) Antietam Creek, Maryland

Point of Interest

09/17/1862 - 09/17/1862

Lat: $39.474346 \quad$ Long: -77.744254

In an effort to draw Union forces out of Northern Virginia and defeat them in their own territory, Confederate General Robert E. Lee invades the North and engages in the bloodiest single day battle of the war at Antietam Creek, Maryland. Although the battle is considered a military draw, with the massive loss of life and 
resources, General Lee is forced to withdrawal his troops back to Virginia. As a result, Lincoln sees this slight victory as way to gain the moral high ground in the war and makes the removal of slavery a war goal by issuing the Emancipation Proclamation on Jan 1, 1863. Lincoln in by doing so, effectively discouraged Britain and France from recognizing the legitimacy the Confederate States of America.

Further Reading: https://en.wikipedia.org/wiki/Battle_of_Antietam Image 13, Map of the Battle of Antietam, Maryland: https://upload.wikimedia.org/wikipedia/commons/1/1b/Antietam_Overview.png Image 13.1, Picture of Battle of Antietam, Maryland: https://upload.wikimedia.org/wikipedia/commons/9/9e/Bodies_on_the_battlefield at_antietam.jpg

14) Corinth, Mississippi

Battlesite 09/21/1862 - 11/01/1862

Lat: $34.932276 \quad$ Long: -88.533276

On October $3^{\text {rd }}$ the Confederate Army finally attacked the fortifications at Corinth, Mississippi. The $15^{\text {th }}$ Iowa occupied an advanced position on the left flank, suffering heavy losses of 11 dead, 67 wounded, and 8 missing, among those was Logan Crawford with a wound to the head. Despite these casualties, the $15^{\text {th }}$ Iowa managed to hold their positions, halting the Confederate advance. On the second day of battle of October $4^{\text {th }}$, the $15^{\text {th }}$ Iowa was reassigned to within the fortifications at Corinth, to where it received little action until the enemy was routed.

After the battle, the regiment went into camp just outside of Corinth, where it remained until early November of 1862.

Further Reading: https://en.wikipedia.org/wiki/Second_Battle_of_Corinth Image 14, Map of the Battle of Corinth: https://upload.wikimedia.org/wikipedia/en/d/d6/Corinth_October_4_1862.png

Image 14.1, Illustration of the Battle of Corinth: http://5f07c4f985a46bdb48d01f322058c06e92daf3184009c3a54cb8.r72.cf1.rackcdn.com/wpcontent/uploads/2013/01/battle_of_corinth_ii.jpg

15) Grand Junction, Tennessee

Encampment $11 / 02 / 1862-11 / 28 / 1862$

Lat: $35.04925 \quad$ Long: -89.187639

On November $2^{\text {nd }}, 1862$ orders arrived for the $15^{\text {th }}$ Iowa to march to Grand Junction, Tennessee, where it arrived on November $5^{\text {th }}$. Grand Junction was the initial position for the beginning of General Grant's Northern Mississippi Campaign. On the $28^{\text {th }}$ of November troops were put in motion toward Northern Mississippi in the hopes of capturing the Confederate stronghold of Vicksburg. Image 15, Illustration of Grand Junction, Tennessee: http://www.sonofthesouth.net/leefoundation/civil-war/1862/december/grandjunction.jpg 
16) Oxford, Mississippi

Encampment

12/19/1862 - 12/21/1862

Lat: $34.36843 \quad$ Long: -89.527592

By mid-December the Union forces had proceeded smoothly 5 miles inside Mississippi and had established a headquarters at Oxford, Mississippi. U.S. General Grant had planned on a two-pronged attack on the Confederate stronghold of Vicksburg. By Grant's plan, he would lead a force from the interior of Mississippi, while his second General Sherman would lead an army down the Mississippi River. If the Confederate's moved to attack him, Sherman would attack Vicksburg. If not, Grant would swing down to attack the city from the rear. Image 16, Map of General Grant's Northern Mississippi Campaign: http://www.angelfire.com/ms2/grantshilohvicksburg/

17) Holly Springs, Mississippi

Point of Interest

$12 / 20 / 1862$ - 12/20/1862

Lat: $34.771866 \quad$ Long: -89.433237

Oxford, Mississippi would be as far south as the bulk of Grant's army would move however. General Grant had underestimated a desperate Confederacy that was unwilling to easily surrender Vicksburg. Confederate cavalry led by Earl Van Dorn attacked Grant's supply lines at Holly Springs, Mississippi on December $20^{\text {th }}$. The successful Confederate raid destroyed all supplies, cut railway and telegraph lines. As a result, Grant had no choice but to retreat to Memphis, Tennessee and rethink his strategy.

Further Reading: http://www.history.com/this-day-in-history/raid-on-hollysprings-mississippi

Image 17, Map of General Van Dorn's Raid on Grant's forces:

https://upload.wikimedia.org/wikipedia/commons/3/3e/VicksburgCampaignDece mber62March63.png

18) Memphis, Tennessee

Aboard Ship

01/13/1863 - 01/19/1863

Lat: $35.141218 \quad$ Long: -90.058481

The $15^{\text {th }}$ Iowa reached Memphis on the $13^{\text {th }}$ of January 1863 , and by the $18^{\text {th }}$ of January General Grant had renewed his expedition against Vicksburg by the way of the Mississippi River. The $15^{\text {th }}$ Iowa and other brigades embarked on a fleet of fifteen steamers destined for Milliken's Bend, Louisiana, a short distance from the mouth of the Yazoo River.

Image 18, Memphis docks: http://www.sonofthesouth.net/leefoundation/civilwar/1862/july/civil-war-memphis-tennessee.jpg

19) Millikins Bend, Louisiana

Encampment 
$01 / 21 / 1863-02 / 08 / 1863$

Lat: $32.4457 \quad$ Long: -91.092397

Upon reaching Millikins Bend, Louisiana on January 21,1863 , the $15^{\text {th }}$ Iowa went into camp and were sent upon a couple of local expeditions. While in camp the Crocker Iowa Brigade, including the $15^{\text {th }}$ Iowa, were transferred to the $17^{\text {th }}$ Army Corps under the command of Major-General McPherson. The Millikins Bend area would serve as a staging area for Union Army's Vicksburg.

Image 19, Soldiers at Millikins Bend:

http://www.rootsweb.ancestry.com/ lamadiso/articles/canals/youngspt.jpg

20) Lake Providence, Louisiana

Encampment

02/10/1863 - 04/21/1863

Lat: $32.805343 \quad$ Long: -91.16899

On the $8^{\text {th }}$ of February, the $17^{\text {th }}$ Corps, including the $15^{\text {th }}$ Iowa Regiment, embarked 70 miles north to Providence, Louisiana. While at Lake Providence, the $15^{\text {th }}$ Iowa was to construct a canal system connecting the Mississippi River to Lake Providence; connecting to the smaller river systems in Louisiana in the hopes of bypassing the strong defenses of Vicksburg. The canal was near completion by the end of March, but General Grant decided that troops would be sent by land through Millikins Bend and work on the Lake Providence Canal was suspended.

Further Reading: http://www.nps.gov/vick/learn/historyculture/lake-providencecanal-february-march-1863.htm

Image 20, Map of canals around Vicksburg:

https://upload.wikimedia.org/wikipedia/commons/thumb/3/3e/VicksburgCampaig nDecember62March63.png/600px-VicksburgCampaignDecember62March63.png Image 20.1, Illustration of Lake Providence Canal: http://www.sonofthesouth.net/leefoundation/civil-war/1863/march/lakeprovidence.jpg

21) Grand Gulf, Mississippi

Encampment 05/15/1863 - 05/18/1863

Lat: $32.029481 \quad$ Long: -91.054439

On the $26^{\text {th }}$ of April, the $15^{\text {th }}$ Iowa began its march south to begin the Vicksburg Campaign, stopping in Hard Times Landing on the $13^{\text {th }}$ of May before crossing by boat to Grand Gulf, Mississippi. Grand Gulf had recently been bombarded by seven Union Ironclad naval ships in an effort to remove Confederate forces from two earthen Forts there on April 29th. General Grant rather than facing a costly frontal assault chose to land farther to the south, forcing the Confederates to abandon Grand Gulf days later.

Further Reading: https://en.wikipedia.org/wiki/Battle_of_Grand_Gulf Image 21, Bombardment of Grand Gulf: http://ironbrigader.com/wpcontent/uploads/2013/01/Battle-of-Grand-Gulf.jpg 
22) Yazoo River, Mississippi

Aboard Ship

05/21/1863 - 05/21/1863

Lat: $32.44468 \quad$ Long: -90.913663

As U.S. forces led by General Grant captured the city of Jackson, east of

Vicksburg, it was of the utmost importance that Confederate General Johnston

forces, located near Canton in central Mississippi, not be allowed to come to the aid of Confederate General Pemberton whose forces were defending the city of Vicksburg. Therefore, a small detachment of Union Calvary was sent north of Vicksburg to capture the strongholds of Snyder's Bluff and Haynes Bluff the night of May $18^{\text {th }}$. Upon the Union Calvary arriving at the Bluffs on the $19^{\text {th }}$ the Confederates quickly surrendered their positions, and learned that Confederate defenses had been moved the night before to help reinforce Vicksburg. Further Reading, the capture of Haynes Bluff by the $4^{\text {th }}$ Iowa Cavalry: http://ir.uiowa.edu/cgi/viewcontent.cgi?article $=7957 \&$ context=annals-of-iowa Image 22, Steamers on the Yazoo: http://etc.usf.edu/clipart/11500/11587/yazoo_11587_lg.gif

23) Haynes Bluff, Mississippi

Encampment $05 / 26 / 1863$

Lat: $32.516246 \quad$ Long: -90.785412

Now that the strongholds of Snyder's and Haynes Bluffs were captured, Union forces were ordered to secure a position to prevent Confederate General Johnston from crossing the Big Black River and potentially attack General Grant's Union Army from the rear. Image 23, Newspaper map of Haynes Bluff: http://images.rarenewspapers.com/ebayimgs/8.46.2009/image069.jpg

24) Mechanicsburg, Mississippi

Battlesite

06/04/1863

Lat: $32.636488 \quad$ Long: -90.51377

Union Major-General Blair in command of the expedition to Haynes Bluff, selected Mechanicsburg to be of the position of the most strategic value, located at narrowest point between the Yazoo and Big Black Rivers, where he could easily maneuver troops. On the $31^{\text {st }}$ of May, General Blair sent a detachment of troops northeast towards Mechanicsburg with orders to burn all resources the Confederate Army could potentially use along the way. On June $4^{\text {th }}$, Union forces finally arrived at Mechanicsburg to discover a small Confederate force that had formed a line of battle to defend the small town, but a Union brigade quickly routed the Confederate defenders and took control of the town.

Further Reading, General Blair's report to Grant on Expedition to Mechanicsburg: https://books.google.com/books?id=t0VHAQAAIAAJ\&pg=PA435\&lpg=PA435 \&dq=advance+on+haynes+bluff + ms + may $+26+1863 \&$ source $=$ bl \&ots=52jMA1I Mbp\&sig=igdQYt2D1WS3D8Nd_zBDqGZVOWU\&hl=en\&sa=X\&ved=0CDkQ 
6AEwBWoVChMI2JDT24G3yAIVQV1jCh3rxgbX\#v=onepage \&q=advance $\% 20$ on\%20haynes\%20bluff\%20ms\%20may\%2026\%201863\&f=false

Image 24, Map of area north of Vicksburg:

https://upload.wikimedia.org/wikipedia/commons/3/3c/VicksburgCampaignAprilJ uly63.png

25) Messenger's Ferry, Mississippi

Battlesite

07/05/1863

Lat: 32.384429 Long: -90.622552

On the $27^{\text {th }}$ of June the $15^{\text {th }}$ Iowa moved south to secure the ford of Messenger's Ferry to secure General Grant's rear position as the bulk of the Union Army surrounded Vicksburg. At night on June $30^{\text {th }}$, Confederate forces moved into position on east bank of the Big Black River opposite of Messenger's Ferry. On the morning of July $1^{\text {st }}$, Confederate forces emerged from the cover of the trees and skirmishes occurred throughout the day, but no major engagements. The next day the entire brigade was called into Messenger's Ferry to reinforce the Union position and the Confederate forces withdrew. The $15^{\text {th }}$ Iowa would remain here throughout the siege of Vicksburg.

Further Reading, Col Belknap's report of Messenger's Ferry: https://books.google.com/books?id=q0AtAAAAYAAJ\&pg=PA638\&lpg=PA638 \&dq=skirmish + at + messengers + ferry\&source $=$ bl\&ots $=$ BmRbSlAFch\&sig $=Y A s p$ Q6tZzOVJu86a7kztC-

w6bmI\&hl=en\&sa $=$ X\&ved=0CC4Q6AEwBGoVChMIsI 155m5yAIVSKKICh0f 7Q9N\#v=onepage \&q=skirmish\%20at\%20messengers\%20ferry\&f=false

Image 25, Map showing area around Messenger's Ferry: http://civilwardailygazette.com/wp-content/uploads/2013/01/may18bigmap.jpg Image 25.1, Illustration of Messenger's Ferry: http://cdn.loc.gov/service/pnp/cph/3a00000/3a01000/3a01300/3a01315r.jpg

26) Gettysburg, Pennsylvania

Point of Interest

07/01/1863 - 07/03/1863

Lat: $39.811539 \quad$ Long: -77.23307

Meanwhile in the Eastern Campaign, Confederate General Lee, encouraged by recent victories in Fredricksburg and Chancellorsville decided to once again move his army north in the attempt to defeat the Union Army in its own territory. The two armies would meet late in the day on July $1^{\text {st }}$ in a small Pennsylvania town called Gettysburg. Confederate forces took advantage of a disorganized Union army, driving them through the town, but could not pursue due to the late hour of the day. On July $2^{\text {nd }}$, Union forces had taken up defensive positions on hills south of Gettysburg, forcing a smaller confederate force to attack uphill, ultimately ending the day in a stalemate. On July $3^{\text {rd }}$, Confederate General Lee decided to attack the center of the Union defenses through an open field, now called "Pickett's Charge." The attack was a disaster for the Confederates and General Lee would be forced to retreat to Virginia. In all, it is estimated that around 
51,000 soldiers died over the course of the 3 day battle, but the Union victory is considered the turning point of the war.

Further Reading: https://en.wikipedia.org/wiki/Battle_of_Gettysburg

Image 26, Map of the Battle of Gettysburg:

https://upload.wikimedia.org/wikipedia/commons/thumb/9/9e/Gettysburg_Battle

Map_Day3.png/350px-Gettysburg_Battle_Map_Day3.png

Image 26.1, Illustration of Pickett's Charge: https://citelighter-

cards.s3.amazonaws.com/p16uhng4s2153131i4ol3tmv280_80765.jpg

Image 26.2, Photograph of Confederate Prisoners:

https://pooreboysingray.files.wordpress.com/2013/07/three-prisoners-at-

gettysburg-cropped.jpg

27) Vicksburg, Mississippi

Point of Interest

07/04/1863 - 07/04/1863

Lat: $32.352193 \quad$ Long: -90.878872

The Siege of Vicksburg, Mississippi, the final Confederate stronghold on the Mississippi River was the last major military action in the Vicksburg Campaign. Commencing on May $18^{\text {th }}$, Union General Grant attempted two costly direct assaults before deciding to besiege the town. For 40 days Grant's forces bombarded the town from gunboats in the Mississippi River and denied any reinforcements or supplies to enter Vicksburg from the east by siege lines. By the end of June, citizens and Confederate forces had dwindled in strength as many suffered from illness from lack of food and many had resorted to eating horses and dogs. On July $3^{\text {rd }}$, Confederate General Pemberton sent a note to General Grant to discuss surrender and met with Grant under an old oak tree. The surrender was finalized on July $4^{\text {th }}$ and the Confederate army was paroled to return home. With the surrender of Vicksburg the Union Army had now successfully cut the Confederacy in two.

Further Reading: https://en.wikipedia.org/wiki/Siege_of_Vicksburg

Image 27, Map of the Siege of Vicksburg:

https://upload.wikimedia.org/wikipedia/commons/5/58/VicksburgSiege.png

Image 27.1, Photograph of man-made cave bunkers in Vicksburg:

http://cfnelson.everythingesteban.com/wpcontent/uploads/2012/10/CavesVicksburg-1024x784.jpg

Image 27.2, Illustration of Confederate General Pemberton surrendering to Union General Grant: http://www.newsms.fm/wp-content/uploads/2013/07/milit004.jpg Image 27.3, New bulletin of Victory in Vicksburg:

https://thecivilwarandnorthwestwisconsin.files.wordpress.com/2013/06/vicksburg -great-victory.jpg

28) Jackson, Mississippi

Encampment

07/10/1863 - 07/18/1863

Lat: $32.298973 \quad$ Long: -90.180417 
After the surrender of Vicksburg, the $15^{\text {th }}$ Iowa took part in General Sherman's expedition against Confederate General Johnston who had occupied the city of Jackson, Mississippi. On July $7^{\text {th }}$, the $15^{\text {th }}$ Iowa left its position at Messenger's Ferry and took positions around Jackson on July 10. Confederate General Johnston chose to evacuate the city and withdrew on July 16, allowing Sherman to easily retake the city on the $17^{\text {th }}$.

Further Reading: https://en.wikipedia.org/wiki/Jackson_Expedition

Image 28, Approaching Jackson, Mississippi: http://civilwardailygazette.com/wpcontent/uploads/2012/12/may14jackson2.jpg

29) Vicksburg, Mississippi

Encampment

07/20/1863 - 02/01/1864

Lat: $32.35306 \quad$ Long: -90.84694

With Jackson, Mississippi now under Union control, the $15^{\text {th }}$ Iowa returned to Vicksburg where it went into camp north of the city. While here, a considerable number of men were given a thirty day furlough, while the rest of the regiment was almost entirely relieved from active duty until the last of January 1864. This long period of inaction was not put to waste, as Colonel Belknap used the opportunity to instruct officers in proper usage of duties while marching and maneuvers in battle. The regiment gain satisfaction of witnessing good results of this instruction and felt pride in the high state of discipline and efficiency. Image 29, Soldiers enter Vicksburg: http://cwmemory.com/wpcontent/uploads/2012/07/P-064-500-e1365951172990.jpg

Image 29.1, Union soldiers reading letters: http://cfnelson.everythingesteban.com/wpcontent/uploads/2012/09/letter_civilwar.jpg

30) Meridian, Mississippi

Encampment $02 / 03 / 1864$ - 02/20/1864

Lat: $32.365051 \quad$ Long: -88.695245

After the Vicksburg Campaign came to a close, Union General Sherman turned his forces east towards the railroad center of Meridian, Mississippi. Sherman's plan was to take the city of Meridian and if possible, push eastward towards Selma, Alabama or turn south and threaten Mobile. The $15^{\text {th }}$ Iowa was assigned to join Sherman on this expedition into the interior of Mississippi and joined the eastern march on February 3,1864.

Unfortunately, Sherman's plan was ill conceived and unraveled as quickly as it came together. Firstly, it counted on General Smith's cavalry to meet Sherman and support his left flank once he had taken Meridian, but General Smith's troops were defeated by Confederate cavalry and were forced to retreat into Tennessee. Secondly, Sherman had not adequately planned for a long march during winter, as many soldiers were not supplied with tents or sufficient rations. Sherman entered Meridian on February $14^{\text {th }}$, unaware of General Smith's defeat 
and waited six days until realizing the expedition was a failure and decided to return to Vicksburg.

Further Reading: https://en.wikipedia.org/wiki/Battle_of_Meridian

31) Vicksburg, Mississippi

Encampment

03/06/1864 - 03/12/1864

Lat: $32.343971 \quad$ Long: -90.851619

The $15^{\text {th }}$ Iowa Regiment received its orders to return to Vicksburg on March $3^{\text {rd }}$. Upon it's return, the regiment went into camp.

As 1863 had come to an end, in response to the U.S. Government's call for more troops, 3/4ths of the $15^{\text {th }}$ Iowa had re-enlisted for three years or until the end of the war.

Image 31, Soldiers sitting while encamped:

http://cfnelson.everythingesteban.com/wp-content/uploads/2012/09/civil-warunion-camp-1862-granger.jpg

32) Keokuk, Iowa

Furlough

03/13/1864 - 04/22/1864

Lat: $40.390946 \quad$ Long: -91.378955

On the $13^{\text {th }}$ of March 1864, the portion of the regiment that had re-enlisted were given a Veteran's furlough to return to their homes in Iowa. A steamer would transfer them to Keokuk, Iowa of which they would have 30 days from the date they reached the port.

Further Reading on Veterans Furlough:

https://books.google.com/books?id=OnEp0wXCnaYC\&pg=PA173\&lpg=PA173

$\& \mathrm{dq}=$ veterans + furlough+civil + war \&source=bl\&ots $=x g H E 4$ nosex \&sig $=\mathrm{HyW}$ No

Qyg1NNhNmyApDh8nrifnM\&hl=en\&sa=X\&ved=0CDgQ6AEwBGoVChMIv7rl

5bbVyAIVDchjCh2PrAes\#v=onepage \&q=veterans\%20furlough\%20civil\%20war

\&f=false

Image 32, Soldiers on furlough:

https://karleeaturner.files.wordpress.com/2010/12/nast-christmas-morning-

furlough-1863.jpg

33) Clifton, Tennessee

Encampment

$05 / 06 / 1864$

Lat: $35.387677 \quad$ Long: -87.994204

At the end of the 30 day furlough, Veterans returned to Keokuk, Iowa where a steamer transferred them to Clifton, Tennessee, rejoining the non-veteran element of the 15th Iowa Regiment on May 6, 1864. Here they received orders to march to Ackworth, Georgia to once again join with General McPherson's Army of the Tennessee. A month of marching preceded through central Tennessee, and through the mountainous districts of northern Alabama and Georgia before arriving at Ackworth on June $8^{\text {th }}$. 
Further Reading about the journey from Clifton, TN to Acworth, GA:

https://books.google.com/books?id=OnEp0wXCnaYC\&pg=PA182\&dq=downing $\% 27 \mathrm{~s}+$ civil+war+diary+chapter+XVII\&hl=en \&sa=X\&ved=0CB0Q6AEwAGoV ChMI3 2cgbrVyAIVTHY-

Ch1goAw2\#v=onepage \&q=downing's\%20civil\%20war\%20diary\%20chapter\%20 XVII\&f $=$ false

Image 33, Ships docking at Clifton, Tennessee:

http://www.gageandtim.com/family/rising/art/cliftontenn.jpg

34) Acworth, Georgia

Encampment

06/06/1864 - 06/09/1864

Lat: $34.067149 \quad$ Long: -84.680701

Upon arriving at Acworth, Georgia, the $15^{\text {th }}$ Iowa reported to McPherson's Army

of the Tennessee and were assigned to the extreme left of Sherman's Grand

Army, composed of the Armies of the Cumberland, Tennessee, and Ohio and began marching towards Atlanta. On June $9^{\text {th }}$, Sherman's forces found

Confederate General Johnston entrenched in Marietta and began a series of skirmish battles. After ten days of maneuvering General Johnston, withdrew his forces to the nearby Kennesaw Mountain where Johnston could protect his supply line and have the strategic value of the high ground.

Further Reading: https://en.wikipedia.org/wiki/Atlanta_Campaign Image 34, Atlanta Campaign until July 2, 1864:

https://upload.wikimedia.org/wikipedia/en/0/05/Atlanta_Campaign_May7Jul2.png

35) Kennesaw Mountain, Georgia

Battlesite

06/10/1864 - 07/04/1864

Lat: $33.950785 \quad$ Long: -84.597245

On the $27^{\text {th }}$ of June 1864 Union General Sherman launched a frontal assault against the Confederate Army of Tennessee. Sherman had hoped by using his superior numbers to stretch out the Confederate lines that he could attack the middle and split Johnston's forces in two. Faint demonstrational attacks would harass the Confederate right while the main attack would happen at the center. Unfortunately, Union forces discovered that their advance was through knee-deep swamps and then up steep cliffs, all the while taking fire from well entrenched Confederates. The Union army was not able to penetrate the Confederate line and Johnston was able to remain in his position. Although a technical victory for the Confederacy, it did not deter Sherman from his main objective of Atlanta. On July $8^{\text {th }}$, Sherman outflanked Johnston's right, forcing his retreat to Atlanta.

Further Reading: https://en.wikipedia.org/wiki/Battle_of_Kennesaw_Mountain Image 35, Map of the Battle of Kennesaw Mountain, GA: https://upload.wikimedia.org/wikipedia/en/0/0e/Kennesaw_Mountain.png Image 35.1, Illustration of the Battle of Kennesaw Mountain, GA: http://www.abbeville.com/images-catalog/full-size/9780789210647.interior08.jpg 
36) Atlanta, Georgia

Battlesite

07/22/1864 - 07/22/1864

Lat: $33.742587 \quad$ Long: -84.347843

Frustrated with General Johnston's continual withdrawals, Confederate President

Davis relieved him of duty and replaced him with the more aggressive General Hood. Hood with a smaller army than Sherman, was charged with the defense of Atlanta and the important railway and industrial center suppling the Confederacy. General Hook was fond of taking risks in the field and his strategy involved attacking the Union center with General Cheatham's corps while General Hardee's corps, along with cavalry, attack the Union left in the hopes of capturing or destroying Sherman's supply line. General Hardee took longer than expected to get into position, however, and the Union left under General McPherson was given enough time to counter in force and repel the first Confederate attack. As the battle waged on, the fight began to turn in the Confederate's favor as the Union left flank began to retreat with the death of General McPherson. Taking the advantage, the Confederate cavalry pressed the offensive to the supply depot, only to find that the fleeing Union Army had managed to escape with the supplies. With the objective now unattainable, Hood had no choice but to recall his forces back to Atlanta.

As for the $15^{\text {th }}$ Iowa, up until the Battle of Atlanta on July $22^{\text {nd }}$, the regiment had only lost 100 men killed or wounded in the Atlanta Campaign. With the battles on the $21^{\text {st }}, 22^{\text {nd }}$, and $28^{\text {th }}$, it was estimated that the regiment lost 190 men of the 428 engaged, a loss of $45 \%$. This included Logan Crawford, who was shot in the chest and taken prisoner by Confederates.

The battle had been costly, the Union had suffered 3,641 casualties, to the Confederate's 5,500. Confederate General Hook still held the city, but Union General Sherman laid siege to the town and maneuvered to cut the southern rail line from Macon. On August $31^{\text {st }}$, Sherman successfully severed all supplies to Atlanta, forcing Hood to remove his troops the next day. Further Reading: https://en.wikipedia.org/wiki/Battle_of_Atlanta Exact location of XVII Corp during battle of Atlanta, Logan Crawford shot and taken prisoner by CSA

Image 36, Map of the Battle of Atlanta:

http://cdn2.americancivilwar.com/americancivilwarcdn/civil_war_map/atlanta_battle.jpg Image 36.1, Illustration of the Battle of Atlanta: https://upload.wikimedia.org/wikipedia/commons/2/21/Battle_of_Atlanta.png

37) Macon, Georgia

POW Camp

08/01/1864

Lat: $32.830779 \quad$ Long: -83.621143

Logan Crawford was moved to Camp Oglethorpe Prisoner Camp, on the south side of the city of Macon, Georgia. Camp Oglethorpe had been a small prison, 
usually holding 1000 men, to temporarily hold officers and enlisted men until a prisoner exchange could be arranged. By the arrival of Crawford in the summer of 1864 , breakdowns in prisoner exchanges had caused the camp to swell to more than 2,300, and food and shelter were barely adequate. Crawford would only be at Camp Oglethorpe a few weeks as Sherman's southern moving forces soon threatened the city of Macon and the camp was shut down by mid-August. Crawford was transferred to Andersonville Prisoner Camp in southern Georgia, but as it was discovered he was an officer, he was then transferred to a military hospital at Rickerville, South Carolina.

Further Reading: http://www.georgiaencyclopedia.org/articles/historyarchaeology/civil-war-prisons

Image 37, Location of Camp Oglethorpe in Macon, GA: http://scvcamp1399.org/images/Macon-map-1854.jpg

38) Charleston, South Carolina

POW Camp

$12 / 13 / 1864$

Lat: $32.773611 \quad$ Long: -79.910964

Rickersville (also known as Rikersville), South Carolina, was a hospital located four miles outside of Charleston. In 1862, the Confederacy was allowed to use the facility to care for wounded Southern soldiers, but by 1863 the hospital was reallocated to a prisoner's hospital. Logan Crawford was transferred to Rickerville in late August of 1864, but little is known about his stay here because he was not allowed to write while being a prisoner. Crawford would remain at Rickersville until December 14, 1864, when he was exchanged at Charleston Harbor and transferred to Davenport, Iowa.

Further Reading: http://www.charlestonrenaissancegallery.com/pages/projects/exhibitionspayoff/28 $\underline{1682}$ http://iagenweb.org/harrison/bio/geneal72.htm

Image 38, Rickersville Hospital: http://www.charlestonrenaissancegallery.com/site/user/images/622113.JPG

39) Savannah, Georgia

Point of Interest

12/10/1864 - 12/21/1864

Lat: $32.074312 \quad$ Long: -81.144897

After the fall of the city of Atlanta, the $15^{\text {th }}$ Iowa accompanied General Sherman on his march to the city of Savannah, Georgia. Believing that the war would only end if the South's economic capacity to make war was destroyed, Sherman embarked on a campaign of scorched earth warfare, destroying any industry, infrastructure, and civilian property considered of economic value. Leaving the Atlanta area on November $15^{\text {th }}$, the Union Army would the 300 mile distance, meeting little Confederate resistance, to Savannah in 25 days. General Sherman would telegraph President Lincoln presenting him the city of Savannah as a Christmas gift. 
Further Reading: https://en.wikipedia.org/wiki/Sherman\%27s_March_to_the_Sea Image 39, Map of the Savannah Campaign: https://cdn2.voxcdn.com/uploads/chorus_asset/file/3598122/Savannah_Campaign.0.png Image 39.1, Photograph of Union troops destroying railroads on the March to Savannah:

https://upload.wikimedia.org/wikipedia/commons/5/5a/Sherman_railroad_destroy noborder.jpg

40) Davenport, Iowa

Encampment

$02 / 19 / 1865$

Lat: $41.531944 \quad$ Long: -90.537222

After being exchanged in Charleston, South Carolina on December 14, 1864, Logan Crawford was transferred to Camp McClellan in Davenport, Iowa. Here he would remain until discharged from service on February 19, 1865 and sent home. After the war Logan Crawford was a supporter of the Republican Party and would go on to hold the local offices of County Surveyor and Justice of the Peace in the Calhoun Township of Iowa.

41) Columbia, South Carolina

Point of Interest

Lat: $33.999921 \quad$ Long: -81.03294

After the successful capture of Savannah by General Sherman in December of 1864, Sherman was ordered by General Grant to embark via ship north to reinforce his troops at Petersburg, Virginia. Sherman persuaded Grant to allow him to march north through the Carolina states instead, to destroy anything of military value and crush Southern morale in the state that started the rebellion. Beginning in late January, Sherman's forces slowly marched north towards Columbia, South Carolina, arriving there on February 17. Fires soon broke out in the city and most of the central part of the town was destroyed due to high winds. Although it is still contested on who started the fire, Sherman stayed true to his word by destroying anything of military value the following day.

After the burning of Columbia, Sherman's forces met little resistance from Confederate forces marching north, until meeting with a reinstated Confederate General Johnston at Bentonville, North Carolina just south of Raleigh on March 19. Johnston only having 21,000 men, launched an attacked that broke the Union lines, but due to smaller numbers halted his troops in a defensive position and awaited an attack. Sherman was unwilling to attack Johnston's position and allowed him to withdraw two days later.

Further Reading: https://en.wikipedia.org/wiki/Carolinas_Campaign http://www.nccivilwar150.com/history/sherman.htm Image 41, Map of the Carolina Campaign: http://thomaslegion.net/sitebuildercontent/sitebuilderpictures/carolinas_campaign. gif 
Image 41.1, Illustration of the burning of Columbia, SC:

https://upload.wikimedia.org/wikipedia/commons/2/2a/The_burning_of_Columbi a,_South_Carolina,_February_17,_1865.jpg

42) Raleigh, North Carolina

Point of Interest

01/14/1865 - 04/14/1865

Lat: $35.780412 \quad$ Long: -78.639394

After the battle at Bentonville, Sherman resumed his Carolina Campaign on April 10 and began marching towards Raleigh. Confederate forces under Johnston had regrouped and were halted to the west at Greensboro. On April 12, the mayor of Raleigh prepared to surrender the city in the hopes that Sherman would spare it from destruction when he arrived on April 13.

Meanwhile, both Union and Confederate forces began to receive news of Confederate General Lee's surrender to General Grant on April $9^{\text {th }}$. A disheartened Confederate General Johnston met with President Jefferson Davis and convinced him to authorize the suspension of hostilities.

Further Reading: http://www.nccivilwar150.com/history/sherman.htm

43) Appomattox Court House, Virginia

Point of Interest

04/09/1865 - 04/09/1865

Lat: $37.377233 \quad$ Long: -78.7972

In the Eastern Campaign, after the Confederate loss at the battle of Gettysburg in the summer of 1863, General Lee had no choice but to withdraw into Virginia and conduct a defensive campaign. Union General Grant was now in charge of U.S. forces to defeat the Confederate Army of Northern Virginia and began an aggressive campaign starting in early 1864 . General Grant was successful in pushing Lee farther and farther south, but eventually the campaign became bogged down when Lee entrenched his troops around the city of Petersburg, Virginia. From June 9, 1864 to March 25, 1865, General Grant laid siege to the city of Petersburg, gradually expanding his lines farther and farther around Lee's flank. By March $25^{\text {th }}$, Lee concluded that he could no longer hold the city and withdrew his troops under the cover of darkness on April 2, hoping to combine his army with General Johnston's in North Carolina.

Lee's first objective before he could march his forces to Johnston's was to resupply his men. Lee began to march west to Appomattox Station, where supplies awaited for him. However, Union cavalry was successful in harassing Lee's rear, delaying his advance and Union forces were allowed to capture Lee's supplies before his arrival on April $8^{\text {th }}$. With no supplies and Union forces closing in on Appomattox, Lee had little option, but to surrender.

On the $9^{\text {th }}$ of April, Grant and Lee met at the Appomattox Courthouse to discuss the surrender of the Confederate Army of Northern Virginia. Grant's terms were generous; no man would be imprisoned or prosecuted for treason, officers could keep their sidearms, and men could take their horses home. In addition, Grant would also provide Lee's starving army with rations to which Lee 
was grateful. On April 10, Lee gave a farewell address to his army and on April 12 Confederate soldiers laid down their arms. Although considered by many as the end of the war, Grant knew there were still many Confederate forces still willing to fight.

Further Reading:

https://en.wikipedia.org/wiki/Battle_of_Appomattox_Court_House

Image 43, Map of the pursuit of General Lee to Appomattox:

http://thomaslegion.net/sitebuildercontent/sitebuilderpictures/appomattoxcampaig

nmap.jpg

Image 43.1, Confederate General Lee surrenders to Union General Grant at

Appomattox: http://gadling.com/wp-content/uploads/2012/05/800px-

theassassinationofpresidentlincoln-currierandives2-1336641582.png

44) Washington, D.C.

Point of Interest

04/14/1865 - 04/14/1865

Lat: $38.896923 \quad$ Long: -77.025745

On April 11, two days after Lee's surrender to Grant, an actor named John Wilkes Booth attended a speech at the White House where Lincoln announced he was in support of giving the right to vote to ex-slaves. An infuriated Booth vowed, "That is the last speech he will ever give."

On April 14, Booth while visiting Ford's Theatre to pick up his mail, learned that the President would be attending the theatre to see Our American Cousin that night. Being an actor in that theatre, Booth easily gained access to restricted areas and slipped into the Presidential booth. Barricading the door with a wooden stick, Booth then waited until a humorous moment to shoot, hoping the applause would muffle the sound of the shot. Booth shot the President in the back of the head at close range and jumped from the booth to the stage floor. It is believed that Booth shouted "Sic semper tyrannis!" the Virginia state motto, meaning "Thus always to tyrants." Pandemonium broke out and Booth was able to escape with a horse he had waiting outside. President Lincoln was rushed across the street where three doctors who were in the audience announced that his wound as mortal. Lincoln would die early the next morning, becoming the first American president to be assassinated.

In the aftermath, Vice-President Andrew Johnson would replace Lincoln as President and Booth would be shot by soldier while trying to escape in Virginia on April 26th.

Further Reading:

https://en.wikipedia.org/wiki/Assassination_of_Abraham_Lincoln

Image 44, Present day Ford's Theatre, Washington D.C.:

https://upload.wikimedia.org/wikipedia/commons/7/7c/Inside_Ford's_Theatre.jpg Image 44.1, Illustration of the assassination of Abraham Lincoln:

http://gadling.com/wp-content/uploads/2012/05/800pxtheassassinationofpresidentlincoln-currierandives2-1336641582.png

45) Durham, North Carolina 
Point of Interest

04/17/1865 - 04/26/1865

Lat: $36.029342 \quad$ Long: -78.975052

On April 14, Sherman received a letter under the flag of truce from Confederate General Johnston seeking to end the war. Sherman agreed to meet with Johnston in-between the lines on a small farm called the Bennett House near Durham, North Carolina. On April 17, the two officers met for the first time in private to discuss the surrender and the recent assassination of President Lincoln. Johnston offered to surrender all Confederate forces still active in the field, in the hopes of preventing guerrilla warfare, but also requested some political amnesty protections. Sherman was unsure if he was authorized to grant political terms, but agreed to terms of surrender on the $18^{\text {th }}$. Many in Washington felt Sherman had veered too far from Lincoln's terms that Grant had offered to Lee and so the original terms of surrender were rejected by the Secretary of War. General Grant would arrive days later and offer Johnston the same terms as Lee. With Johnston surrender, the second largest army of the Confederacy was now dissolved.

Further Reading: http://www.northcarolinahistory.org/encyclopedia/884/entry Image 45, Illustration of the Bennett House during Confederate General Johnston's surrender to Union General Sherman: http://www.illinoiscivilwar150.org/images/chronos_images/1865\%20April\%2026



46) Washington, D.C.

Point of Interest

04/29/1865 - 05/24/1865

Lat: 38.8921 Long: -77.036529

On May 10, President Johnson declared that rebellion resistance was virtually at an end and wanted to honor the troops by having a Grand Review through the streets of Washington.

The $15^{\text {th }}$ Iowa Regiment had already begun its long march from Raleigh and went into camp in Alexandria, Virginia on the $19^{\text {th }}$ of May. On May 24, the $15^{\text {th }}$ Iowa, as part of General Sherman's Army, passed before President Johnson and General Grant to the cheers of joyous on lookers and followed by vast crowds of people who had followed them up from Savannah.

Further Reading: https://en.wikipedia.org/wiki/Grand_Review_of the_Armies Image 46, Soldiers marching during the Grand Review: https://historicist.files.wordpress.com/2012/11/grand-review.jpg Image 46.1, Soldiers marching during the Grand Review: http://4.bp.blogspot.com/-rCtUS0yNb3M/VV0vLtPbSI/AAAAAAAAHzU/tQeplYdCWtc/s1600/GrandReview3.jpg

47) Louisville, Kentucky

Point of Interest

07/24/1865

Lat: $38.231194 \quad$ Long: -85.741062 
On June $1^{\text {st }}$, the 15 th Iowa was ordered to Louisville, KY, arriving on June $12^{\text {th }}$, and remaining in camp until mustering out of service on July 24, 1865. From here the $15^{\text {th }}$ Iowa was transferred by rail back to Iowa where it received its final payment and were allowed to go home.

For three and a half years the $15^{\text {th }}$ Iowa traveled 7,898 miles since March of 1862 and fought battles in 5 states. Of the original 1,763 men who would originally compose the regiment, 1,051 would be either killed, wounded, or disabled for life.

If you would like to know more about Logan Crawford and the $15^{\text {th }}$ Iowa, here are links to:

A Brief biography of Logan Crawford

http://iagenweb.org/harrison/bio/geneal72.htm

The History of the $15^{\text {th }}$ Volunteer Regiment

http://files.usgwarchives.net/ia/state/military/civilwar/book/cwbk_15.txt

Also please visit the Lincoln Memorial Shrine at:

http://www.lincolnshrine.org/ 


\section{Appendix B. Basemaps}



1862 Historical War Map, originally published by Asher \& Co. for the state of Indiana.

Taken from the David Rumsey Collection www.davidrumsey.com 


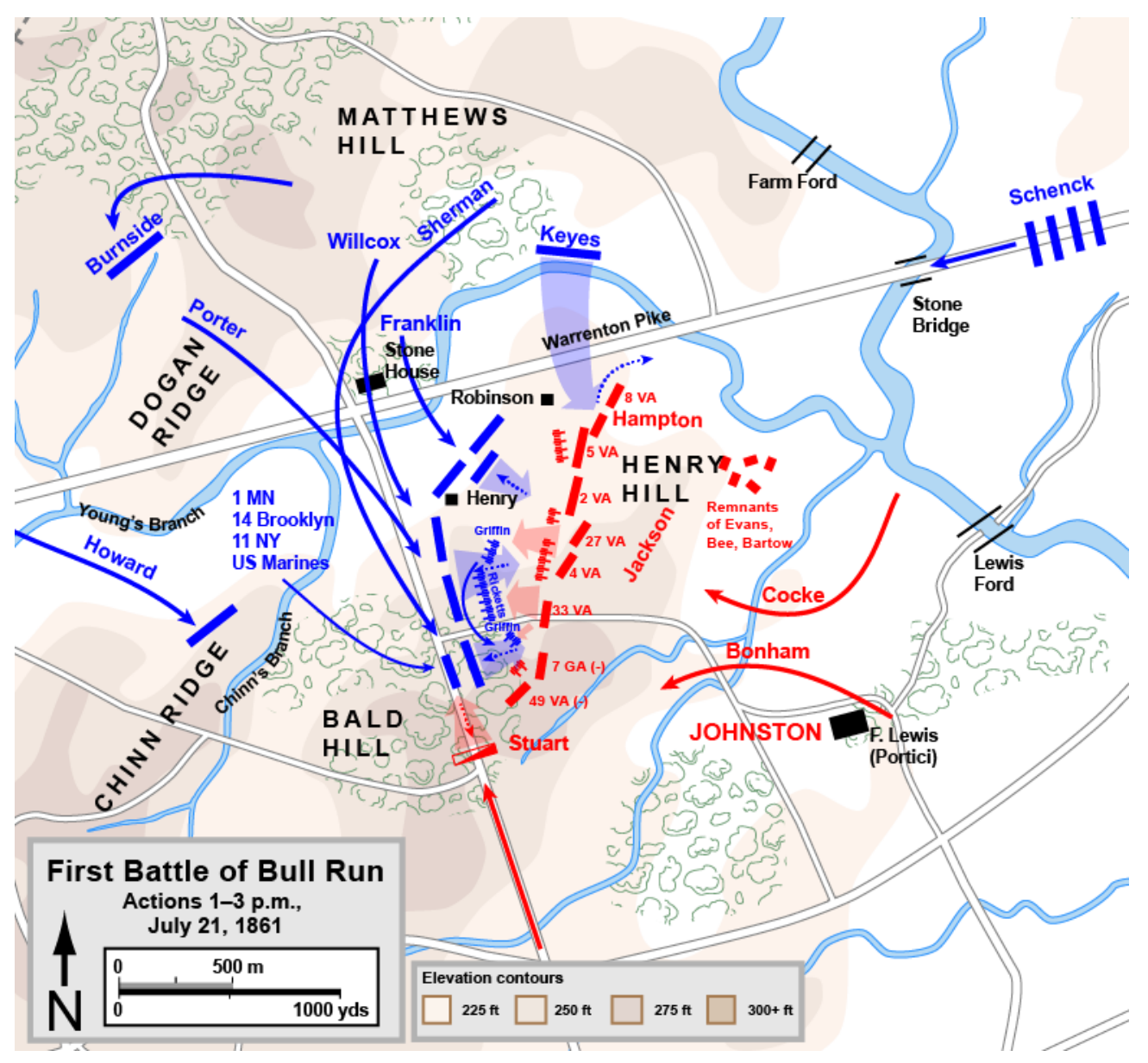

Map of the Battle of Bull Run (Manassas, Virginia).

Taken from Wikipedia.

https://upload.wikimedia.org/wikipedia/commons/9/9b/First_Bull_Run_July21_1400.png 


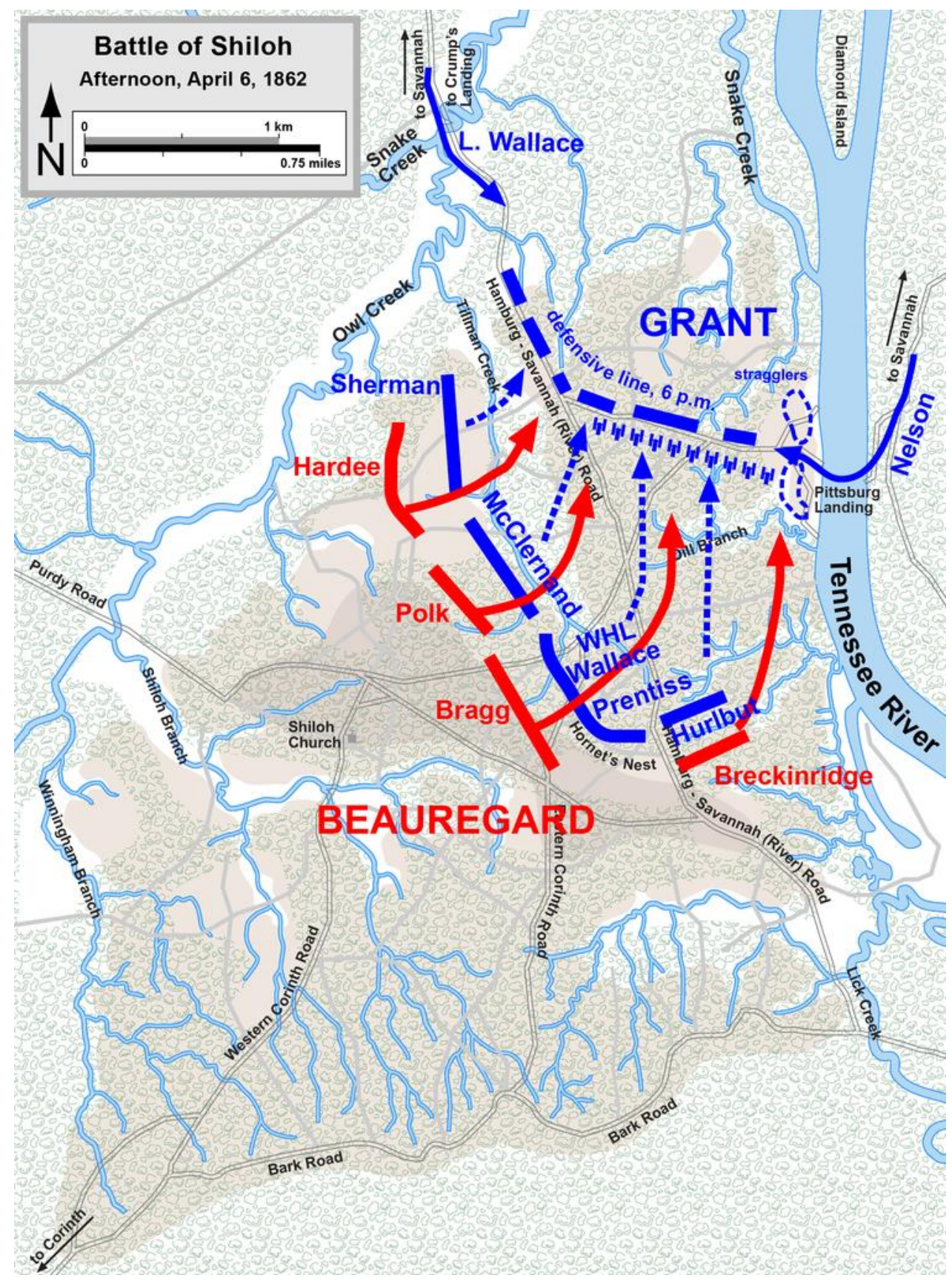

Map of the first day of the battle of Shiloh (Pittsburgh Landing, Tennessee)

Taken from Wikipedia

https://upload.wikimedia.org/wikipedia/commons/thumb/f/fa/Shiloh_Battle_Apr6pm.png

1754px-Shiloh_Battle_Apr6pm.png 


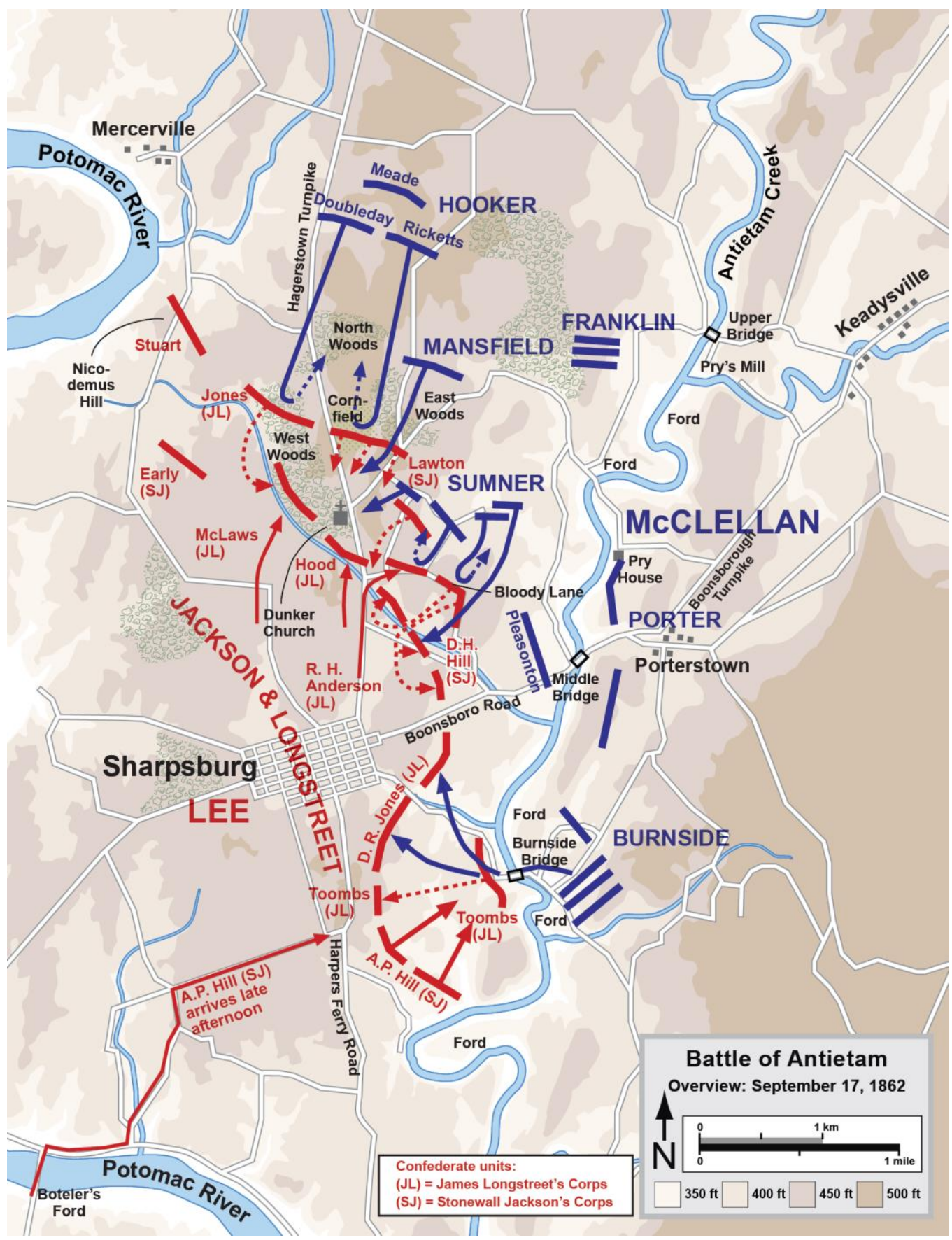

Map of the battle of Antietam (Sharpsburg, Maryland)

Taken from Wikipedia

https://upload.wikimedia.org/wikipedia/commons/1/1b/Antietam_Overview.png 


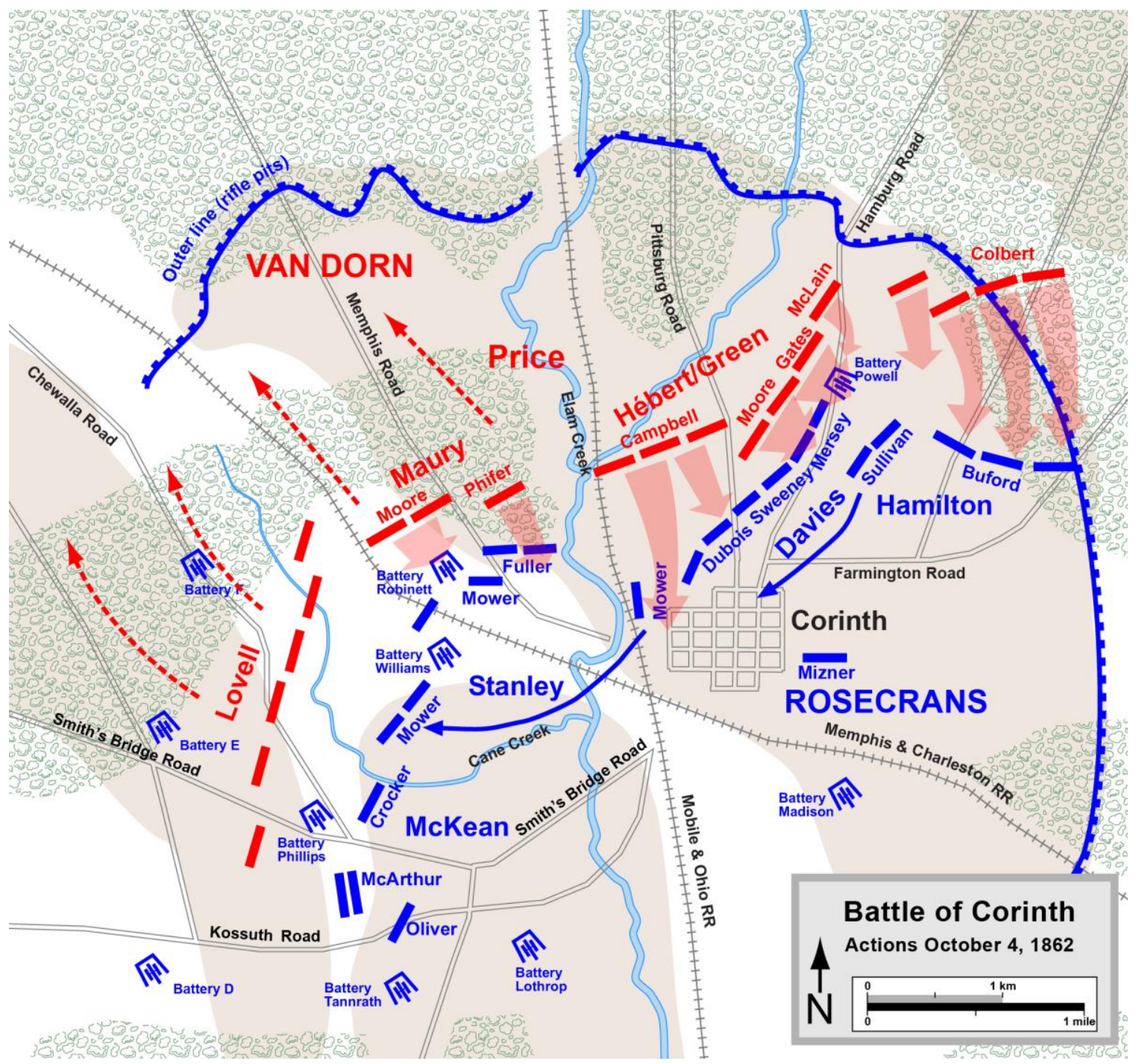

Map of the battle of Corinth, Mississippi

Taken from Wikipedia

https://upload.wikimedia.org/wikipedia/en/d/d6/Corinth_October_4_1862.png 




Map of the battle of Gettysburg, Pennsylvania

Taken from Wikipedia

https://upload.wikimedia.org/wikipedia/commons/thumb/9/9e/Gettysburg_Battle_Map_D

ay3.png/350px-Gettysburg_Battle_Map_Day3.png 




Map of the siege of Vicksburg, Mississippi

Taken from Wikipedia

https://upload.wikimedia.org/wikipedia/commons/5/58/VicksburgSiege.png 




Map of the battle of Kennesaw Mountain (Marietta, Georgia)

Taken from Wikipedia

https://upload.wikimedia.org/wikipedia/en/0/0e/Kennesaw_Mountain.png 


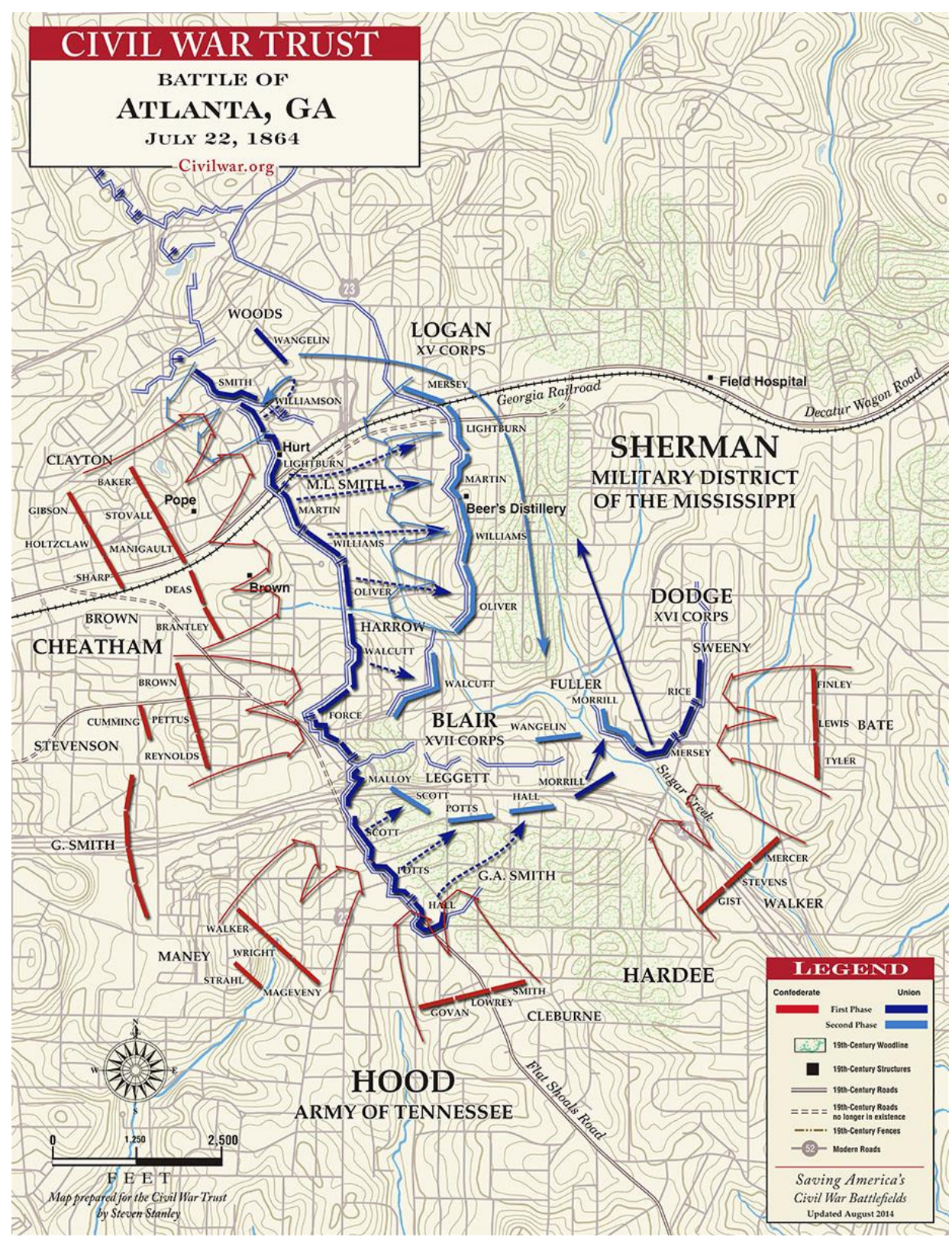

Map of the battle of Atlanta, Georgia

Taken from civilwar.org

http://www.civilwar.org/battlefields/atlanta/atlanta-maps/atlanta-july-22-1864.jpg 


\section{Appendix C. Lincoln Memorial Shrine Project Web Application Script}

The code displayed here in black font was originally produced by Esri as a Journal Map Application. Then the code displayed in blue font is to modify the original Esri application to fulfill the client's requirements.

$<$ !DOCTYPE html $>$

$<$ html $>$

$<$ head $>$

$<$ title $></$ title $>$

$<$ meta http-equiv="Content-Type" content="text/html; charset=utf-8" >

$<$ meta http-equiv="X-UA-Compatible" content="IE=Edge,chrome=1">

$<$ meta name="fragment" content="!">

$<$ meta name="apple-mobile-web-app-capable" content="yes">

$<$ meta name="viewport" content="width=device-width, initial-scale=1.0, maximumscale $=1.0$, user-scalable $=0 ">$

<link type="image/ico" rel="shortcut icon" href="//resources.esri.com/favicon.ico">

<link type="image/ico" rel="icon" href="//resources.esri.com/favicon.ico">

$<!-$

To correctly reference your Map Journal in search engine:

- create and fill out extensively an ArcGIS Online item that link to your final application

- edit the following four tags as well as the title tag above on line 4

$-->$

$<$ meta name="description" content="This story map was created with the Story Map Journal application in ArcGIS Online.">

$<$ !-- Facebook sharing -->

$<$ meta property="og:type" content="article"/>

$<$ meta property="og:title" content="Story Map Journal"/>

$<$ meta property="og:description" content="This story map was created with the Story Map Journal application in ArcGIS Online."/>

<meta property="og:image"

content="http://www.arcgis.com/apps/MapJournal/resources/common/icons/esriglobe.png"/>

$<!--$

This application is released under the Apache License V2.0 by Esri http://www.esri.com/ 
Checkout the project repository on GitHub to access source code, latest revision, developer documentation, FAQ and tips

https://github.com/Esri/map-journal-storytelling-template-js

$-->$

<script type="text/javascript" $>$

$/ /-$

// Application configuration (ignored on ArcGIS Online, Portal and during development)

$/ /-$

var configOptions $=\{$

// Enter an application ID created through the Map Journal builder appid: "d07ce79000e540ba84c5f0db6d8b14be",

// Optionally to secure Journal's access, use an OAuth application ID (example: 6gyOg377fLUhUk6f)

// User will need to sign-in to access the viewer even if your application is public oAuthAppId: "",

// Optionally to be able to use the appid URL parameter, configure here the list of application author

// whose application are allowed to be viewed by this Map Journal deployment

// This is the Portal username of the Journal owner (e.g. ["user1"], ["user1", "user2"]) authorizedOwners: [""]

\};

// Optionally sharing and proxy URLs can be configured in app/config.js. This is only required

// when the webmap is not hosted on ArcGIS Online or a Portal for ArcGIS instance and the application isn't deployed as /home/MapJournal/ or /apps/MapJournal/.

// Optionally Bing Maps key, Geometry and Geocode service's URLs can be configured in app/commonConfig.js. This is only required

// if the Organization or Portal for ArcGIS instance default configuration has to be overwritten. If the application is deployed

// on Portal for ArcGIS as /home/MapJournal/ or /apps/MapJournal/, that configuration is available in ../commonConfig.js

$</$ script $>$

$<!--$

Edit below at your own risk

$-->$

<script type="text/javascript" >

var app $=\{$

version: '1.5.0',

pathJSAPI: 'http://js.arcgis.com/3.14/'

\}; 
$</$ script $>$

$</$ head $>$

$<$ body class="claro" $>$

<style>

/* CUSTOM CSS RULES */

$</$ style $>$

$<$ !-- Builder top panel is injected here -->

$<$ div id="builderPanel" class="hide mainViewAboveMap" $></$ div $>$

$<$ !-- Content -->

$<$ div id="contentPanel" class="mobileView">

$<$ table class $=$ "containerPanelInner" $>$

$<\operatorname{tr}>$

$<$ !-- Text panel of the Side Panel layout -->

$<$ td id="sidePanel" >

$<$ div id="sidePanelInner" class="mainViewSideMap sidePanel sectionPanel" >

$<$ div class="navDots vertical" $>$

$<$ !-- navigation dots -->

$</$ div $>$

$<$ div class="header" aria-hidden="true" $>$

$<$ div class="linkSocialContainer" $>$

$<$ span class="linkContainer" $></$ span $>$

$<$ span class="shareBtns">

$<\mathrm{i}$ class="shareIcon blackHover share_facebook icon-facebook-squared" tabindex="$1 "></ \mathrm{i}>$

$\langle$ i class $=$ "shareIcon blackHover share_twitter icon-twitter" tabindex $="-1 "\rangle\langle/ \mathrm{i}\rangle$

$<$ i class="shareIcon blackHover share_bitly icon-link" tabindex $="-1 "></$ i $>$

$<$ button type="button" class="switchBuilder btn btn-xs btn-primary" tabindex="-

$1 "></$ button $>$

$</$ span $>$

$</$ div $>$

$<$ table class="logoContainer" $>$

$<\operatorname{tr}>$

$<$ td class="logoWrapper" $>$

$<$ a class="logoLink" target="_blank" tabindex="-1">

$<$ img class="logoImg"/>

$</ a>$

$\langle/ \mathrm{td}\rangle$

$</ \operatorname{tr}>$

$</$ table $>$

$</$ div $>$

$<$ div class="appTitle" tabindex="-1" aria-hidden="true" $></$ div $>$

$<$ div class $=$ "separator" $></$ div $>$

$<$ div class="sectionsWrapper" $>$

$<$ div class="panelEditBtn"> 
$\langle$ div class="panelEditBtnInner" $></$ div $>$

$</$ div $>$

$\langle$ div class="sections" $>$

$\langle$ !-- sections injected here -->

$\langle/$ div $\rangle$

$\langle/$ div $\rangle$

$\langle$ div class="builder builder-content-panel">

$<$ div class="builder-content-panel-group builder-add" >

$\langle$ div class="builder-btn" $>\langle/$ div $\rangle$

$<$ div class="builder-lbl" $></$ div $>$

$</$ div $>$

$\langle$ div class="builder-content-panel-group builder-organize" $>$

$\langle$ div class="builder-btn" $>\langle/$ div $\rangle$

$\langle$ div class="builder-lbl" $>\langle/$ div $>$

$\langle/$ div $>$

$\langle/$ div $>$

$<$ !-- $<$ div class="resizer" $></$ div $>-->$

$<$ div class $=$ "scroll" $>$

$\langle$ div class="scrollInner" data-toggle="tooltip" $>\langle/$ div $>$

$</$ div $>$

$\langle$ div class="builder-mask" $\rangle\langle$ div $\rangle$

$<$ div class="firstAddExplain" $></$ div $>$

$\langle/$ div $\rangle$

$</ \mathrm{td}\rangle$

$<!--$ Map -->

$<$ td id="mainStagePanel">

$<$ div id="mainStagePanelInner" $>$

$<$ div class="medias" $>$

$<!--$ Maps and media injected here -->

$</$ div $>$

$\langle$ div id="mainStageLoadingIndicator" class="loadingIndicator">

$<$ img src="resources/tpl/viewer/icons/loading-light.gif" />

$</$ div $>$

$<$ !-- Back button -->

$\langle$ div class="mediaBackContainer" $>$

$<$ div class="backButton" $>$

$\langle$ div class="backArrow" $\rangle\langle/ \operatorname{div}\rangle$

$<$ span class="backLbl" $></$ span $>$

$\langle/$ div $>$

$</$ div $>$

$<$ !-- Builder -->

$\langle$ div id="builderQuotes" class="centerAlignOnFloat" $\rangle\langle$ div $\rangle$

$\langle$ div id="builderLanding" class="centerAlignOnFloat" $\rangle\langle/$ div $\rangle$

$\langle$ div id="builderHelp" class="centerAlignOnFloat" $\rangle\langle/$ div $>$

$<$ div class="firstAddExplain" $></$ div $>$

$</$ div $>$ 
$</ \mathrm{td}\rangle$

$</$ tr $>$

$</$ table $>$

$</$ div $>$

$<!--/$ Content -- $>$

$<$ div id="floatingPanel" class="floatingPanel sectionPanel" $\rangle$

$<$ div class="backdrop" $></$ div $>$

$<$ div class="header" aria-hidden="true" $>$

$<$ div class="linkSocialContainer" $>$

$<$ span class="linkContainer" $></$ span $>$

$<$ span class="shareBtns">

$<$ i class="shareIcon blackHover share_facebook icon-facebook-squared"

title="Share on Facebook" tabindex $="-1 "></ i>$

$<$ i class="shareIcon blackHover share_twitter icon-twitter" title="Share on Twitter" tabindex $="-1 "></ \mathrm{i}>$

$<$ i class $=$ "shareIcon blackHover share_bitly icon-link" title="Share a short link" tabindex $="-1 "></ \mathrm{i}>$

$<$ button type="button" class="switchBuilder btn btn-xs btn-primary" tabindex="$1 "></$ button $>$

$</$ span $>$

$</$ div $>$

$\langle$ table class="logoContainer" $>$

$<\operatorname{tr}>$

$<$ td class $="$ logoWrapper" $>$

$<$ a class="logoLink" target="_blank" tabindex="-1">

$<$ img class="logoImg"/>

$\langle/ a\rangle$

$</ \mathrm{td}\rangle$

$</ \operatorname{tr}>$

$</$ table $>$

$</$ div $>$

$<$ div class="appTitle" tabindex="-1" aria-hidden="true" $></$ div $>$

$<$ div class="separator" $>\langle/ \operatorname{div}\rangle$

$<$ div class="panelEditBtn" $>$

$<$ div class="panelEditBtnInner" $></$ div $>$

$</$ div $>$

$\langle$ div class="sections" $>$

$\langle$ div class="swiper-container" $>$

$<$ div class="swiper-wrapper" $>$

$\langle$ !-- sections injected here -- $>$

$</$ div $>$

$</$ div $>$

$</$ div $>$

$<$ div class="builder builder-content-panel" >

$<$ div class="builder-content-panel-group builder-add" > 
$<$ div class="builder-btn" $>\langle/$ div $>$

$<$ div class="builder-lbl" $></$ div $>$

$</$ div $>$

$<$ div class="builder-content-panel-group builder-organize" $>$

$<$ div class="builder-btn" $></$ div $>$

$\langle$ div class="builder-lbl" $></$ div $>$

$</$ div $>$

$</$ div $>$

$<$ div class="navDots vertical" $>$

$<$ !-- navigation dots -- >

$</$ div $>$

$<$ div class="scroll" $>$

$<$ div class="scrollInner" data-toggle="tooltip" $></$ div $>$

$</$ div $>$

$<$ div class="builder-mask" $>\langle/$ div $>$

$<$ div class="firstAddExplain" $></$ div $>$

$</$ div $>$

$<$ !-- Mobile -->

$<$ div id="mobileView" class="floatingSwiper">

$<$ div class="swiper-container" $\rangle$

$<$ div class="backdrop" $></$ div $>$

$<$ div class="embed-btn-container embed-btn-left" $>$

$\langle$ div class="embed-btn" $></$ div $>$

$</$ div $>$

$<$ div class="swiper-wrapper" $>$

$<$ !-- sections injected here -->

$</$ div $>$

$<$ div class="embed-btn-container embed-btn-right" $>$

$<$ div class="embed-btn" $></$ div $>$

$</$ div $>$

$</$ div $>$

$<$ div class="header" $>$

$<$ div class="backdrop" $></$ div $>$

$<$ div class="linkSocialContainer" $>$

$<$ span class="linkContainer" $></$ span $>$

$<$ span class="shareBtns">

$<$ i class="shareIcon share_facebook icon-facebook-squared" $></$ i $>$

$<\mathrm{i}$ class $=$ "shareIcon share_twitter icon-twitter" $\rangle\langle/ \mathbf{i}\rangle$

$\langle$ i class="shareIcon share_bitly icon-link" $\rangle\langle/$ i $\rangle$

$</$ span $>$

$</$ div $>$

$\langle/$ div $>$

$</$ div $>$

$<$ !-- Loading --> 





margin-left: $-17 \mathrm{px}$;

margin-top: -20px;

\}

$<$ style $>$

$\langle$ div id="loadingOverlay" $>\langle$ div $>$

$<$ div id="loadingIndicator" class="loadingIndicator" $>$

$<$ img src="resources/tp1/viewer/icons/loading-light.gif" />

$</$ div $>$

$\langle$ div id="loadingMessage" $></$ div $>$

$<!--$ Share dialog -->

$<$ div class="modal fade shareDialog" id="shareDialog" role="dialog" databackdrop="static" tabindex="-1" $></$ div $>$

$<!--$ Builder views are injected here -->

$<$ div id="builder-views" $></$ div $>$

$<!--$ Fatal error box -->

$<$ div id="fatalError">

$<$ table border="0" >

$<\operatorname{tr}>$

$\langle$ td width="70px" align="center" id="fatalError-icon" $></$ td $>$

$\langle$ td id="fatalError-msg" $>$

$\langle$ b class="error-title" $>\langle/ \mathrm{b}\rangle$

$\langle$ p class="error-msg" $>\langle/ \mathrm{p}\rangle$

$\langle/ \mathrm{td}\rangle$

$</$ tr $>$

$</$ table $>$

$</$ div $>$

<script type="text/javascript" src="app/main-config.js" $></$ script $>$

<script type="text/javascript">

require(["dojo/topic",

"esri/tasks/query",

"esri/tasks/QueryTask",

"esri/symbols/SimpleFillSymbol",

"esri/symbols/SimpleLineSymbol",

"esri/Color",

"esri/graphic"], function(topic, Query, QueryTask, SimpleFillSymbol, SimpleLineSymbol, Color, Graphic) \{

/*

* Custom Javascript to be executed while the application is initializing goes here */

// The application is ready

topic.subscribe("tpl-ready", function()\{ 





map.graphics.clear();

\}$)$;

//Function to hide rectangles on mouse-out ------> End

//Function to go to a specific page on click of the respective map on the map ------> Start

layer.on("click", function(e)\{

var name = e.graphic.attributes["Name"];

var queryTask $=$ new

QueryTask("http://services.arcgis.com/o6oETlrWetREI1A2/arcgis/rest/services/Delta/Fe atureServer/0");

var query = new Query ();

query.returnGeometry = false;

query.outFields = ["OBJECTID"];

query. where = "Name = "' + name + "'";

queryTask.execute(query, showResults);

function showResults (results) \{

var index = results.features[0].attributes["OBJECTID"];

topic.publish("story-navigate-section", index); //Navigating to the page

based on the clicked polygon

\}

\}$)$;

//Function to go to a specific page on click of the respective map on the map ------> End

\}

clickHandlerIsSetup = true;

\}

\});

\});

\}$)$;

$</$ script $>$

$</$ body $>$

$</$ html $>$ 